University of Louisville

ThinkIR: The University of Louisville's Institutional Repository

$5-2005$

\title{
Role of inducible nitric oxide synthase and p-selectin in platelet- arteriolar wall adhesion and associated arteriolar constriction during lung reperfusion.
}

Alexander V. Ovechkin 1957-

University of Louisville

Follow this and additional works at: https://ir.library.louisville.edu/etd

\section{Recommended Citation}

Ovechkin, Alexander V. 1957-, "Role of inducible nitric oxide synthase and p-selectin in platelet-arteriolar wall adhesion and associated arteriolar constriction during lung reperfusion." (2005). Electronic Theses and Dissertations. Paper 1087.

https://doi.org/10.18297/etd/1087

This Doctoral Dissertation is brought to you for free and open access by ThinkIR: The University of Louisville's Institutional Repository. It has been accepted for inclusion in Electronic Theses and Dissertations by an authorized administrator of ThinkIR: The University of Louisville's Institutional Repository. This title appears here courtesy of the author, who has retained all other copyrights. For more information, please contact thinkir@louisville.edu. 


\title{
ROLE OF INDUCIBLE NITRIC OXIDE SYNTHASE AND P-SELECTIN IN PLATELET-ARTERIOLAR WALL ADHESION AND ASSOCIATED ARTERIOLAR CONSTRICTION DURING LUNG REPERFUSION
}

\author{
By \\ Alexander V. Ovechkin \\ M.D., Perm State Medical Academy, 1981
}

\begin{abstract}
A Dissertation
Submitted to the Faculty of the

Graduate School of the University of Louisville

In Partial Fulfillment of the requirements

For the Degree of

Doctor of Philosophy

Department of Physiology and Biophysics

University of Louisville

Louisville, Kentucky
\end{abstract}

May 2005 


\title{
ROLE OF INDUCIBLE NITRIC OXIDE SYNTHASE AND P-SELECTIN IN PLATELET-ARTERIOLAR WALL ADHESION AND ASSOCIATED ARTERIOLAR CONSTRICTION DURING LUNG REPERFUSION
}

\author{
By \\ Alexander V. Ovechkin \\ M.D., Perm State Medical Academy, 1981
}

A Dissertation Approved on

February 23,2005

Date

by the following Dissertation Committee:

Andrew M. Roberts, $\mathrm{PhD}$

\section{Dissertation Director}

Dr. Irving Joshua, $\mathrm{PhD}$

Dr. David Gozal, MD

Dr. John Fleming, PhD

Dr. John Passmore, PhD 


\section{DEDICATION}

This dissertation is dedicated to

My Family 


\section{ACKNOWLEDGMENTS}

This project would not have been possible without the support and help of many people. First of all, I would like to express my deepest gratitude to my teacher and mentor, Dr. Andrew M. Roberts, for his guidance, encouragement, and invaluable friendship.

I extend my appreciation to the dissertation committee members, Dr. Irving Joshua, Dr. David Gozal, Dr. John Fleming, and Dr. John Passmore for their support, comments and suggestions over the past years.

I would like to acknowledge the help and guidance provided by Dr. Suresh Tyagi, Dr. David Lominadze, Dr. Richard Benton and Dr. Tonya Robinson. Special thanks are due to Kara Collins-Sedoris, M.S., Dr. John Mowbray and Mark Zellers, B.S. for their assistance in my experiments.

Finally, I wish to thank the faculty members and staff of the Department of Physiology and Biophysics at the University of Louisville whose support enabled me to conduct this research.

The project was supported in part by the American Lung Association of Kentucky. 


\begin{abstract}
ROLE OF INDUCIBLE NITRIC OXIDE SYNTHASE AND P-SELECTIN

IN PLATELET-ARTERIOLAR WALL ADHESION AND ASSOCIATED ARTERIOLAR CONSTRICTION DURING LUNG REPERFUSION
\end{abstract}

\author{
Alexander V. Ovechkin
}

February, 2005

Reperfusion of the ischemic lung causes pulmonary arteriolar vasoconstriction and reduces alveolar perfusion. Lung ischemia-reperfusion (IR) injury leads to platelet and leukocyte activation which could contribute to decreased alveolar perfusion during reperfusion by platelet-arteriolar wall interactions (rolling and adhesion) and subsequent microvascular constriction. During the oxidative stress of ischemia and reperfusion, formation of reactive nitrogen species (RNS) may promote platelet adhesion to the vascular wall with subsequent formation of microthrombi and release of vasoactive substances. Platelets play an important role in causing reperfusion injury in the systemic vasculature through accumulation and release of mediators, but information is lacking about consequences of their interactions with 
the arteriolar wall in the pulmonary microcirculation over the time course of lung reperfusion. During IR induced oxidative stress, overproduction of nitric oxide (NO) could contribute to formation of harmful RNS by interactions with oxygen radicals. The emphasis of the present study was to investigate the relationship between inducible nitric oxide synthase (iNOS), RNS, P-selectin and platelet-arteriolar wall rolling/adhesion and microvascular constriction in the intact lung during the time course of pulmonary ischemia-reperfusion injury.

We examined the hypothesis that pulmonary IR induces platelet-arteriolar wall rolling and adhesion (interactions) via a P-selectin dependent mechanism that contributes to pulmonary microvascular constriction during reperfusion. Increased P-selectin expression results from elevated iNOS activity and subsequent RNS generation. Subpleural arterioles, labeled platelets, and leukocytes were examined in anesthetized, open-chest rabbits by intravital fluorescence microscopy. Ischemia was caused by reversibly occluding the right pulmonary artery for $5 \mathrm{~min}, 1 \mathrm{~h}$ or 2 $\mathrm{h}$ (5minIR group, 1IR group and 2IR group, respectively).

During reperfusion, postischemic platelet rolling and adhesion were independent from leukocyte-arteriolar wall interactions and correlated with pulmonary arteriolar constriction in proportion to the length of ischemia. After 1-h occlusion during reperfusion, platelet rolling was significantly greater than in the $5 \mathrm{minIR}$ or control group. Although arteriolar diameters decreased during the first $0.5 \mathrm{~h}$ of 
reperfusion, platelet adhesion was not increased and arteriolar diameters returned to the baseline by $1 \mathrm{~h}$ of reperfusion. However, after two hours of ischemia, platelet rolling increased and platelet adhesion was accompanied by arteriolar constriction that was correlated with the level of platelet adhesion after both 1-h and 2-h ischemia. Blockade of systemic P-selectin by Fucoidan (the selectin ligand) inhibited platelet rolling, adherence, and vasoconstriction. Pretreatment of only exogenously labeled platelets with monoclonal antibody (MoAb) to P-selectin prevented platelet rolling and adherence, but not vasoconstriction. In rabbits that were treated with an iNOS inhibitor (1400W) before occlusion (2IR+1400W group), platelet-arteriolar wall interactions and vasoconstriction were prevented. In lung tissue subjected to IR, iNOS activity and expression were markedly greater than control and were also dependent on ischemia duration. Immunochemically detected P-selectin and nitrotyrosine expression in ischemic lung tissue, and the plasma level of soluble P-selectin in IIR and 2IR groups, were significantly higher than in non-ischemic lungs and were inhibited by pretreatment with $1400 \mathrm{~W}$.

These results indicate that during reperfusion of the intact lung, pulmonary IR causes platelet rolling and adhesion along arteriolar walls and suggest that this process is mediated by platelet and endothelial P-selectin. The results show that platelet adhesion and arteriolar constriction during early reperfusion can result from increased iNOS activity and is highly correlated with RNS and P-selectin expression. 


\section{TABLE OF CONTENTS}

\section{PAGE}

ACKNOWLEDGEMENTS

iv

ABSTRACT

LIST OF TABLES

LIST OF FIGURES

\section{CHAPTER I:}

INTRODUCTION

1. PULMONARY ISCHEMIA-REPERFUSION (IR) INJURY

2. MICROVASCULAR EFFECTS OF PULMONARY IR

3. LEUKOCYTES AND PLATELETS IN PULMONARY IR

4. ROLE OF ADHESION MOLECULES IN PULMONARY IR

5. IR-INDUCED OXIDATIVE STRESS

6. ROLE OF NITRIC OXIDE IN PULMONARY IR

SUMMARY

HYPOTHESIS AND SPECIFIC AIMS

CHAPTER II:

METHODS AND MATERIALS

CHAPTER III:

RESULTS

CHAPTER IV:

DISCUSSION

99-113

REFERENCES

CURRICULUM VITAE 
TABLES

\section{LIST OF TABLES}

1. Arterial blood pressure and heart rate at baseline before

1. $\quad$ and during lung reperfusion.

PAGE

2. Arterial blood gases and $\mathrm{pH}$ at baseline and during lung reperfusion

3. Labeled platelets rolling or adhered during reperfusion 46 


\section{LIST OF FIGURES}

1. General hypothesis. 47

2. Schematic diagram of P-selectin and P-selectin 48 glycoprotein ligand.

3. Experimental model. 49

4. Intravital video microscopy system. 50

5. Experimental protocols. 52

6. Responses of a subpleural pulmonary arteriole to 2-h 53 ischemia.

7. Comparison of effects of $1 \mathrm{~h}$ and $2 \mathrm{~h}$ of pulmonary ischemia on pulmonary arteriolar diameter during reperfusion.

8. Platelet-arteriolar wall interactions during reperfusion of 56 the right lung after $1 \mathrm{~h}$ and $2 \mathrm{~h}$ of pulmonary ischemia

9. Adhered platelets in a pulmonary arteriole in the right 58 lung during reperfusion after a 2-h pulmonary ischemia observed by intravital fluorescence microscopy.

10. Correlation between arteriolar constriction or platelet 60 rolling/adhesion with duration of reperfusion.

11. Arteriolar constriction as a function of platelet rolling or adhesion during reperfusion. 
12. Platelet and leukocyte rolling in the right lung during the 64 reperfusion time course after $2 \mathrm{~h}$ of pulmonary ischemia-reperfusion.

13. Rolling and adhered platelets and leukocytes in a pulmonary arteriole observed by intravital microscopy.

14. Comparison of effects of MoAb or Fucoidan treatment 68 on changes in pulmonary arteriolar diameters during the reperfusion time course after $2 \mathrm{~h}$ ischemia.

15. Platelet-arteriolar wall interactions during reperfusion of 70 the right lung after $2 \mathrm{~h}$ of pulmonary ischemiareperfusion.

16. iNOS expression and total NOS activity in the right lung.

17. Platelet rolling and arteriolar constriction during reperfusion time course in 2IR group compared to the $2 \mathrm{IR}+1400 \mathrm{~W}$ group.

18. Platelet and leukocyte rolling during reperfusion of the right lung after $2 \mathrm{~h}$ of pulmonary ischemia-reperfusion.

19. Platelet adhesion in subpleural arterioles after topical 78 application of peroxynitrite.

20. Comparison of nitrotyrosine expression as a marker of RNS in lung tissue after $2 \mathrm{~h}$ of ischemia with and without $1400 \mathrm{~W}$ treatment.

21. Effect of ischemia duration and 1400W treatment on nitrotyrosine expression in lung tissue.

22. Comparison of immunofluorescence staining of $\mathrm{P}$ selectin in lung tissue after $2 \mathrm{~h}$ of ischemia and $2 \mathrm{~h}$ of ischemia with $1400 \mathrm{~W}$ treatment. 
23. Scatter diagram of lung P-selectin, plasma P-selectin, and lung nitrotyrosine expression from animals that underwent no ischemia, 5-min, 1-h, or 2-h lung ischemia.

24. Effect of ischemia duration and $1400 \mathrm{~W}$ treatment on P86 selectin expression in lung tissue after $2 \mathrm{~h}$ of reperfusion.

25. Effect of pulmonary 2IR with and without $1400 \mathrm{~W}$ treatment on concentration of soluble P-selectin in plasma after $2 \mathrm{~h}$ of reperfusion.

26. Effects of $1400 \mathrm{~W}$ treatment on platelet-arteriolar wall interactions during reperfusion of the right lung after $2 \mathrm{~h}$ of pulmonary ischemia-reperfusion.

27. Comparison of effects of $1400 \mathrm{~W}$ treatment on changes in pulmonary arteriolar diameters during the reperfusion time course after $2 \mathrm{~h}$ ischemia.

28. Comparison of effects of MoAb, Fucoidan or $1400 \mathrm{~W}$ treatment on changes in pulmonary arteriolar diameters during reperfusion after $2 \mathrm{~h}$ ischemia.

29. Platelet-arteriolar wall interactions during reperfusion of 94 the right lung after $2 \mathrm{~h}$ of pulmonary ischemiareperfusion.

30. Comparison of changes in arteriolar diameter, platelet 96 rolling, and platelet adhesion after $1 \mathrm{~h}, 2 \mathrm{~h}$ or $2 \mathrm{~h}$ of pulmonary ischemia with $1400 \mathrm{~W}$ treatment.

31. Effect of pulmonary ischemia on nitrotyrosine 98 expression in lung tissue, P-selectin expression in lung tissue, and plasma soluble P-selectin after $2 \mathrm{~h}$ of reperfusion. 


\section{CHAPTER I}

\section{INTRODUCTION}

Pulmonary ischemia-reperfusion (IR) injury may result from trauma, atherosclerosis, pulmonary embolism, pulmonary thrombosis and surgical procedures such as cardiopulmonary bypass and lung transplantation (152). These conditions are associated with respiratory distress syndrome which is a form of acute lung injury where there is a significant inflammatory response, as well as extravascular fibrin deposition and thrombosis (147). During IR, injury elicited by ischemia is amplified by incomplete restoration of blood flow due to postischemic vasoconstriction and ventilation/perfusion mismatch $(29,48)$.

High morbidity and mortality associated with IR, and complications induced by IR, require further research to understand the pathophysiological mechanisms of pulmonary IR injury. In view of the problem relating to alveolar perfusion, elucidation of mechanisms of microvascular responses at the alveolar level will improve the effectiveness of therapy for IR injury $(112,147)$. 


\section{PULMONARY IR INJURY}

Lung IR leads to post-ischemic vasoconstriction $(13,29)$ and significant dysfunction of vasodilator and vasoconstrictor mechanisms $(25,26,51,70)$. Vascular abnormalities may include pulmonary hypertension, altered vascular reactivity, vascular obstruction, intrapulmonary shunting, increased vascular permeability (pulmonary edema), and ventilation/perfusion mismatch $(48,13,150)$. In IR, the vascular response appears to occur in at least two phases: 1) ischemia, which is associated with lack of oxygen, cell damage, and activation of cytotoxic enzymes, and 2) reperfusion, which is associated with formation of reactive oxygen intermediates, platelet and neutrophil activation, endothelial cell injury, increased vascular permeability, cytokine activity and complement activation $(15,43)$. During the ischemic phase of IR injury, when oxygen, ATP and other high-energy phosphates are depleted, conversion from aerobic to anaerobic cellular metabolism causes formation of cytotoxic metabolites $(7,135,136)$. With re-establishment of perfusion, the injury elicited by reperfusion can be more severe than that caused by ischemia per se (43). The dysfunction of ATP-dependent enzymes affects ion transport systems, causing accumulation of intracellular calcium. This cytosolic calcium leads to activation of several calcium sensitive-enzymes, such as phospholipases, with degradation of the membrane phospholipids (182). Nevertheless, it has been 
suggested that tissue injury mainly occurs during reperfusion (49), leading to the formation of reactive oxygen species (ROS): superoxide anion, hydrogen peroxide, and hypochlorous acid (71). The importance of oxygen radicals in the pathophysiologic process of IR injury was demonstrated when injection of free radical scavengers or enzymes, such as superoxide dismutase, catalase or glutathione peroxidase, prevented damage occurring during reperfusion $(50,54,180)$. The incomplete restoration of blood flow during reperfusion may amplify the injury by prolonging "no-reflow" ischemia (13) due to post-ischemic vasoconstriction (150). Pulmonary IR injury is different from IR in other systemic vascular beds where oxygen is re-introduced during reperfusion. In the ventilated, but non-perfused lung, although there is a small oxygen gradient which limits the diffusion, the alveolar wall can be directly oxygenated before reperfusion $(148,149)$. In the lung, as in other tissues, ischemic and reperfusion damage can be identified separately, and are not simply caused by endothelial cell dysfunction due to lack of oxygen (148). Therefore, this suggests that the IR injury requires both ischemia and reperfusion $(39,149)$.

\section{MICROVASCULAR EFFECTS OF PULMONARY IR}

Post-ischemic lung perfusion is characterized by progressive microvascular obstruction associated with formation of thrombi and vasoconstriction $(15,43)$. 
Hypoxia can induce endothelial cells and macrophages to develop procoagulant properties, which may contribute to the formation of microvascular thrombosis and compromise blood flow during reperfusion (108). Clinical and experimental studies have shown that IR induces a rapid release of thrombin and proinflammatory cytokines such as tumor necrosis factor alpha (TNF $\alpha)$, interleukin 1beta (IL-1 $\beta)$, IL6, IL-9 and IL-10 which are potent cell activators and promoters of vasoactive mediators $(6,42,109,110,179)$. Proinflammatory cytokines participate in ischemiareperfusion injury of the heart, kidney, small bowel, skin, and liver, but little is known about their roles in pulmonary IR injury (143). Cytokines modulate vascular smooth muscle tone and modify the inflammatory response by regulating the expression of adhesion molecules $(15,47,163)$. This process leads to platelet- and leukocyte-endothelial adhesion and formation of obstructive microembolic debris in the capillary network $(32,46,70,152)$. In addition, activated and adhered platelets and leukocytes can release mediators such as serotonin, thromboxane $\mathrm{A} 2$, and platelet activating factor, which contribute to vasoconstriction and edema formation $(11,14,113)$.

\section{ROLE OF LEUKOCYTES AND PLATELETS IN PULMONARY IR}

Leukocyte-endothelial cell adhesion and activation are implicated in microvascular dysfunction associated with IR in different tissues 
$(4,137,138,151)$, but their role in reperfusion injury is not yet clear $(180)$. Several studies demonstrated a role of leukocytes in the process of IR lung injury (10). Others, however $(3,8,40,140,181)$, observed tissue damage in the absence of leukocytes and concluded that neutrophils did not participate in the damage during ischemia and reperfusion. Neutrophil depletion in rats failed to prevent or decrease lung injury that was caused by clamping the bronchus, pulmonary artery and vein for 90 or $180 \mathrm{~min}$ before reperfusion (182). On further analysis, it appears that there is a bimodal pattern of IR injury, consisting of an early neutrophil-independent and a later neutrophil-mediated increase in microvascular permeability $(10,21,30,86)$.

During reperfusion, platelets have a very important role in post-ischemic systemic hypoperfusion $(18,20,25,32,164)$. Although, platelet activation and accumulation are implicated in causing reperfusion injury in tissues such as intestine, liver, pancreas, brain, and kidney $(45,25,43)$, information is lacking about their response and involvement over the time-course of reperfusion in the ischemic lung (9). Okada et al found that accumulation of platelets in preserved and subsequently reperfused rat lungs, correlated with the degree of reperfusion injury in a lung transplant model (32). Platelet accumulation significantly correlated with capillary congestion, suggesting that platelets contributed to the lung injury, at least in part, by promoting hemostasis and forming micro-thrombi $(9,26,53,45,70)$. Platelets which are adhered to post-ischemic vascular 
endothelium, cause tissue damage by releasing free radicals and inflammatory mediators, such as serotonin, leukotrienes and thromboxane $A_{2}(81)$ which are involved in post-ischemic leukocyte recruitment $(12,82-84)$. Platelets have been implicated early during the IR injury process, when formation of reactive oxygen radicals, endothelial disruption, and release of cytokines promote their activation and adhesion to the vascular wall $(18,25,26)$. ROS can promote platelet activation and cause up-regulation of the adhesion molecule, P-selectin, which is expressed on the surface of platelets and endothelial cells $(48,45,120)$ and can lead to plateletendothelial adhesion during pulmonary IR. Platelet activation and accumulation could mediate IR injury through endothelial adhesion and thrombi formation, as well as by interactions with leukocytes $(77,124)$.

\section{ROLE OF ADHESION MOLECULES IN PULMONARY IR}

Adhesion molecules are divided into two major groups: selectins and integrins. The current understanding is that selectins are responsible for initial adhesive interactions and integrins are involved in subsequent firm platelet and leukocyte adhesion to the endothelium and to each other $(38,80,113)$. Platelet and leukocyte adhesion both involve the sequential events of activation, rolling, and firm adhesion. Rolling is dependent on selectin-mediated interaction between endothelial cells (P-selectin and E-selectin), platelets (P-selectin) and leukocytes 
(L-selectin). Firm adherence and activation of leukocytes occurs when leukocyte ß1-integrin or B2-integrin binds to endothelial cells expressing intercellular adhesion molecule-1, or vascular endothelial adhesion molecule-1, respectively $(19,89,44,51)$. Blockade of adhesion molecules such as E-selectin, P-selectin, intercellular adhesion molecule-1, and CD18 during reperfusion, can reduce lung reperfusion injury $(79,98-102)$. L-selectin blockade may also be beneficial for prevention of leukocyte adhesion after several hours of reperfusion when neutrophils have a predominant role $(99,103,104)$. When given before reperfusion, analogs of the oligosaccharides, potent ligands for selectin adhesion molecules, have also been shown to reduce IR injury $(89,105-107)$.

Over-expression of selectins is a major cause of platelet-endothelial cell adherence $(2,5)$. P-selectin (CD62P, granule membrane protein 140 or plateletdependent granule or external membrane protein), the largest of the selectins with a mass of $140 \mathrm{kDa}$, is constitutively expressed in the $\alpha$-granules platelets (169) and the Weibel--Palade bodies of endothelial cells (170). P-selectin is a membrane protein with an $\mathrm{N}$-terminal lectin domain followed by an epidermal growth factor motif, nine regulatory protein repeats, a transmembrane section and a short intracytoplasmic C-tail $(113,114,168)$. P-selectin is trans-located to the surface of platelets and endothelial cells within minutes when these cells are activated by stimuli such as thrombin, histamine, hydrogen peroxide or hypoxia $(36,52,113)$. As rapidly as two minutes after stimulation, P-selectin is expressed at the surface, but 
this expression can be short lived, reaching its peak after only 10 minutes and declining to baseline after 3 hours (115-117). Additional synthesis of P-selectin is brought about within 2 hours by different stimuli such as cytokines, tumor necrosis factor- $\alpha$, thrombin or oxygen radicals (116-118). Following platelet stimulation, Pselectin expressed on the platelet surface, becomes rapidly shed and forms the soluble fraction of plasma P-selectin (171), which may have its own physiological activity $(28,168)$. In contrast, P-selectin expressed on the surface of the endothelial cells does not contribute to the soluble P-selectin fraction (172).

The primary ligand for P-selectin is P-selectin glycoprotein ligand (PSGL-1), a homodimeric mucin rich in $\mathrm{O}$ - and N-glycans consisting of two $120 \mathrm{kDa}$ polypeptide chains, which is constitutively expressed mostly on endothelial cell and leukocyte membranes (173) (Fig. 2). PSGL-1 is a non-specific ligand and also acts as a ligand for the other selectins (175). From P-selectin-PSGL-1 interactions, multiple downstream signaling events are generated involving their cytoplasmic tails. These events include intracellular signaling with tyrosine phosphorylation of cytoplasmic proteins (174) that triggers a functional upregulation of the integrins $(\mathrm{CD} 11 \mathrm{~b} / \mathrm{CD} 18$, Mac-1) which mediates firm adhesion of platelets and leukocytes (168).

Physiological intravascular shear stress, which causes a normal concentration of NO, is an inhibitory regulator of P-selectin expression $(119,120)$. P-selectin expression on activated platelets may not simply aid platelet-endothelial adhesion and also may be important for inter-platelet 
aggregation $(121,158)$. It has been suggested that P-selectin plays a role in inflammation and atherogenesis by further activating the endothelium and regulating production of platelet activating factor by monocytes (122), and inducing the formation of tissue factor $(123,124)$.

E-selectin occurs on endothelial cells after activation by inflammatory cytokines and typically takes hours to express (34). Expression of P-selectin appears to be involved in myocardial IR injury, where it may cause early reperfusion-induced tissue damage attributed to neutrophil infiltration (33). Cooper D. et al (45) found that IR induces time-dependent platelet-endothelial adhesion in postcapillary venules via a mechanism that involves both platelet and endothelial P-selectin, with platelet P-selectin playing a greater role.

Recent studies suggest that platelets are important in IR injury, not only through adhesion and thrombi formation, but also through participation in inflammatory interactions with leukocytes (77). IR leads to an inflammation reaction by leukocyte infiltration and subsequent organ dysfunction $(74,75)$. Activated platelets contribute to leukocyte adhesion to the vascular wall enabling them to transfer to the surface of the endothelium $(76,77)$. Moreover, Nishijima et al (2004) demonstrated in vivo that platelet depletion suppresses leukocyte rolling and accumulation in post-ischemic tissues. They showed that platelets play a major role in the leukocyte recruitment after ischemia-reperfusion through expression of platelet P-selectin (73). 


\section{IR INDUCED OXIDATIVE STRESS}

IR causes oxidative stress which is characterized by the formation of superoxide anion, hydrogen peroxide and hydroxyl radicals, collectively known as reactive oxygen species (ROS) $(89,90)$. Pulmonary endothelial cells, smooth muscle cells, and lung macrophages have all been shown to generate superoxide, under both basal and stimulated conditions $(95,96,129-131)$. The endothelial cell content of superoxide is also modulated by mechanical forces such as physiological shear stress which was found to reduce superoxide $(132,177)$. During ischemia, the absence of shear stress triggers endothelial cell membrane depolarization which leads to activation of $\mathrm{NADPH}$ oxidase, nuclear factor- $\mathrm{kB}$, and iNOS $(95,97)$.

ROS have diverse actions on pulmonary tissue, including smooth muscle contraction, interaction with redox enzymes, cell proliferation, and gene transcription $(128,145)$. ROS produce endothelial cell injury by lipid peroxidation of their membranes $(90,139,144)$, and downregulate nitric oxide (NO) released from the endothelium, thus compromising endothelium-dependent relaxation $(125,126)$. In addition, overproduction of superoxide antagonizes the effects of a wide range of NO donors by reacting with NO (127). Mechanisms of ROS formation include accumulation of hypoxanthine and conversion of the 
enzyme xanthine dehydrogenase into xanthine oxidase during hypoxia, with the degradation of hypoxanthine into superoxide after reoxygenation (91). An NADPH oxidase-dependent mechanism forms ROS by reduction of oxygen into hydrogen peroxide and superoxide anion (92). IR of the ventilated lung has to be considered differently from other tissues, if oxygen is present in the alveoli during the ischemic period. On the one hand, alveolar oxygen helps maintain aerobic metabolism and prevents hypoxic ROS formation $(92,93)$. On the other hand, the absence of blood flow with a low oxygen gradient in the lung tissue and a high concentration of oxygen in the gas mixture can cause ROS formation $(91,94)$. Reactive oxygen metabolites can promote the formation of inflammatory agents by lipid peroxidation and subsequently activate and recruit leukocytes to post-ischemic tissue (43).

When NO reacts with ROS, it forms secondary reactive products such as nitrosonium cation $\left(\mathrm{NO}^{+}\right)$, nitroxil anion $\left(\mathrm{NO}^{-}\right)$and peroxynitrite $\left(\mathrm{ONOO}^{-}\right)(65,159)$ known as reactive nitrogen species (RNS) $(128,134)$. Peroxynitrite, the most common form of RNS, has been suggested to be responsible for significant cytotoxic effects and platelet activation (134). Reperfusion injury in skeletal muscle tissue (141), and platelet activation in vitro (142), can be prevented by superoxide free-radical scavengers (162). Following intestinal ischemia, increased iNOS expression and NO overproduction caused pulmonary damage by nitrosylation of tyrosine residues (88). Peroxynitrite reacts with most biological molecules, making 
peroxynitrite, a selective oxidant. Peroxynitrite modifies tyrosine in proteins to create nitrotyrosine, which is a RNS footprint that has been detected in vivo in major pathological conditions including IR $(111,153)$.

\section{ROLE OF NITRIC OXIDE IN PULMONARY IR}

Nitric oxide has become a well known signaling molecule critical to maintaining many physiological functions, including vascular tone. However, it has been shown that NO can be both protective (61-63) and deleterious to vascular homeostasis (64) through direct effects on cell signaling, as well as indirect actions. Overproduction of NO via the inducible nitric oxide synthase (iNOS) pathway is an important component in the pathogenesis of IR injury (55$57,72)$. During IR, excess NO production has been attributed to iNOS that is not stimulated under normal conditions, but can be induced within $2 \mathrm{~h}$ of lung reperfusion (65) and results in upregulation of adhesion molecules (68). The direct effects of NO are related to low and brief NO production. These effects are usually involved in protective mechanisms such as arterial vasodilatation, which leads to improved perfusion and oxygen delivery, and antithrombotic activity, principally by inhibiting platelet function under normal physiologic conditions. In contrast, indirect effects occur under high and sustained flux of NO under pathophysiologic circumstances (65). Administration of NO during ischemia in a 
systemic vascular bed was reported to be protective in IR (87), but administration of NO during reperfusion is associated with endothelial dysfunction and increased vascular permeability (86). These pathological effects could relate to the interaction of NO with reactive oxygen species, since they are prevented by superoxide free radical scavengers $(141,142)$. Physiological concentrations of NO inhibit platelet activation by downregulating platelet P-selectin $(31,157)$ through activation of platelet soluble guanilate cyclase and increasing levels of cGMP (161). A regulatory effect of NO on endothelial P-selectin expression that modulates leukocyte-endothelial cell interactions to preserve vascular homeostasis also has been shown (119).

NO is synthesized by nitric oxide synthase (NOS), a complex enzyme which acts on a pair of substrates (molecular oxygen and L-arginine) to produce NO and L-citrulline $(58,155)$. This process requires five essential cofactors $\left(\mathrm{FMNH}_{2}, \mathrm{FADH}, \mathrm{NADPH}\right.$, calmodulin and tetrahydrobiopterin) and two divalent cations: $\mathrm{Ca}^{2+}$ and heme $\mathrm{Fe}^{2+}$. Three distinct isoforms of NOS have been identified: neuronal NOS (nNOS or NOS 1), endothelial NOS (eNOS or NOS 3), and inducible NOS (iNOS or NOS 2). All 3 known NOS isoforms are expressed in the lung, including nNOS and eNOS, which are calcium-dependent and usually expressed constitutively. However, iNOS is calcium-independent and is expressed only when cells are stimulated $(59,60,156)$. The iNOS has been implicated in the pathogenesis of IR injury, shock and inflammation $(48,55-57)$. 
Following intestinal ischemia, Virlos et al (2003) (88) found that pulmonary damage is associated with increased iNOS expression, NO overproduction and consequent nitrosylation of protein tyrosine residues in the lung which leads to, and aggravates pulmonary injury. Under stress, when cellular L-arginine is depleted, NO synthase is capable of generating superoxide (133). In addition, inhibition of physiological NO production leads to increased leukocyte (146) and platelet $(157,165)$ rolling and adhesion in various vascular beds, and adhesion molecule P-selectin is implicated in these processes (146).

During IR, excess NO production has been attributed to iNOS that is not present under normal conditions, but can be induced within $2 \mathrm{~h}$, reaching significant levels by 4 to $6 \mathrm{~h}$ of lung reperfusion $(59,60)$. The iNOS inhibitor aminoguanidine, as we showed previously (167), attenuates increased pulmonary vascular resistance during lung IR (184). The local release of large amounts of NO by iNOS is linked to the production of harmful oxidative products such as peroxynitrite, when NO reacts with other molecules such as superoxide (65-67). In experiments with "iNOS-knock out" mice, Cuzzocrea S. et al (68) showed that that the induction of iNOS and NO production are essential for the upregulation of the inflammatory response in splanchnic IR. Both iNOS and NO participate in end-organ damage by upregulation of adhesion molecules, neutrophil infiltration, as well as oxidative and nitrosative stress. ROS, produced during IR, have also been implicated in a number of signal transduction pathways (69). Normal concentrations of NO act as an inhibitory 
regulator of P-selectin expression (119), and inhibition of physiological NO production leads to increased platelet and leukocyte rolling and adhesion in various vascular beds $(146,157)$. In contrast, high and sustained flux of NO under pathophysiologic circumstances leads to increased P-selectin expression $(65,119)$ which may promote to platelet-vascular wall interactions.

\section{SUMMARY}

IR induces oxidative stress and is characterized by formation of ROS and reactive nitrogen species. As a consequence of the oxidative stress, there are platelet-endothelial interactions and release of vasoactive substances. IR induced oxidative stress can up-regulate the adhesion molecule, P-selectin, which is rapidly expressed on the surface of stimulated platelets and endothelial cells and leads to platelet-arteriolar wall rolling and adhesion. These platelet-endothelial interactions play an important role in causing post-ischemic hypoperfusion and may contribute to the arteriolar vasoconstriction during reperfusion by releasing mediators such as serotonin, thromboxane $\mathrm{A}_{2}$, and platelet activating factor and cause further endothelial damage associated with microvascular hypoperfusion. Overproduction of NO via the iNOS is an important component in the pathogenesis of ischemia-reperfusion injury. When NO reacts with ROS, it form secondary reactive products known as reactive nitrogen species. Peroxynitrite is 
the most common form of RNS and has been suggested to be responsible for significant cytotoxic effects, as well as platelet activation that may result in upregulation of adhesion molecules. This mechanism of injury may be particularly important during pulmonary IR with increased iNOS activity in the presence of oxidative stress.

\section{HYPOTHESIS AND SPECIFIC AIMS}

Reperfusion of the ischemic lung causes pulmonary arteriolar vasoconstriction and reduces alveolar perfusion. During the oxidative stress of ischemia and reperfusion, formation of reactive nitrogen species may promote platelet adhesion to the vascular wall with subsequent formation of microthrombi and release of vasoactive substances. Platelets play an important role in causing reperfusion injury in the systemic vasculature. However, information is lacking about consequences of their interactions with the arteriolar wall in the pulmonary microcirculation over the time course of lung reperfusion. During IR induced oxidative stress, overproduction of NO could contribute to formation of harmful RNS. The emphasis of the present study was to investigate the relationship between iNOS, RNS, P-selectin and platelet-arteriolar wall rolling/adhesion and microvascular constriction in the intact lung during the time course of pulmonary ischemia-reperfusion injury. The overall goal of this research was to investigate 
mechanisms causing increased platelet interaction with endothelium which could lead to pulmonary arteriolar constriction and decreased alveolar blood flow. We examined the hypothesis that pulmonary IR induces platelet-arteriolar wall interactions via a P-selectin dependent mechanism and contributes to pulmonary microvascular constriction during reperfusion. Increased Pselectin expression results from elevated iNOS activity and subsequent RNS generation (Fig.1).

The specific aims were:

1. To determine if platelet rolling and/or adhesion along pulmonary arterioles occurs during lung reperfusion and, if so, could those interactions contribute to pulmonary postischemic microvascular constriction.

2. To examine if platelet and/or lung tissue P-selectin is involved in plateletarteriolar wall interactions during pulmonary reperfusion.

3. To investigate if there is an increase in iNOS activity which leads to RNS formation, and P-selectin dependent platelet-arteriolar wall interactions during reperfusion. 


\section{CHAPTER II}

\section{MATHERIALS AND METHODS}

General. Approved by IACUC, experiments were done acutely on male rabbits (2.2 $\pm 0.2 \mathrm{~kg}$ body weight) (178). Anesthesia was induced with a ketaminexylazine mixture $(1 \mathrm{ml} / \mathrm{kg}$; containing ketamine $37.5 \mathrm{mg} / \mathrm{ml}$ and xylazine 5 $\mathrm{mg} / \mathrm{ml}$ ) given intramuscularly followed by aliquots of sodium pentobarbital ( 5 $\mathrm{mg} / \mathrm{kg}$ ) given slowly through an ear vein to gradually reach a loading dose of approximately $40 \mathrm{mg} / \mathrm{kg}$. A catheter (PE 90) was placed in the left femoral vein for subsequent injections of supplemental doses of sodium pentobarbital (approximately $6-10 \mathrm{mg} / \mathrm{kg}$ or $25 \mathrm{mg} / \mathrm{h}$ ) to maintain an adequate level of anesthesia as defined by absence of an active corneal reflex, whisker twitching, and a pedal reflex to a toe pinch. Spontaneous breathing was suppressed at this level of anesthesia. The trachea was cannulated below the larynx and the lungs 
were ventilated with air by a volume-cycled ventilator (CWE, model CTP-930, Ardmore, PA) with $0-3 \mathrm{~cm} \mathrm{H}_{2} \mathrm{O}$ positive end-expiratory pressure. Tracheal pressure was measured through a sideport of the tracheal catheter that was attached to a volumetric pressure transducer (Grass PT-5, Quincy, MA). Tidal volume and frequency were adjusted as necessary to achieve normal blood gas values during control. PE-90 was placed in the left femoral artery to monitor arterial blood pressure by a transducer (Statham P23ID, Gould, Oxnard, CA) and to periodically removing blood samples for $\mathrm{PO}_{2}, \mathrm{PCO}_{2}$, and $\mathrm{pH}$ measurements (NOVA Biomedical, STAT Profile 1 analyzer, Waltham, MA). Catheter patency was maintained by using $0.5-1.0 \mathrm{ml}$ of heparinized (10 units $/ \mathrm{ml}) 0.9 \%$ saline to clear the catheter after obtaining blood samples (Fig.3). In all animals, after the initial surgery, the lungs were ventilated with $50 \% \mathrm{O}_{2}$ in $\mathrm{N}_{2}$ to keep arterial $\mathrm{PO}_{2}$ above $100 \mathrm{mmHg}$ during IR. Tidal $\mathrm{CO}_{2}$ was monitored by a $\mathrm{CO}_{2}$ analyzer (Nellcore, model BP-1000, Haward, CA) and kept at about $40 \mathrm{~mm} \mathrm{Hg}$ by adjusting ventilation. PE 90 was placed in the right atrium via the right jugular vein to inject rhodamine, fluorescently labeled platelets, and to infuse $1400 \mathrm{~W}$. The signals representing tracheal pressure, arterial blood pressure, and heart rate were amplified and recorded continuously by a polygraph system (Grass model 7D, Quincy MA). 
Microvascular Observations. With the rabbit on a temperature-controlled heating pad on the stage of a modified trinocular microscope (Zeiss, Thornwood, NY) equipped with epi-illumination, the chest was opened mid-sternally and the right pulmonary artery was exposed at the hilum of the lung. The rabbit was placed on its left side and the right side of the chest was opened in the fifth intercostal space. The objective lens (Leitz L10, numerical aperture 0.22 ) with a glass dipping cone (5-mm diameter at the tip) was positioned above the right lung and lowered to the pleural surface using a technique for observing subpleural vessels and ventilated alveoli in the intact lung (37) when the lung was held inflated for brief periods (about $1 \mathrm{~min}$ ) by switching from the ventilator to a system that delivered $\mathrm{O}_{2}$ at a constant pressure of approximately $10 \mathrm{~cm} \mathrm{H}_{2} \mathrm{O}$. A lightsensitive silicon-intensified target (SIT) camera (C2400, Hamamatsu Photonics, Japan) was used to transfer images to a high-resolution monitor that were stored on videotape for off-line analysis (Fig.4). Arterioles were identified, and internal vessel diameters and segment lengths were measured from the monitor screen with a caliper that was calibrated using a stage micrometer. From images recorded continuously during observation periods, measurements were made at 3-s intervals over a period of $30 \mathrm{~s}$. Between observations, the surface of the lung was kept moist by spraying it with physiological saline solution kept at about $37^{\circ} \mathrm{C}$. 
Pulmonary Artery Occlusion-Reperfusion. A removable surgical clip was placed on the right main pulmonary artery to occlude pulmonary blood flow to the right lung (ischemia) and then removed to initiate reperfusion. The effectiveness of occlusion (and reperfusion) was verified by microvascular examination for the presence of subpleural blood flow.

Fluorescent Labeling of Platelets, Platelet Counting and Analysis of their Behavior. Blood ( $2.2 \mathrm{ml} / \mathrm{kg}$ of body weight) was removed before pulmonary artery occlusion from the femoral artery catheter with a syringe containing $3.2 \%$ trisodium citrate (with a ratio of 1 part of citrate to 9 parts blood; final citrate concentration, $10.9 \mathrm{mM}$ ) and centrifuged at $200 \times \mathrm{g}$ for $15 \mathrm{~min}$. The platelet-rich plasma was carefully collected from the centrifuge tubes with a fine-tip plastic pipette, transferred to separate tubes, and centrifuged at $800 \times \mathrm{g}$ for $10 \mathrm{~min}$. The supernatant was discarded and the platelet pellet was resuspended in $3 \mathrm{ml}$ of calcium-free Tyrodes buffer (TBSS; composition in $\mathrm{mM}$ : $\mathrm{NaCl}, 137 ; \mathrm{KCl}, 2.6$; $\mathrm{NaH}_{2} \mathrm{PO}_{4}, 0.4 ; \mathrm{MgCl}_{2}, 1.0$; and glucose, 5.6, $\mathrm{pH}=7.4$ ) containing $10 \mathrm{mM}$ HEPES and $0.25 \%$ bovine serum albumin (24). The suspension was centrifuged at $800 \times \mathrm{g}$ for $10 \mathrm{~min}$, and then the platelet pellet was resuspended in $1 \mathrm{ml}$ of TBSS and $8 \quad \mu 1$ BCECF, AM (2 ${ }^{1}, 7^{1}$-bis-(2-carboxyethyl)-5-[and -6]carboxyfluorescein, acetoxymethyl ester (Molecular Probes, Inc., Eugene, OR). The suspension was gently mixed and incubated for $15 \mathrm{~min}$ at $37^{\circ} \mathrm{C}$ with 
occasional gentle agitation. After incubation, the conjugate suspension was centrifuged at $800 \times \mathrm{g}$ for $5 \mathrm{~min}$ to remove excess fluorescence. The fluorescently labeled platelets were then resuspended in $1.0 \mathrm{ml}$ of TBSS without albumin. A $20-\mu 1$ sample was used for platelet counting and examination in a hemocytometer. An inverted microscope (Zeiss Axiovert 10, Germany) equipped with a blue filter (450-490 nm) was used for platelet counting and to ensure that platelets in the sample were labeled, and that there was an absence of platelet aggregates. The remainder of the platelet suspension was drawn into a 1-ml syringe for subsequent injection into the right jugular vein. In some experiments, nonlabeled platelets were counted from arterial blood samples taken before pulmonary artery occlusion and at the end of the experiment after $2 \mathrm{~h}$ of reperfusion. The behavior of the labeled platelets in microvessels was detected using a fluorescence filter $(450-490 \mathrm{~nm})$ on the light source $(100 \mathrm{~W}$ mercury arc lamp) of the microscope and the light-sensitive video camera using off-line, frame-by-frame video analysis similar to methods reported by others (9). Platelets were classified as free flowing, rolling, or adherent according to their interaction with the endothelium. Free flowing platelets were those that passed an imaginary line perpendicular to the vessel axis in the area of interest, without apparent endothelial interaction. Adherent platelets were defined as those platelets that did not detach from the endothelium for a period of at least $3 \mathrm{~s}$. Rolling platelets were defined as those platelets that moved along the 
endothelium of the vessel, touching a visible wall. These platelets moved at a much slower velocity than the platelets in the center of the vessel and even stopped periodically (for less than $3 \mathrm{~s}$ ). Platelet rolling was quantified as the number of rolling platelets per square millimeter of vessel area during $30 \mathrm{~s}$. Platelet adherence was quantified as the average number of adherent platelets per square millimeter of vessel area over $30 \mathrm{~s}$. To control for differences in the number of platelets flowing per time, for each measurement period, platelet rolling and adherence were also normalized. The above values were divided by the total number of platelets that could be observed entering the vessel segment during the measurement interval (30 s) and expressed as a percent. Observations were made in arterioles that were approximately one to two branching orders upstream of the pulmonary capillaries (37), and platelets were counted along relatively straight sections (on average, approximately $250 \mu \mathrm{m}$ long) between the visible branches. Internal arteriolar diameter was taken as the average of measurements at the proximal, middle, and distal end of the observed segment, and the area of the vessel segment in the focal plane of the objective was calculated. The same arteriolar segments were observed over the course of an experiment, and length and diameter measurements were repeated for each $30-\mathrm{s}$ observation period. 


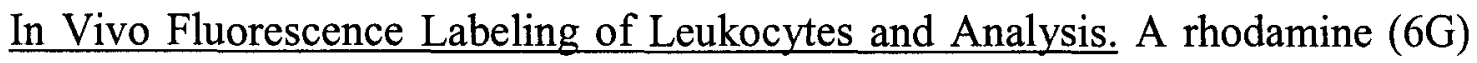
dye solution $0.2 \mathrm{ml} / \mathrm{kg}$ body weight) prepared by dissolving rhodamine in saline $(0.02 \mathrm{~g} / 100 \mathrm{ml})$ and used according the methods of Kuhnle et al (21), was injected into jugular vein. Leukocyte flux in the vessel was quantified as the number of leukocytes rolling or adhered per time unit. The observation period was $15-30$ seconds. Leukocytes intermittently interacting with the vessel endothelium (rolling cells) were identified as those cells moving considerably slower than leukocytes in the center stream and making intermittent contact with the endothelium. They were expressed as cells/endothelial area (calculated as number of cells/length of observed vessel segment $\mathrm{x}$ vessel diameter).

Administration of Fucoidan, 1400W and Use of Monoclonal Antibodies to PSelectin. In experiments with the 2IR+Fucoidan group, Fucoidan (Sigma Co., St. Louis, MO) was infused $(27 \mu \mathrm{g} / \mathrm{kg} / \mathrm{min}, 0.57 \mathrm{ml} / \mathrm{h})$ into the right jugular vein approximately 10 min before reperfusion was started. This dose of Fucoidan has been shown to inhibit P- and L-selectins in similar types of experiments (33). Infusion was continued throughout the reperfusion period. In another series of experiments, to inhibit platelet $\mathrm{P}$-selectin expression, a monoclonal anti-human P-selectin antibody (CD-62P, $25 \mu \mathrm{g} / \mathrm{ml}$ ) we added to the fluorescently labeled platelets before they were injected (2IR + MoAb group). Rabbit P-selectin has been found to have a $74 \%$ homology with human P-selectin (36). For a control, 
in other rabbits, the same concentration of an isotype-matched nonblocking antibody (IgG1 $\kappa$ ) was added to the labeled platelets before injection (antibodies were purchased from Ancell Corporation, Bayport, MN) (2IR+ IgG group). In the $2 \mathrm{IR}+1400 \mathrm{~W}$ group, approximately 10 minutes before the occlusion period was started, an iNOS blocker (1400W, $10 \mathrm{mg} / \mathrm{kg}, 4.1 \mathrm{ml} / \mathrm{h}$ ) was infused through the right jugular vein catheter during $1 \mathrm{~h}$ prior to a 2 -h occlusion (166).

Topical application of peroxynitrite to the subpleural arterioles. Sodium peroxynitrite solutions were prepared according to manufacturer instructions (Cayman chemical, Ann Arbor, MI). 0.5 or $1.0 \mu \mathrm{M}$ of peroxynitrite was applied to subpleural arterioles in $100 \mu 1$ aliquot immediately after a control period during microvascular observation. The vehicle control was done by replacing 0.5 and $1.0 \mu \mathrm{M}$ of peroxynitrite to $0.3 \mathrm{~N} \mathrm{NaOH}(0.044 \mathrm{mM}$ and $0.088 \mathrm{mM}$, respectively) in saline.

Lung tissue samples. After 2-h reperfusion, both lungs from all animals were perfused with $60 \mathrm{ml}$ of ice-cold saline via the main pulmonary artery, removed from the animal, frozen in liquid nitrogen, and stored at $-80^{\circ} \mathrm{C}$.

Western Blot Analysis For iNOS. After 2-h reperfusion, the lungs were perfused with $60 \mathrm{ml}$ of ice-cold saline via the main pulmonary artery, removed from the 
animal, frozen in liquid nitrogen, and stored at $-80^{\circ} \mathrm{C}$. Lung tissue was homogenized on ice in a buffer containing Tris $(25 \mathrm{mM})$, EDTA $(10 \mathrm{mM})$, EGTA $(10 \mathrm{mM}), \mathrm{NaF}(10 \mathrm{mM})$, PMSF $(100 \mathrm{mM})$, Aprotonin $(1 \mathrm{mg} / \mathrm{ml})$, Leupeptin $(1 \mathrm{mg} / \mathrm{ml})$, and $10 \%$ Triton-X. Homogenized lung samples were sonicated on ice and centrifuged at $10,000 \mathrm{x}$ g for 15 minutes. Cell membrane and cytosolic fractions were separated by ultracentrifugation of the supernatant at $100,000 \times \mathrm{g}$ for 1 hour and the cytosolic fraction was used for Western blot analysis of iNOS. Proteins $(100 \mu \mathrm{g})$ were separated by SDS-PAGE on a $4-12 \%$ gradient denaturing gel and electro-blotted onto nitrocellulose membranes. Gel transfer efficiency and equal loading of proteins was verified by Ponceau staining of nitrocellulose membranes. The membrane was blocked for $1 \mathrm{~h}$ in $5 \%$ nonfat milk in Tris-buffered saline with Tween-20 (0.05\%) (TBS-T) and incubated overnight with a rabbit polyclonal anti-iNOS primary antibody (Upstate; Lake Placid, NY; 1:1000 dilution). The nitrocellulose membranes were washed with TBS-T and then incubated with a horseradish peroxidase (HRP)conjugated anti-rabbit antibody (Cell Signaling Technologies; Beverly, MA), and washed with TBS-T. Proteins were visualized by a standard chemiluminescence (ECL) method (Amersham Biosciences). Equal loading of proteins was verified by probing the membrane with a mouse monoclonal anti- $\beta$-actin primary antibody (Sigma, 1:20,000 dilution). The films were scanned by an optical scanner (UMAX Powerlook II, Dallas, TX) and quantified by measuring the 
density of each band and subtracting the background density using UN-SCAN-IT software (Silk Scientific, Inc.; Orem, UT). To correct for possible unequal loading, each band's optical density was normalized by its $\beta$-actin density.

NOS Activity Measurements were quantified by counting the radioactivity of the eluate (citrulline) with a liquid scintillation counter using a NOS activity assay kit (Cayman Chemical). Lung tissue $(100 \mathrm{mg})$ was homogenized in a buffer containing $250 \mathrm{mM}$ Tris-HCL (pH 7.4), $10 \mathrm{mM}$ EDTA, and $10 \mathrm{mM}$ EGTA and centrifuged at $10,000 \mathrm{x}$ g for 15 minutes at $4^{\circ} \mathrm{C}$. Forty $\mu \mathrm{g}$ of protein from the supernatant was incubated with a reaction buffer containing $50 \mathrm{mM}$ Tris- $\mathrm{HCl}$ ( $\mathrm{pH}$ 7.4), $6 \mu \mathrm{M}$ tetrahydrobiopterin $\left(\mathrm{BH}_{4}\right), 2 \mu \mathrm{M}$ flavin adenine dinucleotide, 2 $\mu \mathrm{M}$ flavin adenine mononucleotide, and ${ }^{14} \mathrm{C}$ or ${ }^{3} \mathrm{H}$ arginine $(1 \mu \mathrm{Ci} / \mu \mathrm{l})$ for $1 \mathrm{hr}$. After incubation, the reaction was stopped with a buffer containing $50 \mu \mathrm{M} \mathrm{N}-2$ hydroxyethylpiperazine-N'-2-ethanesulfonic acid (HEPES pH 5.5) and 5mM EDTA. An equilibrated resin, which binds unreacted arginine, was added to the reaction mixture and the entire solution was placed into spin cups to separate arginine and citrulline. Activity was expressed as counts per minute (CPM)/40 $\mu \mathrm{g}$ protein. Positive and negative (no sample) controls were used to check reaction efficiency and control for background readings respectively. 
Fluorescence Immunohistochemistry for lung tissue P-selectin and Nitrotyrosine expression analysis. Sections $(10 \mu \mathrm{m})$ were cut from snap-frozen tissue blocks, air dried for $2 \mathrm{~h}$, and fixed at room temperature $\left(20-25^{\circ} \mathrm{C}\right)$ in acetone for $10 \mathrm{~min}$. After complete dehydration and removal of the media around tissue, slides were washed in $0.1 \mathrm{M}$ TBS for 5 min and blocked with $10 \%$ donkey serum in $0.1 \mathrm{M}$ TBS $+0.3 \%$ triton $+0.5 \%$ BSA solution for $1 \mathrm{~h}$. Primary antibodies (mouse antiP-selectin CD62P or anti-Nitrotyrosine $\operatorname{IgG}_{1}$ isotype, $1: 200$ ) in $0.1 \mathrm{M}$ TBS $+0.3 \%$ triton $+0.5 \% \mathrm{BSA}+5 \%$ serum were applied for $24 \mathrm{~h}$ at $4^{\circ} \mathrm{C}$, followed by a 10 min rinse in $0.1 \mathrm{M}$ TBS. After being washed in $0.1 \mathrm{M}$ TBS $(3 \times 10 \mathrm{~min})$, slides were covered with fluorescently labeled secondary antibodies in $0.1 \mathrm{M}$ TBS + $0.3 \%$ triton $+5 \%$ serum, and incubated in the dark at room temperature for $1 \mathrm{~h}$. The slides were washed the same way again, and covered using a Prolong Antifade kit (Molecular Probe, Eugene, OR). A negative control was prepared by replacing specific antibodies with non-specific $\mathrm{IGg}_{1}$ antibodies. The expression was detected on a fluorescent microscope (Nikon Eclipse E800) with 10x/0.30 Plan Fluor Objective and RT Color Spot Camera (Diagnostic Instruments Inc., Sterling Heights, MI). Five fields from every tissue section were randomly selected using a UV-2A filter followed by switching to a FITC-HYQ filter. Quantitative analysis was done using an Image Pro program (IMAGE-PRO Media Cybernetics, Silver Spring, MD). Data were expressed in area $\left(\mathrm{px}^{2}\right)$ of marker and averaged for each group. 
Plasma sP-selectin concentration detection. Citrated plasma samples were taken during baseline and after $2 \mathrm{~h}$ of reperfusion (85). Quantitative analysis of soluble P-selectin (sP-selectin) was done using the ZyQuik sP-selectin enzyme-linked immunosorbent sandwich assay (ELISA) Kit (Zymed Laboratories Inc., San Francisco, CA) and SpectraMax M2 Analyzer (Molecular Device, Sunnyvale, $\mathrm{CA}$ ) according to the manufacturer's instructions. The data were expressed as sPselectin concentration in plasma $(\mathrm{ng} / \mathrm{ml})$.

\section{EXPERIMENTAL DESIGN}

The specific aim \#1 was to determine if platelet rolling and/or adhesion along pulmonary arterioles occurs during lung reperfusion and, if so, could those interactions contribute to pulmonary postischemic microvascular constriction. This aim was investigated by examining the effects of pulmonary artery ischemia on platelet-/leukocyte-arteriolar wall interactions and vasoconstriction in subpleural arterioles during the time course of pulmonary reperfusion. To investigate the "dose response", the right pulmonary artery had been clipped for different time periods. Animals with shorter occlusions (5 min) served as sham controls and animals without occlusion were controls for animals where the right pulmonary artery was clipped for $1 \mathrm{~h}$ or $2 \mathrm{~h}$. Subpleural arterioles in the right lung 
identified during a control period were subsequently observed over 30 -s periods during occlusion and reperfusion. Fluorescently labeled platelets and rhodamine dye (in experiments when leukocyte behavior was studied) were usually injected approximately 2-10 min before releasing the occlusion, and the lung was examined to confirm the absence of platelets in the pulmonary circulation. After releasing the occlusion, arterioles were examined after $0.5,1$, and $2 \mathrm{~h}$ of reperfusion.

The specific aim \#2 was to examine if platelet and/or lung tissue P-selectin is involved in platelet-arteriolar wall interactions during pulmonary reperfusion. This aim was investigated by examining the effects of 2-h pulmonary ischemia with and without blocking P-selectin, on platelet-arteriolar wall interactions and vasoconstriction during reperfusion. To assess the general role of selectins in mediating the platelet responses during reperfusion of the intact lung, Fucoidan was given systemically throughout the reperfusion period in a group of animals. To investigate the role of platelet $\mathrm{P}$-selectin, monoclonal antibodies with a high specificity for immuno-neutralization of rabbit P-selectin, were mixed with the platelet sample $15 \mathrm{~min}$ before injection in another group of animals. In separate animals, as a control before injection, labeled platelets were pretreated with the nonspecific IgG1א antibody. P-selectin expression in lung tissue after IR was detected by immunohistochemistry. Concentration of soluble P-selectin (sPselectin) was measured in plasma samples from the left atrium by ELISA. 
The specific aim \#3 was to investigate if there is an increase in iNOS activity which leads to RNS formation and P-selectin-dependent platelet-arteriolar wall interactions during reperfusion. This aim was investigated by examining the effects of 2-h pulmonary ischemia on platelet-arteriolar wall interactions and vasoconstriction during reperfusion in the presence or absence of iNOS inhibitor. In the animals after 2-h pulmonary ischemia, during reperfusion, an iNOS blocker $(1400 \mathrm{~W}, 10 \mathrm{mg} / \mathrm{kg})$ was infused through the right jugular vein catheter. To verify that RNS can cause platelet activation, peroxynitrite was applied topically in a $100 \mu 1$ aliquot to subpleural arterioles in animals without IR. Effects of IR on iNOS expression and activity were examined by Western blotting and radioimmunoassay of lung tissue. P-selectin /RNS expression in lung tissue and concentration of $\mathrm{sP}$-selectin after IR were detected by immunohistochemistry and ELISA (Fig.5).

Data analysis. Arterial blood pressure, heart rate, and tracheal pressure were recorded continuously and measurements were taken during microvascular observations. Each measurement period lasted for approximately $30 \mathrm{~s}$. In each animal, one to three arterioles and approximately three branches of each vessel in the area of interest were examined. Platelet determinations were averaged for each observation so that each animal counted equally in the analysis. Arterioles were observed during a control period, during pulmonary artery occlusion, and at 
$0.5,1$ and $2 \mathrm{~h}$ during reperfusion of the ischemic lung. Values are reported as mean \pm SEM. Differences between observation periods and between groups were compared by one-way analysis of variance (ANOVA) with repeated measurements and multiple comparisons (consideration given to within-sample variability of observations). When comparing the means of only two experimental groups, a non-paired t-test was used. Correlation coefficient (r) and the linear regression analysis were used to test the relationship between two variables. A probability level of $\mathrm{p}<0.05$ was used to indicate statistical significance. 


\section{CHAPTER III}

\section{RESULTS}

Mean arterial blood pressure and heart rate for all animals $(n=50)$ averaged $81 \pm 6 \mathrm{~mm} \mathrm{Hg}$ and $193 \pm 7$ beats/min during baseline before occlusion and they were not significantly different when the lungs were statically inflated for observations. In the different experimental groups there were no significant differences in blood pressure or heart rate (Table 1). During reperfusion at 0.5 , 1.0 , and $2.0 \mathrm{~h}$ of reperfusion, blood pressure generally tended to be lower $(72 \pm 3$ $\mathrm{mm} \mathrm{Hg}, 71 \pm 3 \mathrm{~mm} \mathrm{Hg}$ and $73 \pm 4 \mathrm{~mm} \mathrm{Hg}$, respectively), but the decrease was not significant. Heart rate also was not significantly different from the preocclusion baseline $(183 \pm 4$ beats/min at $0.5 \mathrm{~h}$ and $176 \pm 5$ beats $/ \mathrm{min}$ at 1.0 and $2.0 \mathrm{~h}$, respectively) (Table 1$)$.

Arterial $\mathrm{PO}_{2}, \mathrm{PCO}_{2}$ and $\mathrm{pH}$ before occlusion $(186 \pm 11 \mathrm{~mm} \mathrm{Hg}, 42 \pm 3$

$\mathrm{mm} \mathrm{Hg}$ and $7.39 \pm 0.02$, respectively) were not significantly different during reperfusion $(214 \pm 8 \mathrm{~mm} \mathrm{Hg}, 41 \pm 2 \mathrm{~mm} \mathrm{Hg}$ and $7.41 \pm 0.03$, respectively) (Table 2). Injection of labeled platelets, Rhodamine, Fucoidan, infusion of 
$1400 \mathrm{~W}$, or blood sampling did not significantly affect blood pressure, heart rate, arterial blood gases or $\mathrm{pH}$.

Effect of IR on platelet-arteriolar wall interactions and arteriolar vasoconstriction: In five animals, in which labeled platelets were injected without occluding the pulmonary artery (control group), platelets were not found rolling or adhered along arteriolar walls. Furthermore, arteriolar diameters did not change significantly from baseline during a 2-h observation period.

In 12 arterioles that were examined in five animals in which the right pulmonary artery was clipped for 5-min (sham group), diameter averaged $48 \pm 4$ $\mu \mathrm{m}$ during baseline (before occlusion). After the clip was removed, diameters were not significantly different after $0.5,1$ or $2 \mathrm{~h}(50 \pm 2 \mu \mathrm{m}, 53 \pm 2 \mu \mathrm{m}$, and $55 \pm 1 \mu \mathrm{m}$ at $0.5,1.0$, and $2.0 \mathrm{~h}$, respectively). In these arterioles, during reperfusion, an insignificant amount of the labeled platelets were observed rolling $(0.08 \pm 0.02 \%)$, and no platelets were found adhered to the arteriolar wall.

In the 1IR group (five animals), 16 arterioles with an average baseline diameter of $52 \pm 2 \mu \mathrm{m}$ before occlusion, were examined. Arteriolar diameters at $0.5 \mathrm{~h}$ of reperfusion were significantly less $(34 \pm 3 \mu \mathrm{m}, \mathrm{p}<0.05)$, but soon began to recover and at 1 and $2 \mathrm{~h}$ of reperfusion $(45 \pm 5 \mu \mathrm{m}$ and $48 \pm 4 \mu \mathrm{m}$, respectively) were not significantly different from baseline (Fig. 7). In these arterioles, $15.0 \pm 3.2 \%, 13.1 \pm 4.0 \%$ and $8.3 \pm 2.2 \%$ of flowing labeled platelets 
were rolling at $0.5,1$, and $2 \mathrm{~h}$ of reperfusion respectively, but platelet adhesion was not observed (Fig. 8). For the 1IR group, the change in arteriolar diameter did not correlate with reperfusion time, but the amount of platelet rolling decreased as a function of reperfusion time (Fig. 10A and 10C).

In the 2IR group (six animals), 17 arterioles (3 arterioles per animal generally) with an average baseline diameter $55 \pm 3 \mu \mathrm{m}$ were examined. In contrast to the 1IR group, arteriolar diameters were significantly $(p<0.05)$ less than baseline at all three observation periods during reperfusion $(31 \pm 2 \mu \mathrm{m}, 34 \pm$ $3 \mu \mathrm{m}$ and $40 \pm 3 \mu \mathrm{m}$, respectively) (Fig. 6 and 7). After $2 \mathrm{~h}$ of ischemia, as soon as blood flow begun to return, platelets were rolling and adhering to arteriolar walls (Fig. 9). Approximately twice as many platelets were observed rolling along the arteriolar walls at $0.5,1.0$ and $2.0 \mathrm{~h}$ of reperfusion than in the 1IR group (Fig. 8A). In addition, platelet adhesion was increased significantly above control throughout the 2 -h reperfusion period (Fig. 8B). This observation was consistent when the data were expressed as a fraction of the number of labeled platelets that entered the arteriolar segment during the observation period or normalized per area of that segment (Table 3). The number of rolling and adhering platelets and amount of vasoconstriction tended to decrease with reperfusion time (Fig. 8). For the 2IR group, vasoconstriction and platelet adhesion significantly correlated with reperfusion time (Fig. 10Band 10E) and 
amount of vasoconstriction correlated with the numbers of rolling and adhered platelets over the reperfusion time course (Fig. 11).

Leukocyte-arteriolar wall interactions and arteriolar vasoconstriction: In three rabbits that underwent 2-h lung ischemia, in addition to platelets, the behavior of leukocytes was also examined during the same reperfusion times (2IR $+\mathrm{L}$ group). During $2 \mathrm{~h}$ of reperfusion, significantly more $(25 \pm 4.4 \%)$ leukocytes were rolling than during baseline (Fig. 12A), but leukocyte adhesion was not observed. In contrast to platelets (Fig. 12B), the number of rolling leukocytes was relatively constant and did not have a tendency to decrease with progression of reperfusion time (Fig. 12A). Platelets and leukocytes had different rolling velocities $(30 \pm 3 \mu \mathrm{m} / \mathrm{sec}$ and $10 \pm 2$ $\mu \mathrm{m} / \mathrm{sec}$, respectively) and were rolling at different sites (Fig. 13).

Effect of Fucoidan on platelet-arteriolar wall interactions and vasoconstriction: Pretreatment with Fucoidan (2IR+Fucoidan group, five animals) prevented vasoconstriction during reperfusion after 2-h ischemia (Fig. 14). In the 13 arterioles that were observed, average baseline diameter before occlusion $(52 \pm 8 \mu \mathrm{m})$ was not significantly changed during reperfusion $(42 \pm 4 \mu \mathrm{m}, 55 \pm 8 \mu \mathrm{m}$, and $47 \pm 8 \mu \mathrm{m}$ at $0.5,1.0$, and $2.0 \mathrm{~h}$, respectively). In these arterioles, there was no significant platelet rolling or adhesion. No platelets were observed adhering in three of the five animals 
from this group. In the two remaining animals, only $0.42 \%$ of the observed platelets were rolling, and only $0.13 \%$ were adhered during reperfusion (Fig. 15).

Effects of P-selectin monoclonal antibody on platelet-arteriolar wall interactions: In the group in which labeled platelets were pretreated with monoclonal antibody $(2 \mathrm{IR}+\mathrm{MoAb}$ group, five animals) to P-selectin before they were injected, 17 arterioles were examined. Baseline diameter $(59 \pm 5 \mu \mathrm{m})$ decreased significantly at $0.5,1$ and $2 \mathrm{~h}$ of reperfusion $(36 \pm 4 \mu \mathrm{m}, 42 \pm 2 \mu \mathrm{m}$ and $44 \pm 4 \mu \mathrm{m}$, respectively). This decrease was similar to that of the 2IR group (Fig. 14). On average, during reperfusion, only $0.15 \pm 0.03 \%$ and $0.1 \pm 0.02 \%$ of the observed platelets were rolling and adhering, respectively and platelet-arteriolar wall interactions were prevented (Fig. 15).

As a control, labeled platelets were pretreated with the nonspecific IgG1 $\kappa$ antibody in four separate animals (2IR+IgG group, 10 arterioles). On average, during reperfusion, $21.0 \pm 5.0 \%$ and $2.7 \pm 0.8 \%$ of flowing labeled platelets were rolling and adhering, respectively. This was similar to what was found in the 2IR group (Fig. 15). Arteriolar constriction was also not prevented ( $62 \pm 4 \mu \mathrm{m}$ before and $39 \pm 2 \mu \mathrm{m}$ at $0.5 \mathrm{hr}, 44 \pm 3 \mu \mathrm{m}$ at $1 \mathrm{~h}, 43 \pm 5 \mu \mathrm{m}$ at $2 \mathrm{~h}$ of reperfusion). The effectiveness of Fucoidan and MoAb treatment in preventing platelet rolling and adhering was similar (Fig 15). 
Effects of IR on iNOS expression and activity: Lung tissues from rabbits that underwent 2 -h ischemia and 2-h reperfusion showed a significant increase (28 \pm 4\%) in INOS expression compared to control animals ( $n=5)$ (Fig.16A). Radioimmunoassay of lung tissue from this 2IR group indicated a 3 fold increase in total NOS activity compared to control lungs (Fig. 16B). In a separate group (five animals), after $3 \mathrm{~h}$ of occlusion and $2 \mathrm{~h}$ of reperfusion, there was 3.5 fold increases in total NOS activity compared to control. In the animals treated with $1400 \mathrm{~W}$ before $2 \mathrm{~h}$ of ischemia ( $2 \mathrm{IR}+1400 \mathrm{~W}$ group, $\mathrm{n}=5)$, there was no increase in total NOS activity (Fig. 16C).

Effect of $1400 \mathrm{~W}$ on platelet- and leukocyte-arteriolar wall interactions: In the $2 \mathrm{IR}+1400 \mathrm{~W}$ group (five animals), in contrast to the 2IR group, the number of rolling and adhering platelets at $0.5,1$ and $2 \mathrm{~h}$ of reperfusion significantly decreased (Fig. 17A). Moreover, pretreatment with $1400 \mathrm{~W}$ prevented pulmonary microvascular vasoconstriction during reperfusion (Fig. 17B). In the 10 arterioles that were observed, average baseline diameter before occlusion $(49 \pm 6 \mu \mathrm{m}) \mathrm{did}$ not significantly change during reperfusion ( $43 \pm 5 \mu \mathrm{m}, 52 \pm 6 \mu \mathrm{m}$, and $48 \pm 7 \mu \mathrm{m}$ at $0.5,1$, and $2 \mathrm{~h}$, respectively).

In $2-\mathrm{h}$ ischemic rabbits treated with $1400 \mathrm{~W}$, in which leukocytes were labeled in addition to platelets ( $2 \mathrm{IR}+\mathrm{L}+1400 \mathrm{~W}$ group, three animals), the number of rolling leukocytes was not significantly different from the $2 \mathrm{IR}+\mathrm{L}$ rabbits during 
the reperfusion time course (Fig.18). Pretreatment with $1400 \mathrm{~W}$ significantly decreased platelet-arteriolar wall interactions and vasoconstriction (Fig. 17B and 17A), but had no affect on leukocyte rolling (Fig. 18).

RNS expression in lung tissue: Immunohistochemical examination of lung tissue after 2-h reperfusion from 2IR animals revealed that there was a significant increase in nitrotyrosine expression compared to the control (Fig. 20B and 20C) and IIR groups (Fig. 21). The amount of nitrotyrosine expression increased with the duration of ischemia. There was no difference in nitrotyrosine expression in the left (non-ischemic) lungs between any groups (Fig. 21). When the level of nitrotyrosine expression was plotted as a function of ischemia time, there was a high correlation $(\mathrm{r}=0.97)$ (Fig. 23A). In the lungs of animals pretreated with 1400W that underwent 2-h IR, RNS expression was not different from sham animals (Fig. 21).

Lung tissue and platelet P-selectin expression: Immunohistochemistry for Pselectin in serial lung tissue sections from the frozen blocks that were used to detect nitrotyrosine, showed that a significant increase in P-selectin expression in 2IR animals compared to the control group (Fig. 22A and 22B). However, Pselectin expression in non-ischemic lungs was not increased (Fig. 24). Similarly to nitrotyrosine expression, the correlation between expression of lung tissue P- 
selectin and duration of ischemia was high (Fig. 23B). Moreover, when the levels of tissue P-selectin were plotted against RNS levels, the linear correlation was also high ( $\mathrm{r}=0.89)$ (Fig. 23C).

Similarly to tissue P-selectin, soluble P-selectin (sP-selectin) concentration in plasma samples was significantly increased in animals that underwent 2-h ischemia and 2-h reperfusion compared to the controls (Fig. 25).

Effect of $1400 \mathrm{~W}$ on platelet and lung tissue P-selectin and lung tissue nitrotyrosine expression: Pretreatment of 2IR animals with $1400 \mathrm{~W}$ significantly attenuated nitrotyrosine and P-selectin expression in ischemic lung tissue (Fig. 22 and 24), as well as sP-selectin in plasma (Fig. 25). 
Table 1. Arterial blood pressure and heart rate at baseline (b-line) before and during lung reperfusion. Values are means $\pm S E M$; $n=$ number of animals. $0.5,1.0$ and $2.0(\mathrm{~h})$ are the observation time points during $2 \mathrm{~h}$ of reperfusion. 
Table 1

\begin{tabular}{|c|c|c|c|c|c|c|c|c|c|}
\hline & & \multicolumn{4}{|c|}{$\mathrm{BP}(\mathrm{mm} \mathrm{Hg})$} & \multicolumn{4}{|c|}{ HR (beats/min) } \\
\hline & \multirow[t]{2}{*}{$\mathrm{n}$} & \multicolumn{4}{|c|}{ Reperfusion (h) } & \multicolumn{4}{|c|}{ Reperfusion (h) } \\
\hline & & 0 & 0.5 & 1.0 & 2.0 & 0 & 0.5 & 1.0 & 2.0 \\
\hline Sham & 5 & $83 \pm 5$ & $75 \pm 3$ & $72 \pm 3$ & $73 \pm 4$ & $192 \pm 4$ & $179 \pm 3$ & $178 \pm 5$ & $174 \pm 3$ \\
\hline Control & 5 & $82 \pm 3$ & $73 \pm 2$ & $70 \pm 2$ & $75 \pm 3$ & $189 \pm 3$ & $182 \pm 2$ & $179 \pm 3$ & $181 \pm 5$ \\
\hline Control+RNS & 4 & $83 \pm 4$ & $71 \pm 3$ & $72 \pm 3$ & $74 \pm 3$ & $185 \pm 7$ & $183 \pm 5$ & $178 \pm 5$ & $177 \pm 4$ \\
\hline 1IR & 5 & $77 \pm 5$ & $77 \pm 3$ & $70 \pm 3$ & $78 \pm 3$ & $197 \pm 2$ & $184 \pm 4$ & $180 \pm 5$ & $180 \pm 5$ \\
\hline 2IR & 6 & $78 \pm 3$ & $69 \pm 2$ & $71 \pm 2$ & $72 \pm 2$ & $189 \pm 3$ & $187 \pm 3$ & $181 \pm 5$ & $179 \pm 3$ \\
\hline $2 \mathrm{IR}+\mathrm{L}$ & 3 & $79 \pm 4$ & $70 \pm 3$ & $70 \pm 6$ & $69 \pm 4$ & $190 \pm 7$ & $181 \pm 6$ & $174 \pm 6$ & $173 \pm 6$ \\
\hline 2IR+Fucoidan & 5 & $77 \pm 6$ & $67 \pm 3$ & $67 \pm 2$ & $71 \pm 2$ & $189 \pm 3$ & $185 \pm 3$ & $175 \pm 3$ & $175 \pm 3$ \\
\hline $2 \mathrm{IR}+\mathrm{MoAb}$ & 5 & $79 \pm 4$ & $75 \pm 4$ & $72 \pm 2$ & $72 \pm 6$ & $194 \pm 5$ & $184 \pm 4$ & $176 \pm 4$ & $176 \pm 4$ \\
\hline $2 \mathrm{IR}+\mathrm{IgG}$ & 4 & $78 \pm 5$ & $77 \pm 3$ & $75 \pm 3$ & $74 \pm 3$ & $188 \pm 4$ & $183 \pm 5$ & $172 \pm 5$ & $172 \pm 5$ \\
\hline $2 \mathrm{IR}+1400 \mathrm{~W}$ & 5 & $80 \pm 3$ & $72 \pm 3$ & $71 \pm 4$ & $71 \pm 4$ & $179 \pm 2$ & $187 \pm 3$ & $174 \pm 3$ & $178 \pm 5$ \\
\hline $2 \mathrm{IR}+\mathrm{L}+1400 \mathrm{~W}$ & 3 & $79 \pm 6$ & $69 \pm 5$ & $69 \pm 4$ & $70 \pm 5$ & $194 \pm 5$ & $178 \pm 5$ & $173 \pm 6$ & $174 \pm 6$ \\
\hline
\end{tabular}


Table 2. Arterial blood gases $\left(\mathrm{PO}_{2}\right.$ and $\left.\mathrm{PCO}_{2}\right)$ and $\mathrm{pH}$ at baseline (b-line) before and during lung reperfusion. Values are means $\pm S E M$; $n=$ number of animals. $0.5,1.0$ and $2.0(\mathrm{~h})$ are the observation time points during $2 \mathrm{~h}$ of reperfusion. 
Table 2

\begin{tabular}{|c|c|c|c|c|c|c|c|}
\hline & \multirow[b]{2}{*}{$\mathrm{n}$} & \multicolumn{2}{|c|}{$\mathrm{PO}_{2}(\mathrm{~mm} \mathrm{Hg})$} & \multicolumn{2}{|c|}{$\mathrm{PCO}_{2}(\mathrm{~mm} \mathrm{Hg})$} & \multicolumn{2}{|c|}{$\mathrm{pH}$} \\
\hline & & B-line & Reperf. & B-line & Reperf. & B-line & Reperf. \\
\hline Sham & 5 & $189 \pm 10$ & $214 \pm 8$ & $42 \pm 4$ & $40 \pm 2$ & $7.38 \pm 0.003$ & $7.40 \pm 0.003$ \\
\hline Control & 5 & $192 \pm 12$ & $233 \pm 9$ & $44 \pm 2$ & $41 \pm 2$ & $7.37 \pm 0.002$ & $7.39 \pm 0.003$ \\
\hline Control+RNS & 4 & $193 \pm 11$ & $229 \pm 7$ & $43 \pm 3$ & $42 \pm 3$ & $7.39 \pm 0.002$ & $7.38 \pm 0.004$ \\
\hline IIR & 5 & $194 \pm 9$ & $220 \pm 6$ & $43 \pm 5$ & $39 \pm 4$ & $7.39 \pm 0.003$ & $7.40 \pm 0.003$ \\
\hline $2 \mathrm{IR}$ & 6 & $182 \pm 13$ & $218 \pm 7$ & $40 \pm 2$ & $41 \pm 2$ & $7.40 \pm 0.002$ & $7.38 \pm 0.002$ \\
\hline $2 \mathrm{IR}+\mathrm{L}$ & 3 & $187 \pm 10$ & $222 \pm 10$ & $39 \pm 4$ & $40 \pm 2$ & $7.37 \pm 0.004$ & $7.42 \pm 0.002$ \\
\hline 2IR+Fucoidan & 5 & $188 \pm 12$ & $234 \pm 9$ & $43 \pm 2$ & $44 \pm 3$ & $7.38 \pm 0.002$ & $7.39 \pm 0.003$ \\
\hline $2 \mathrm{IR}+\mathrm{MoAb}$ & 5 & $189 \pm 11$ & $233 \pm 4$ & $42 \pm 3$ & $41 \pm 4$ & $7.39 \pm 0.002$ & $7.41 \pm 0.003$ \\
\hline $2 \mathrm{IR}+\mathrm{IgG}$ & 4 & $183 \pm 8$ & $224 \pm 8$ & $41 \pm 1$ & $43 \pm 2$ & $7.38 \pm 0.003$ & $7.40 \pm 0.003$ \\
\hline $2 \mathrm{IR}+1400 \mathrm{~W}$ & 5 & $180 \pm 13$ & $225 \pm 7$ & $42 \pm 3$ & $45 \pm 2$ & $7.40 \pm 0.002$ & $7.38 \pm 0.004$ \\
\hline $2 \mathrm{IR}+\mathrm{L}+1400 \mathrm{~W}$ & 3 & $179 \pm 14$ & $219 \pm 9$ & $41 \pm 4$ & $40 \pm 3$ & $7.39 \pm 0.002$ & $7.41 \pm 0.003$ \\
\hline
\end{tabular}


Table 3. Labeled platelets rolling or adhered during reperfusion after $\mathbf{2}$ h of ischemia. Values are means $\pm S E M ; n=$ number of arterioles in 6 animals. Note that there were no differences between the values for rolling or adhered platelets at $0.5,1.0$, or $2.0 \mathrm{~h}$ of reperfusion expressed by different methods. 
Table 3

\begin{tabular}{lcccccc} 
& \multicolumn{7}{c}{ Reperfusion time } \\
\cline { 2 - 7 } & \multicolumn{2}{c}{$\begin{array}{c}0.5 \mathrm{hr} \\
(\mathrm{n}=17)\end{array}$} & $\begin{array}{c}1.0 \mathrm{hr} \\
(\mathrm{n}=18)\end{array}$ & $\begin{array}{c}2.0 \mathrm{hrs} \\
(\mathrm{n}=18)\end{array}$ \\
\cline { 2 - 7 } & Rolling & Adhered & Rolling & Adhered & Rolling & Adhered \\
\cline { 2 - 7 } Platelets / mm & $852 \pm 170$ & $159 \pm 39$ & $771 \pm 106$ & $127 \pm 15$ & $607 \pm 70$ & $115 \pm 20$ \\
\hline Platelets / $\mathrm{mm}^{2} /$ & $11.7 \pm 1.8$ & $3.5 \pm 0.7$ & $10.3 \pm 1.3$ & $2.9 \pm 0.55$ & $9.2 \pm 1.2$ & $2.2 \pm 0.4$ \\
/ platelets flowing & & & & & & \\
\hline Platelets/ & $26.5 \pm 4.3$ & $4.5 \pm 0.9$ & $22.0 \pm 2.9$ & $4.1 \pm 0.5$ & $20.5 \pm 2.8$ & $3.7 \pm 0.4$ \\
/platelets flowing x $100(\%)$ & & & & & & \\
\hline
\end{tabular}




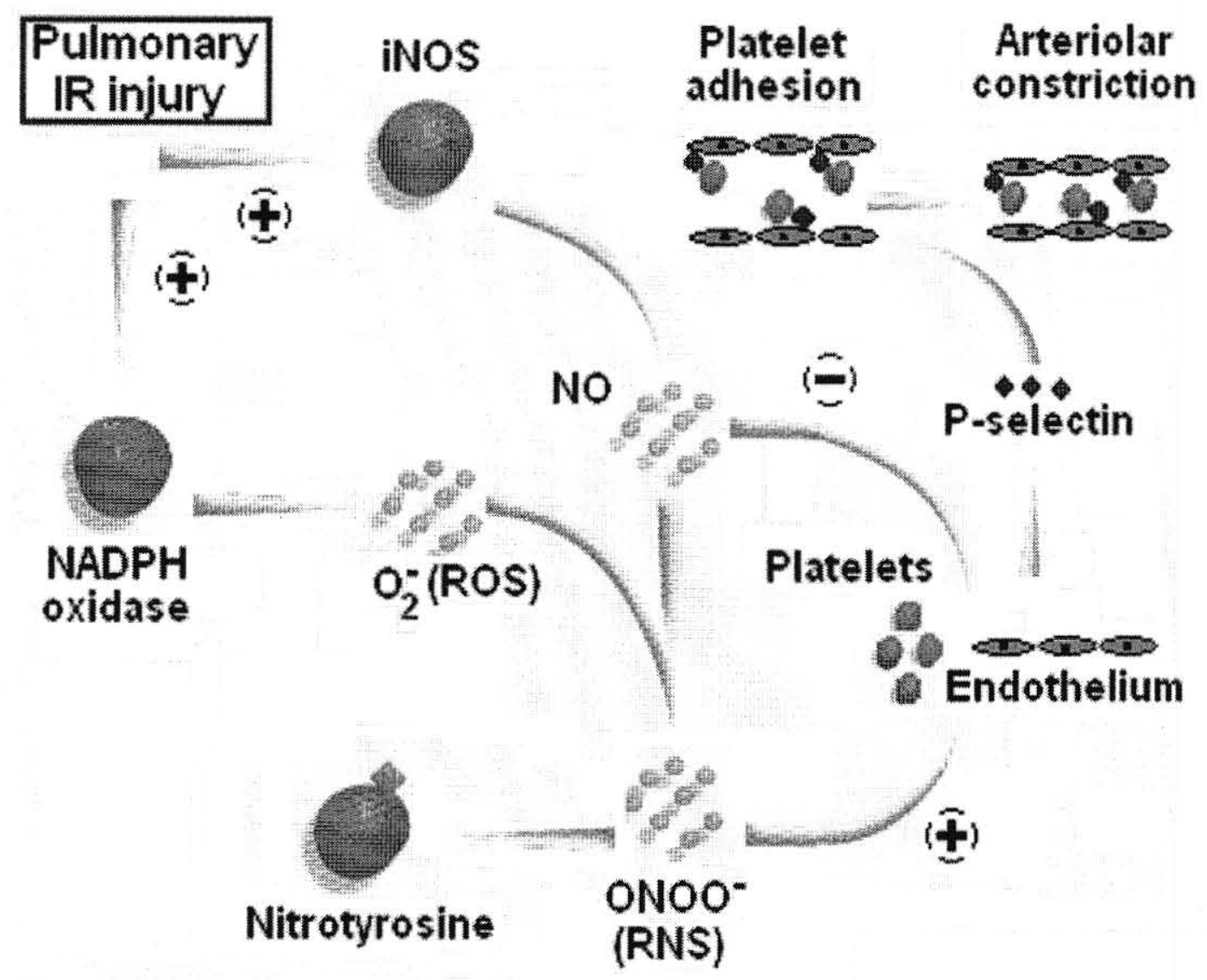

Figure 1. General hypothesis. In the oxidative stress induced by pulmonary IR, formation of RNS may promote platelet activation and adhesion to the arteriolar wall with subsequent release of vasoactive substances and vasoconstriction. We examined the hypothesis that pulmonary IR induces platelet-arteriolar wall interactions via a P-selectin dependent mechanism and contribute to pulmonary microvascular constriction during reperfusion. Increased P-selectin expression results from elevated iNOS activity and subsequent RNS generation. 


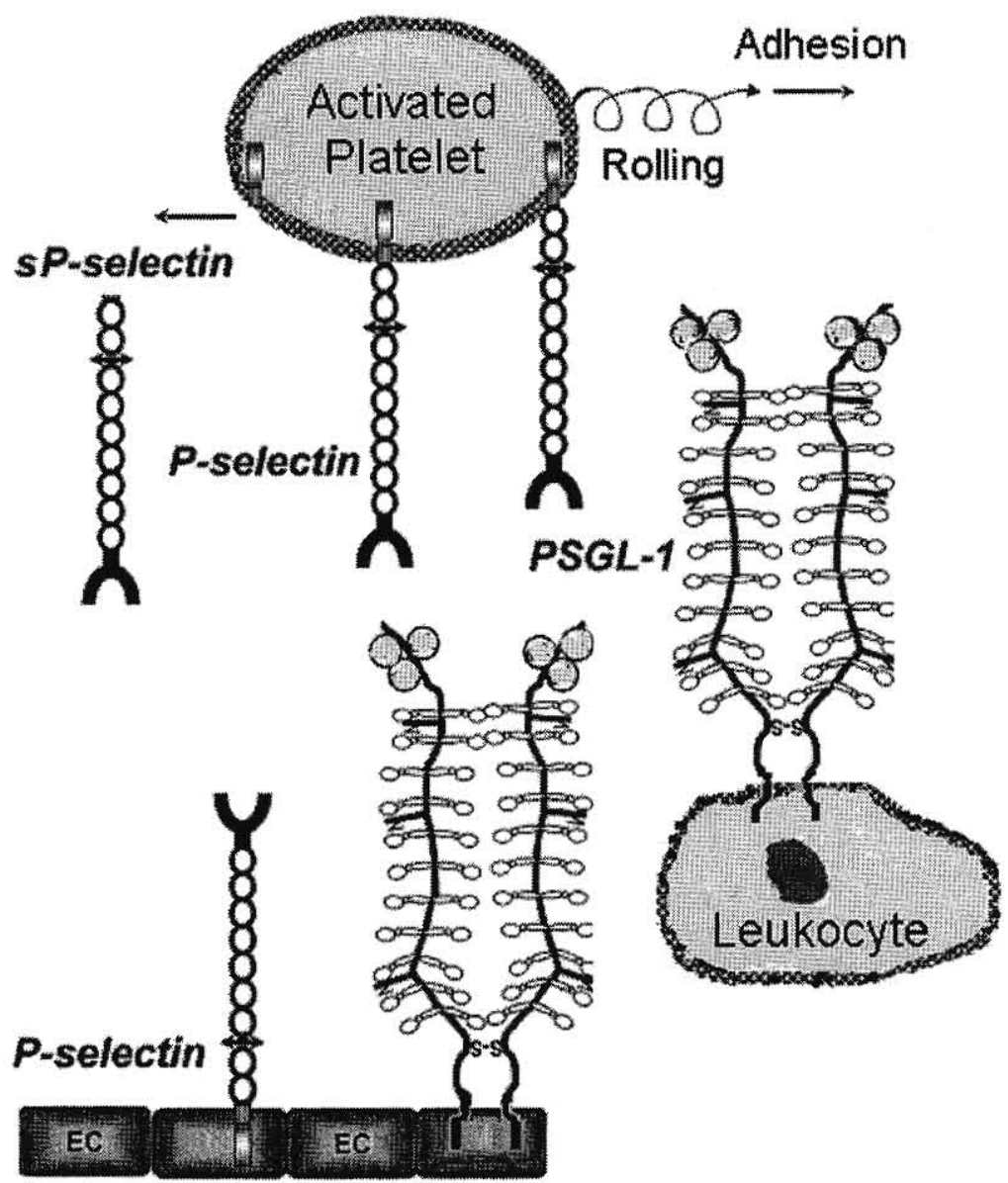

Figure 2. Schematic diagram of P-selectin and P-selectin glycoprotein ligand (PSGL-1). Upon stimulation, P-selectin is expressed on the surface of platelets and endothelial cells. Platelet P-selectin can be cleaved, generating the soluble fragment of P-selectin (sP-selectin). PSGL-1 is constitutively expressed on the surface of endothelial cells and leukocytes. P-selectin is able to trigger tyrosine phosphorylation of several cytoplasmic proteins via interaction with PSGL-1. This leads to the activation of integrins and subsequent firm platelet adhesion to the endothelium (168). 


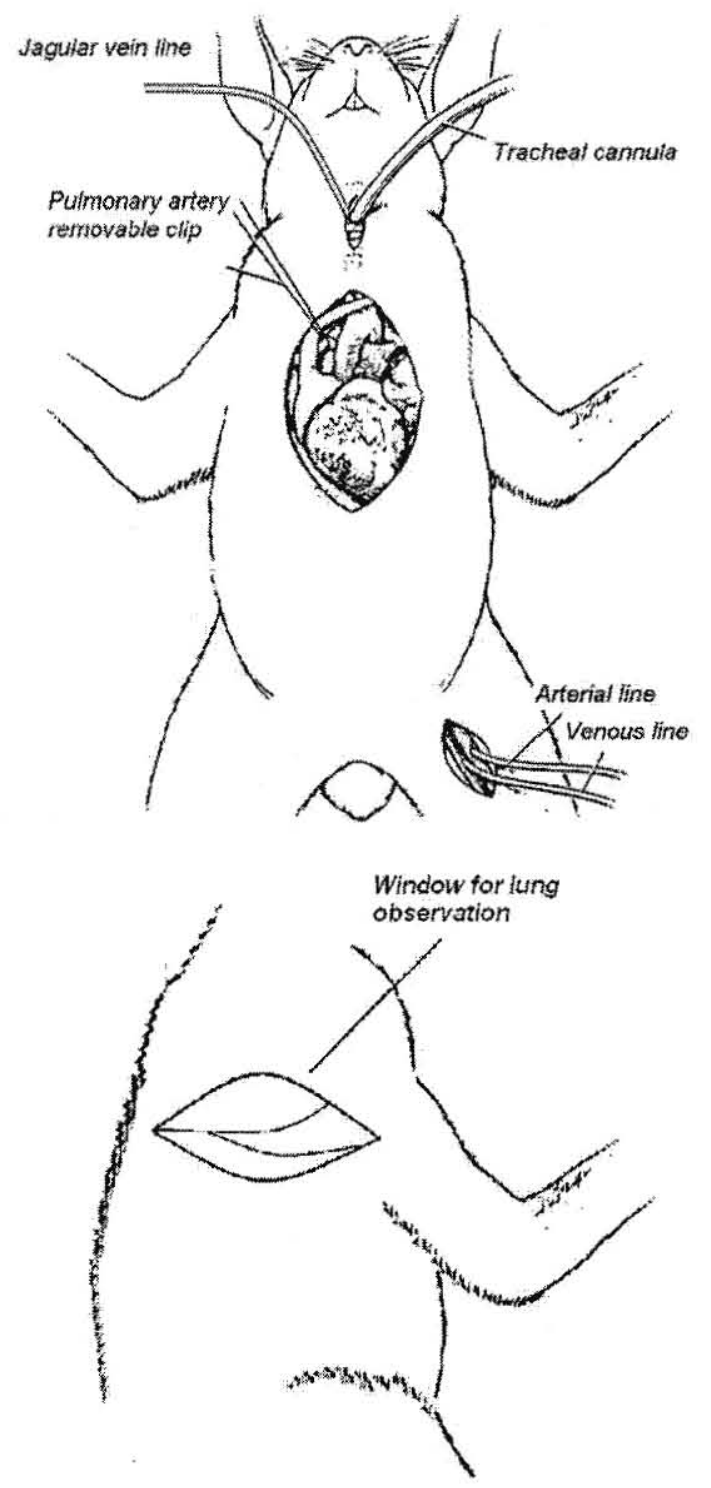

Figure 3. Experimental model. The subpleural pulmonary arterioles were observed in anesthetized rabbits with open chest and ventilated lungs using intravital video microscopy. IR was caused by reversibly occluding the right pulmonary artery. 


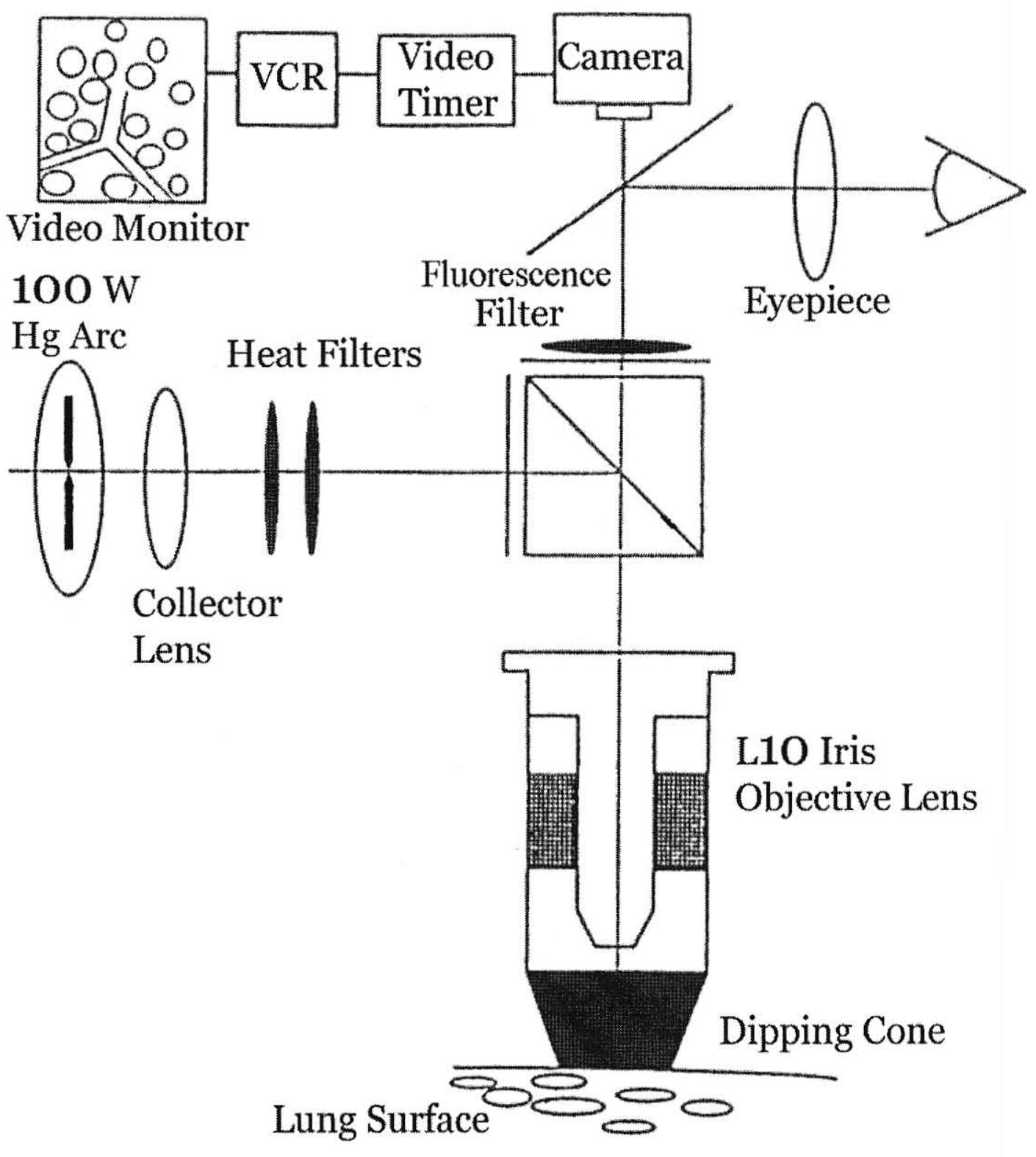

Figure 4. Intravital video microscopy system. Drawing of the incident illumination microscope with attached video camera. The objective lens (L10 iris) was attached to a glass dipping cone. 
Figure 5. Experimental protocols. Subpleural arterioles, platelets and leukocytes were examined by intravital fluorescence microscopy. Ischemia was caused by reversibly occluding the right pulmonary artery for different periods of time ( $5 \mathrm{~min}, 1 \mathrm{~h}$ or $2 \mathrm{~h}$ ) and the right lung was observed after $0.5,1$ and $2 \mathrm{~h}$ of reperfusion. The different protocols included systemic pretreatment with Fucoidan (a selectin ligand), 1400W (iNOS inhibitor), labeled platelets treated with P-selectin monoclonal antibody (MoAb) or nonspecific IgG1א antibody. At the end of experiments, the lungs were removed for iNOS expression or NOS activity measuring and P-selectin/Nitrotyrosine immunohistochemistry. The plasma samples were taken before and after reperfusion for soluble P-selectin measuring. 


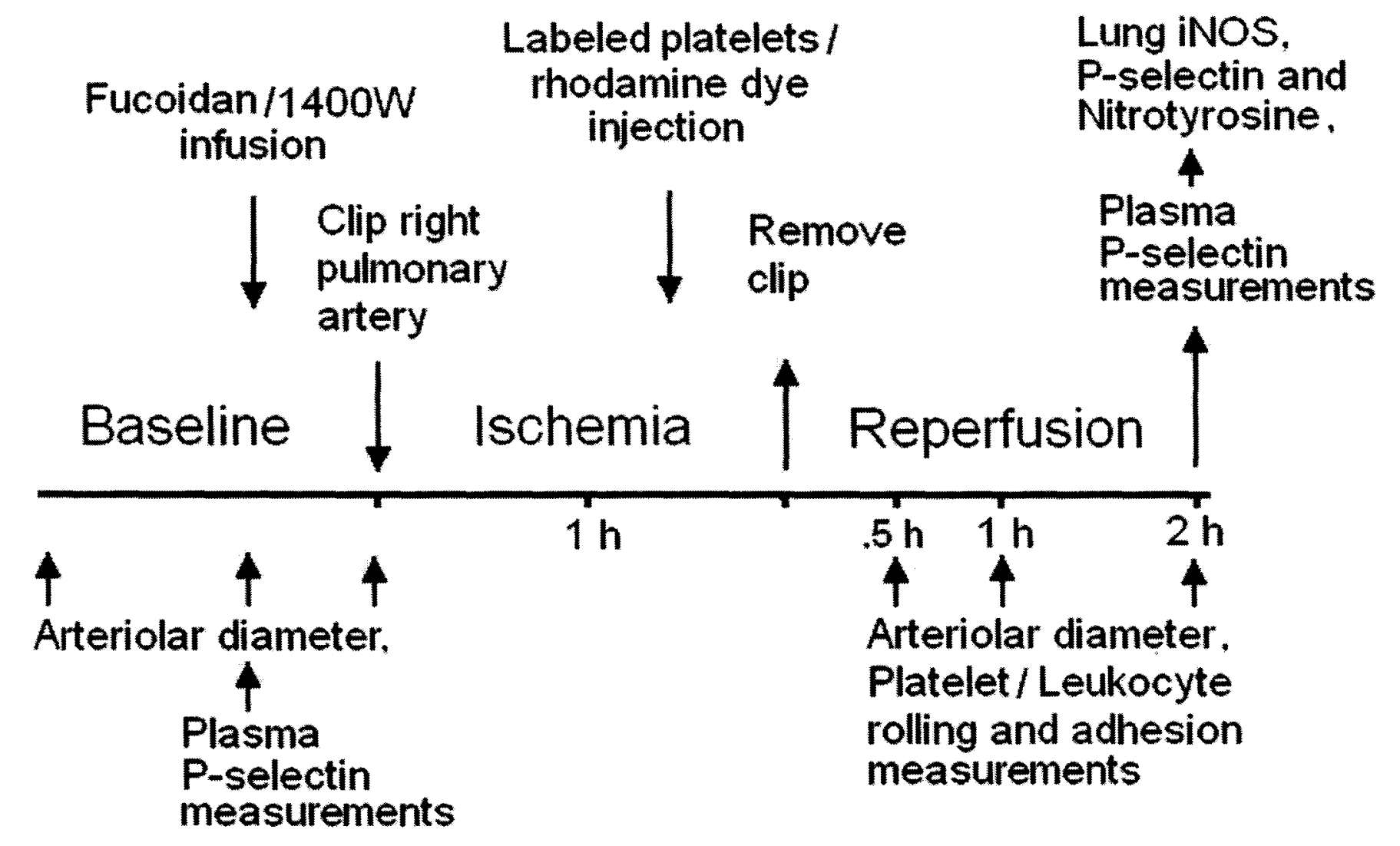



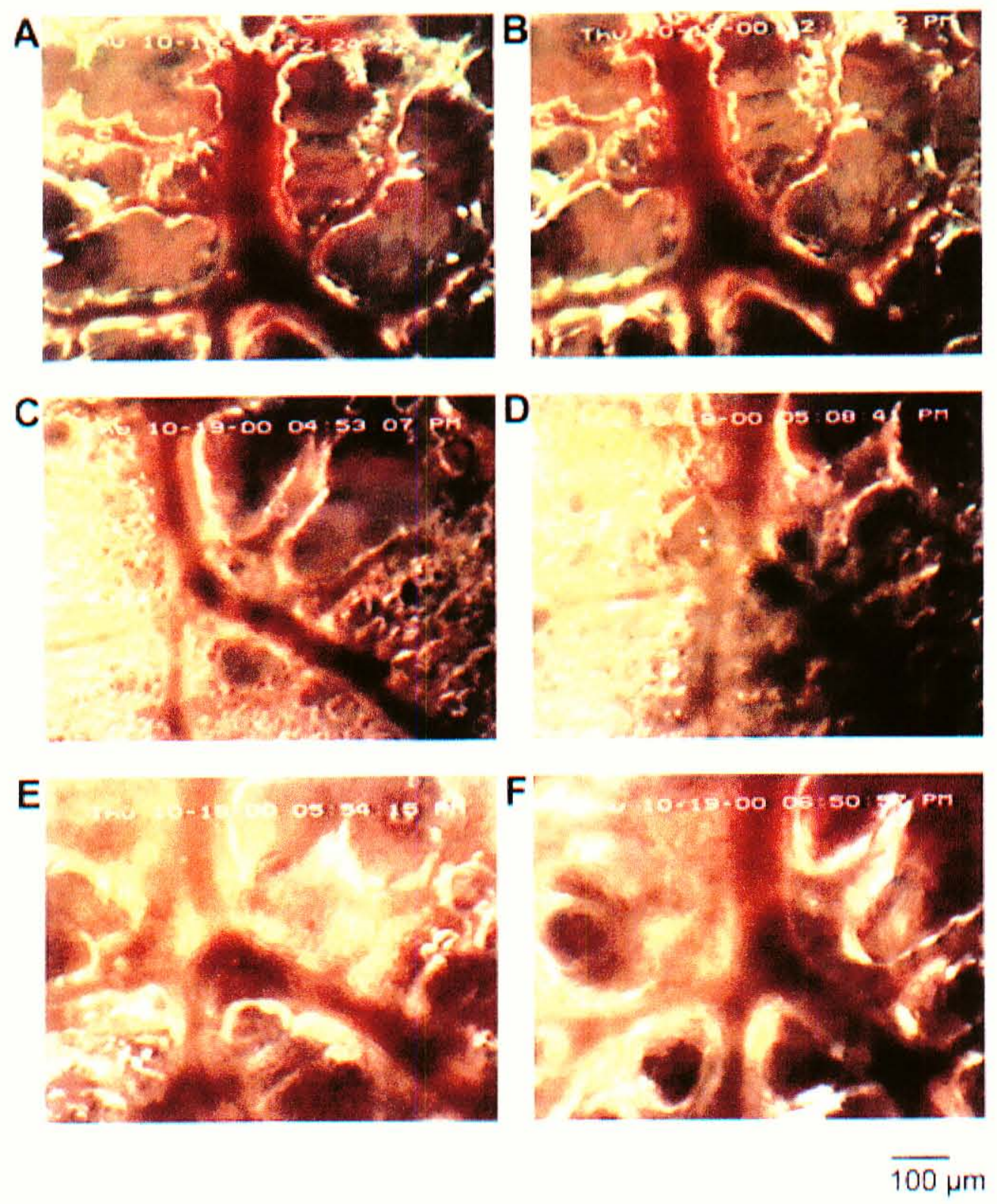

Figure 6. Responses of a subpleural pulmonary arteriole to 2 -h ischemia.

$\mathrm{A}$ and $\mathrm{B}$, at beginning and end of the baseline period; $\mathrm{C}-\mathrm{F}$, during reperfusion after 10,30, 60 and 120 min respectively. 


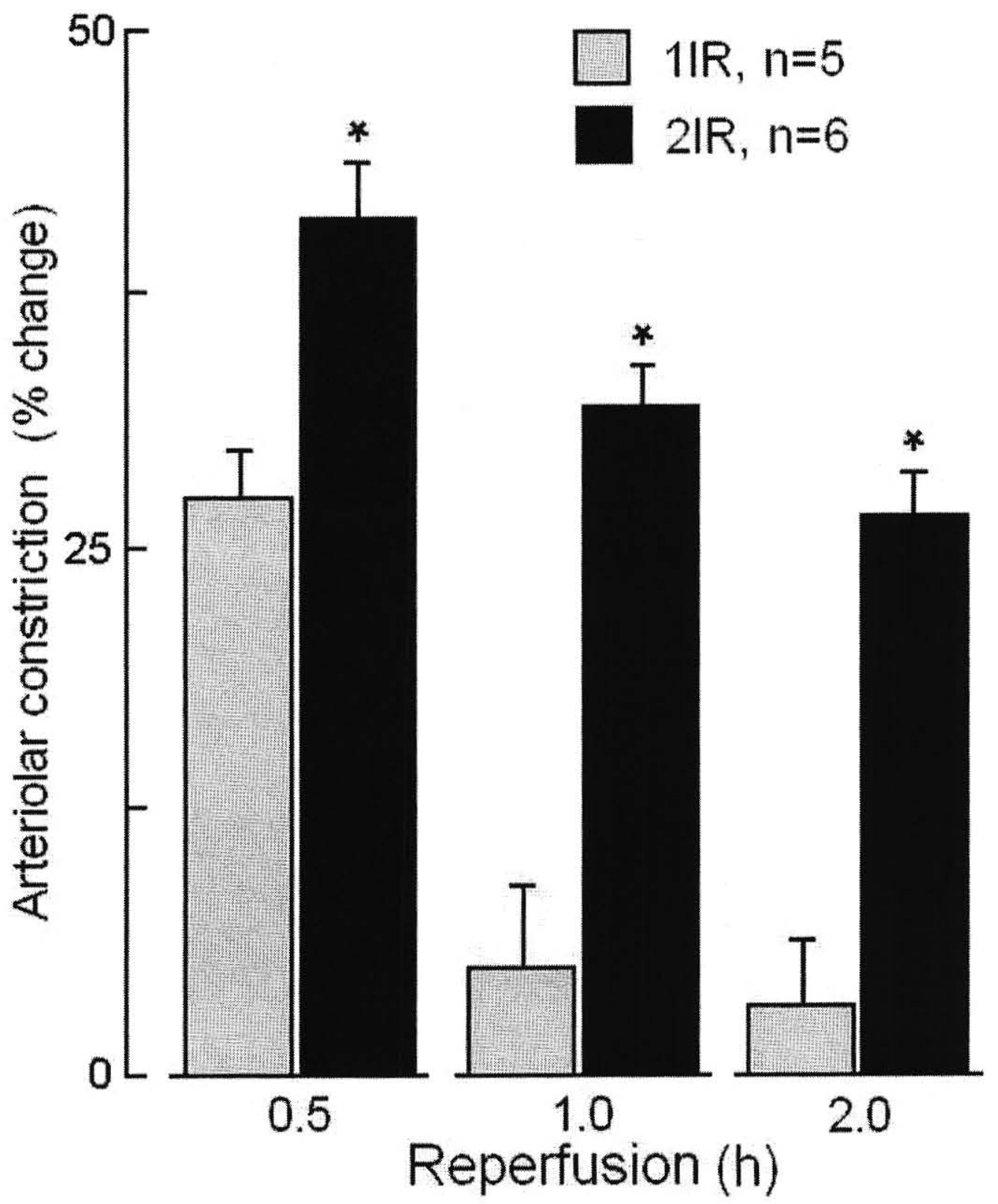

Figure 7. Comparison of effects of $1 \mathrm{~h}$ and $2 \mathrm{~h}$ of pulmonary ischemia on changes in pulmonary arteriolar diameter during reperfusion. 1IR, 1-h ischemia-reperfusion group; 2IR, 2-h ischemia-reperfusion group. * denotes $\mathrm{P}<0.05$ for comparison of 1 IR and 2IR groups. $\mathrm{n}=$ number of animals. 
Figure 8. Platelet-arteriolar wall interactions during reperfusion of the right lung after $1 \mathrm{~h}$ and $2 \mathrm{~h}$ of pulmonary ischemia-reperfusion. (A) Rolling platelets. (B) Adhering platelets. Scale bars indicate means \pm SEM, $n=$ number of animals. * denotes $\mathrm{P}<0.005$ for comparison of 1 IR and 2IR. $\dagger$ denotes no significant adhesion. 

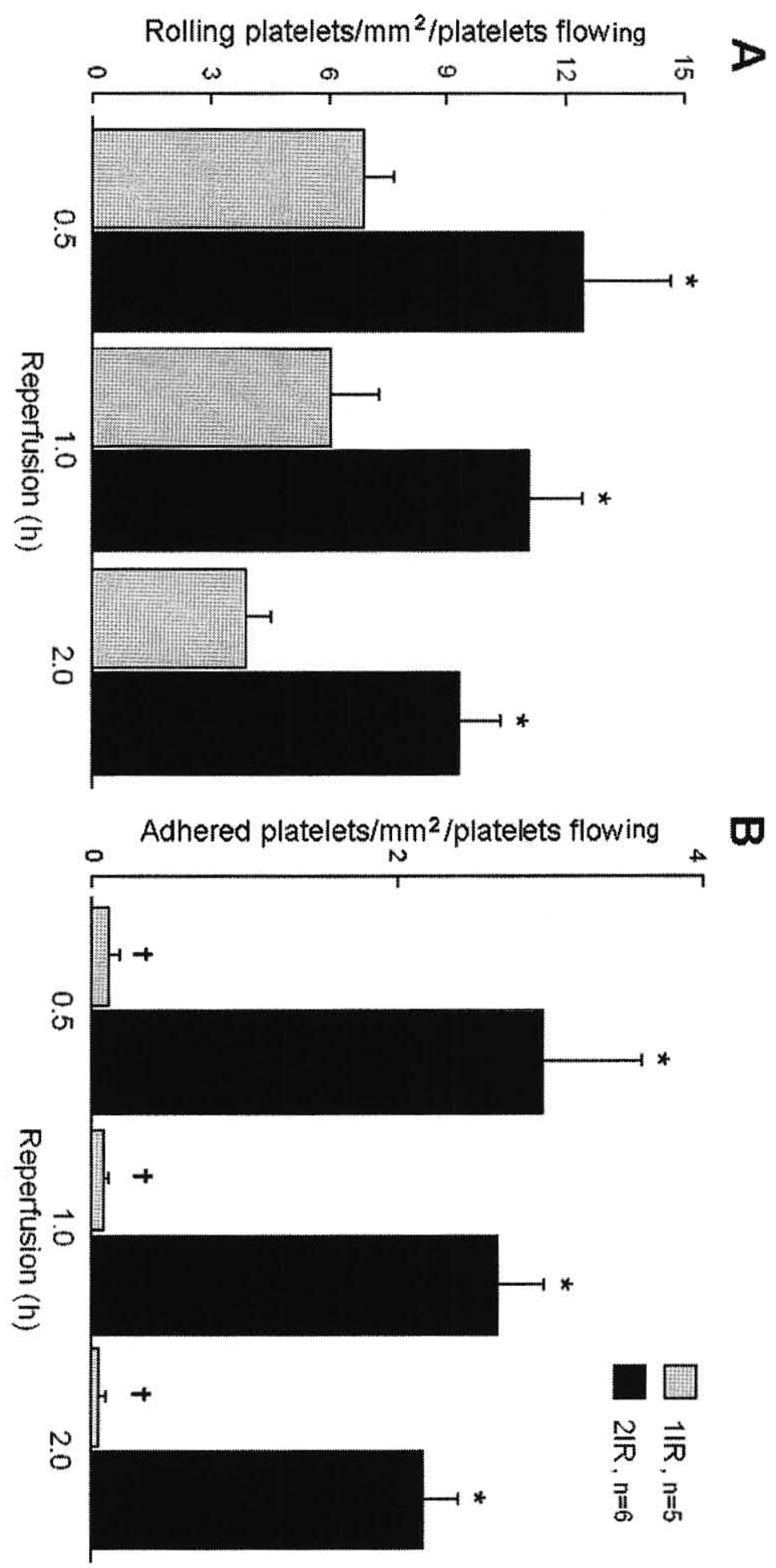

Figure 8 
Figure 9. Adhered platelets in a pulmonary arteriole in the right lung observed by intravital fluorescence microscopy during reperfusion after a 2-h pulmonary ischemia. (A) During occlusion of the right pulmonary artery after labeled platelets were injected ( $8 \mathrm{~min}$ before reperfusion). Note that no labeled platelets were present. (B) After 14 min of reperfusion. (C) After 70 min of reperfusion. (D) After $124 \mathrm{~min}$ of reperfusion. Arrows indicate examples of platelets adhered to the arteriolar wall. 


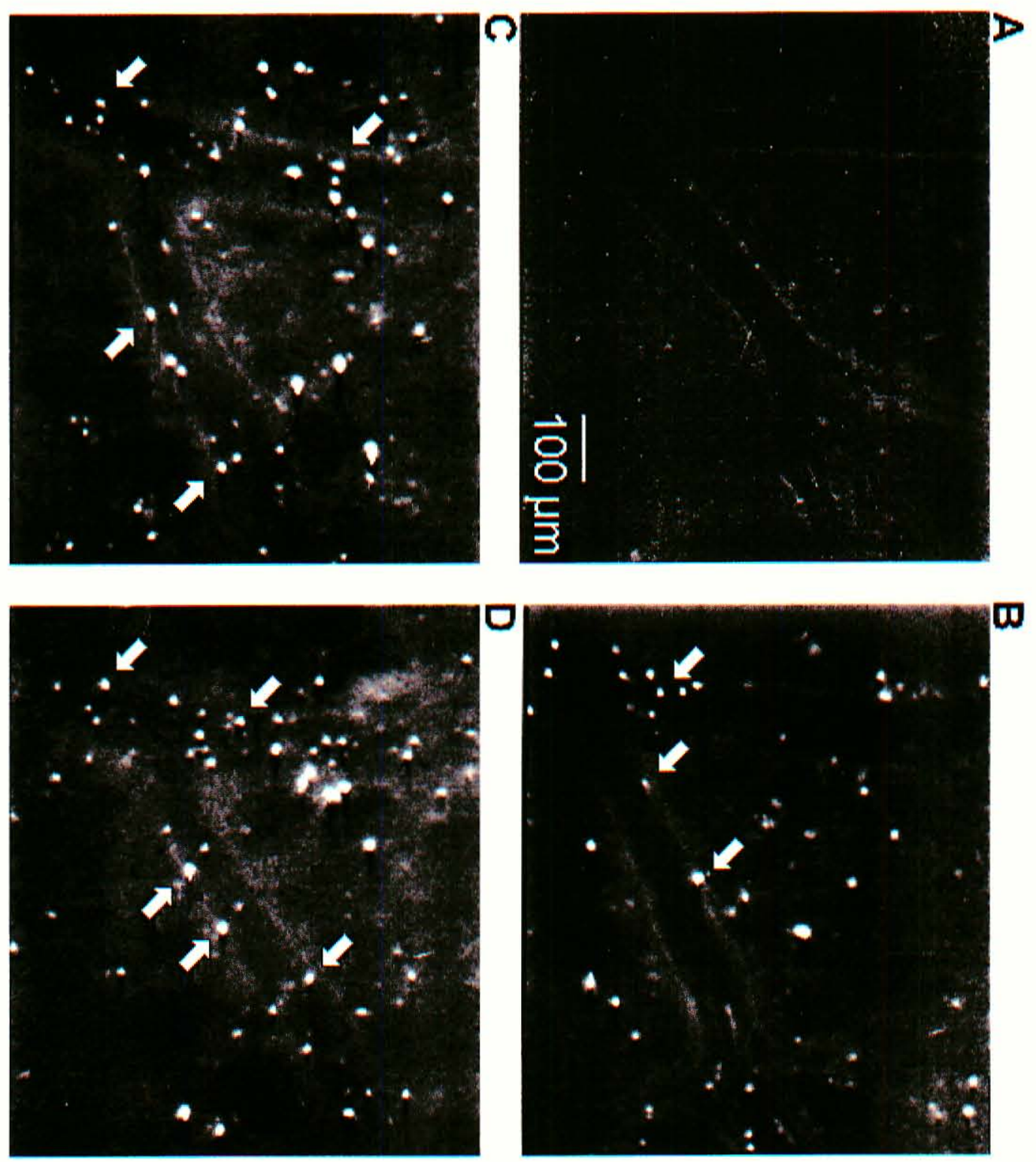

Figure 9 
Figure 10. Correlation between arteriolar constriction or platelet rolling/adhesion with duration of reperfusion. A - Arteriolar constriction vs. reperfusion time in 1IR group (A) and in 2IR group (B). Amount of platelet rolling after 1-h ischemia (C) and 2-h ischemia (D) vs. reperfusion time. Amount of platelet adhesion after 2-h ischemia vs. reperfusion time (E). Note that correlation coefficients (r) on panel (A) and (D) are low. 

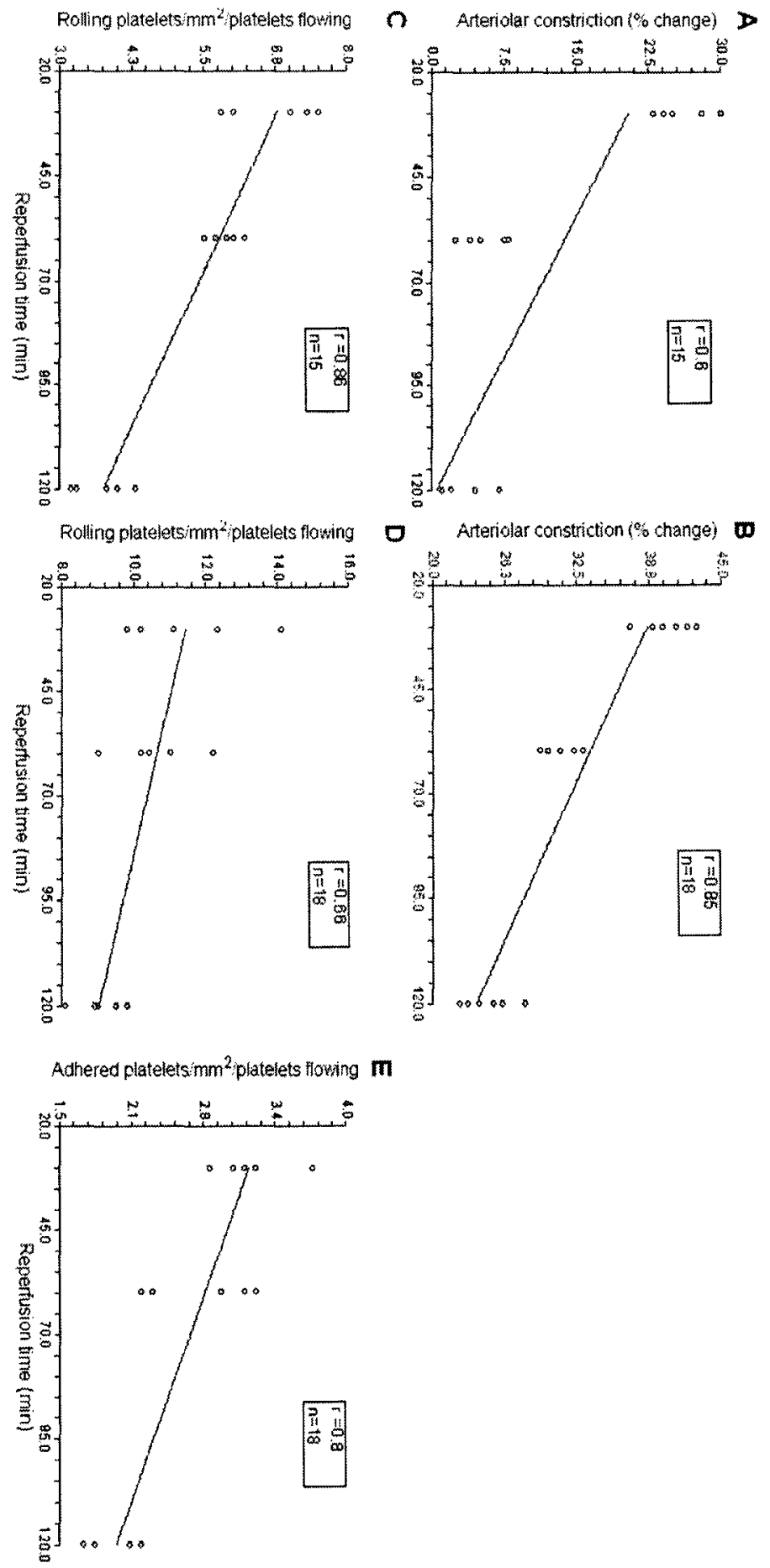

Figure 10 
Figure 11. Arteriolar constriction as a function of platelet rolling or adhesion during reperfusion. A - after 1-h ischemia, B and C.- after 2-h ischemia. Note that after $1-\mathrm{h}$ ischemia platelet adhesion was not different from baseline. 

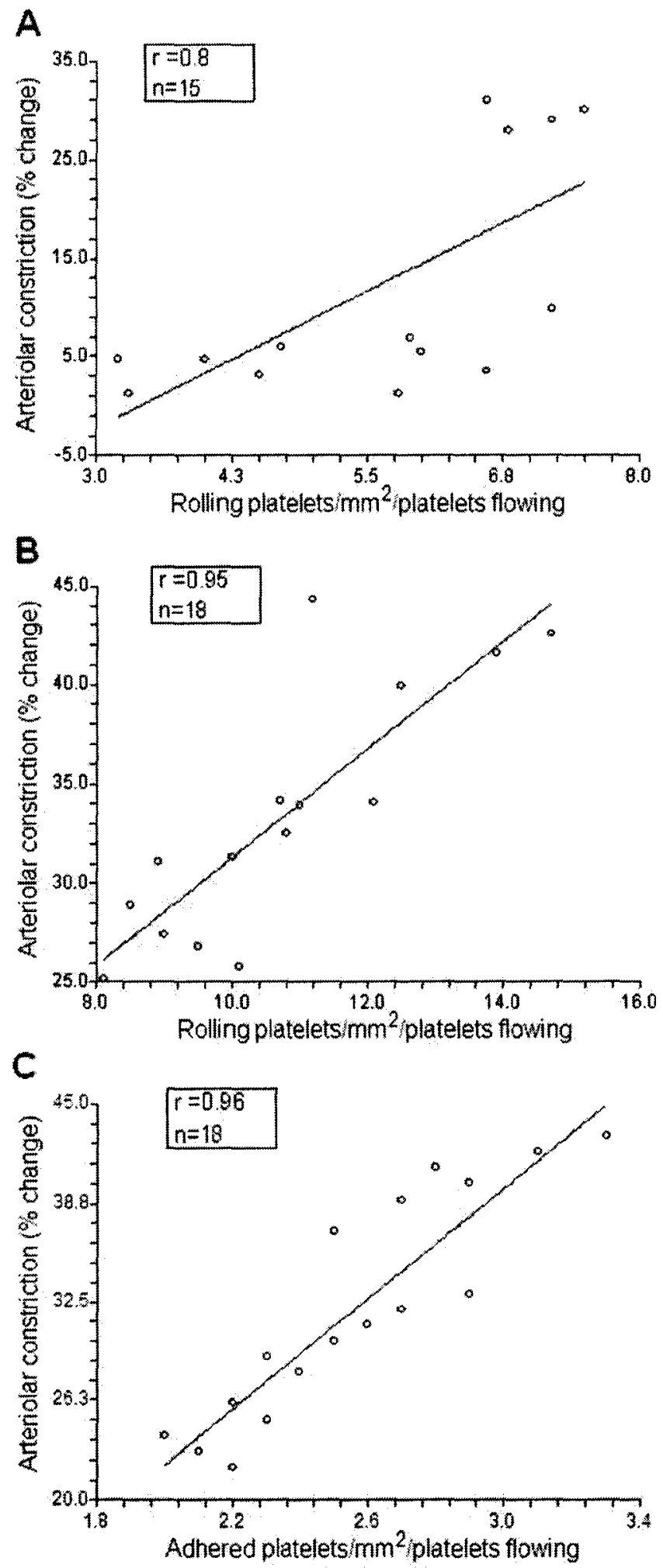

Figure 11 
Figure 12. Platelet and leukocyte rolling in the right lung during the reperfusion time course after 2 h of pulmonary ischemia-reperfusion. (A) Rolling platelets. (B) Rolling leukocytes. Scale bars indicate means \pm SEM, $n$ $=$ number of animals. ${ }^{*}$ Indicates $\mathrm{P}<0.05 . \dagger$ denotes no significant rolling. 

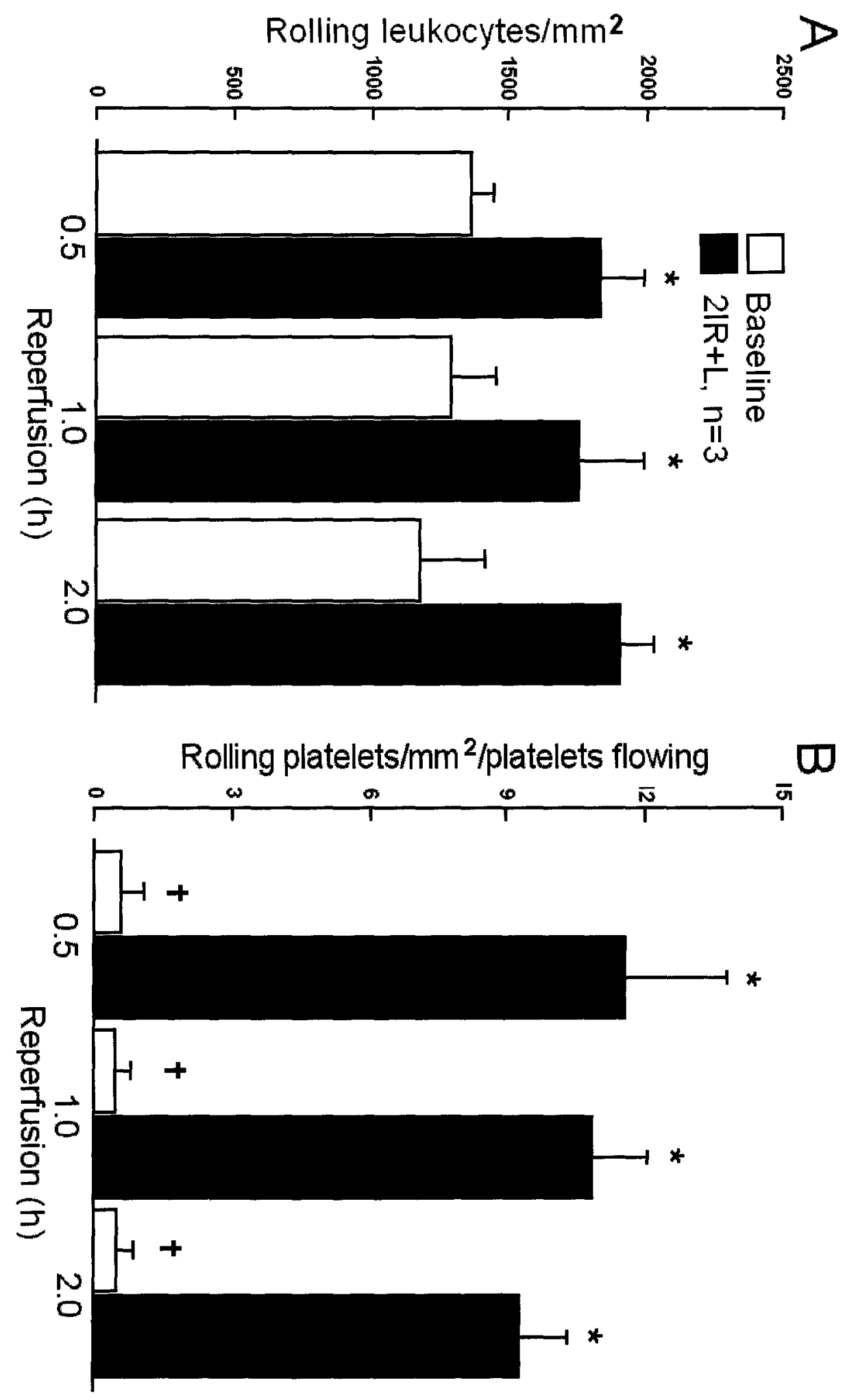

Figure 12 
Figure 13. Rolling and adhered platelets (A and C) and leukocytes (B and D) in a pulmonary arteriole observed by intravital microscopy. Circles indicate regions shown in inset boxes enlarged $2 \mathrm{X}$. In $\mathrm{A}$ and $\mathrm{C}$ (1.2 sec later), white arrows indicate a rolling platelet and black arrows indicate adhered platelets. In $\mathrm{B}$ and $\mathrm{D}$ (1.2 sec later) the stripped arrows indicate rolling leukocytes. Note that the platelets and leukocytes had different rolling speed (30 $\mu \mathrm{m} / \mathrm{sec}$ and $10 \mu \mathrm{m} / \mathrm{sec}$ respectively) and adhered and rolled at different sites. 

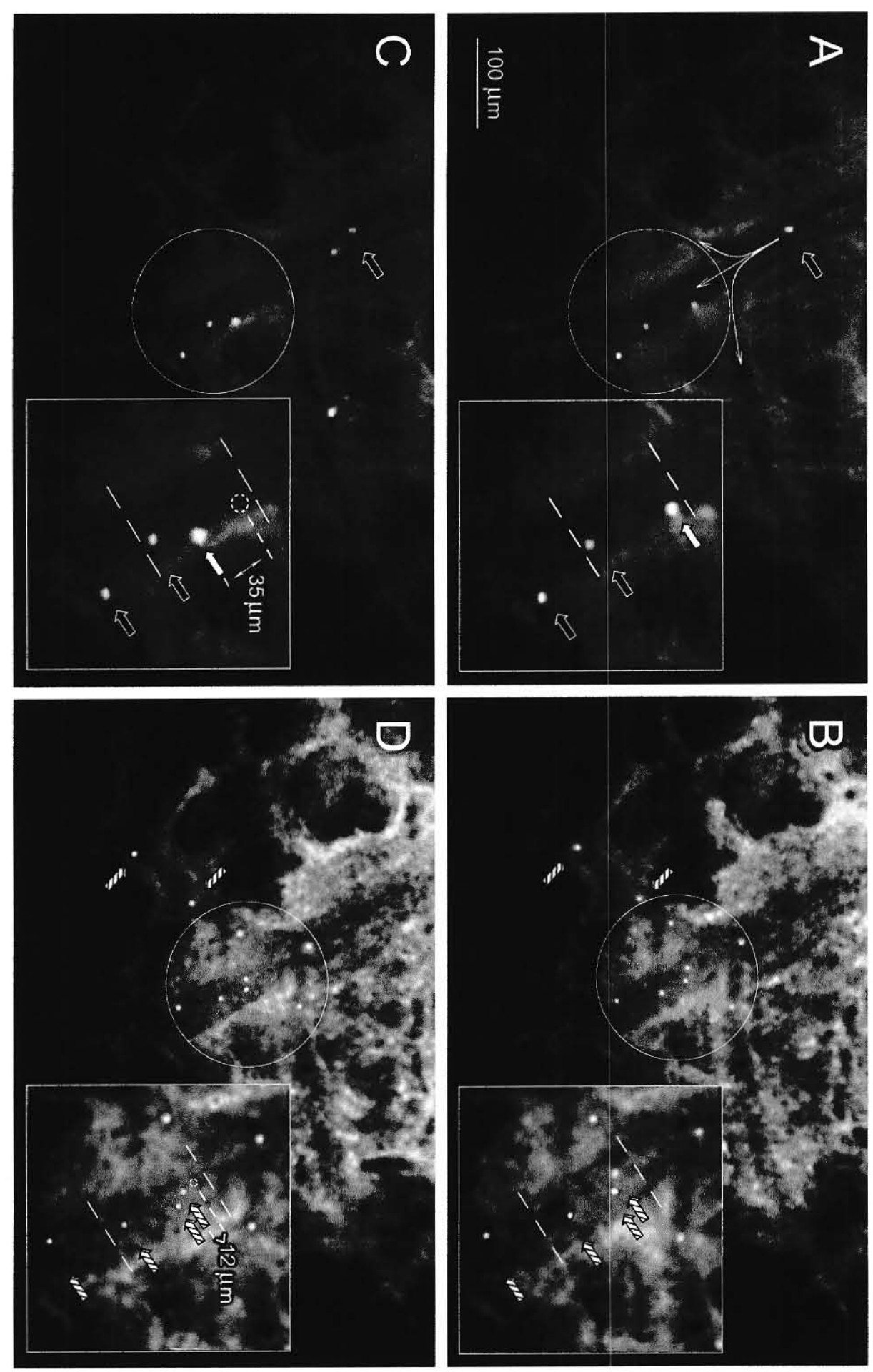

Figure 13 
Figure 14. Comparison of effects of MoAb or Fucoidan treatment on changes in pulmonary arteriolar diameters during the reperfusion time course after $2 \mathrm{~h}$ ischemia. 2IR, ischemia-reperfusion alone (21 arterioles in 6 animals); IR $+\mathrm{MoAb}$, ischemia-reperfusion plus labeled platelets treated with monoclonal antibody to P-selectin (17 arterioles in 5 animals); 2IR+Fucoidan, ischemia-reperfusion plus treatment with Fucoidan (13 arterioles in 5 animals) given I.V.* denotes $\mathrm{P}<0.005$ for comparison of $2 \mathrm{IR}+$ Fucoidan with $2 \mathrm{IR}$ and $\mathrm{IR}+\mathrm{MoAb}$ groups. 


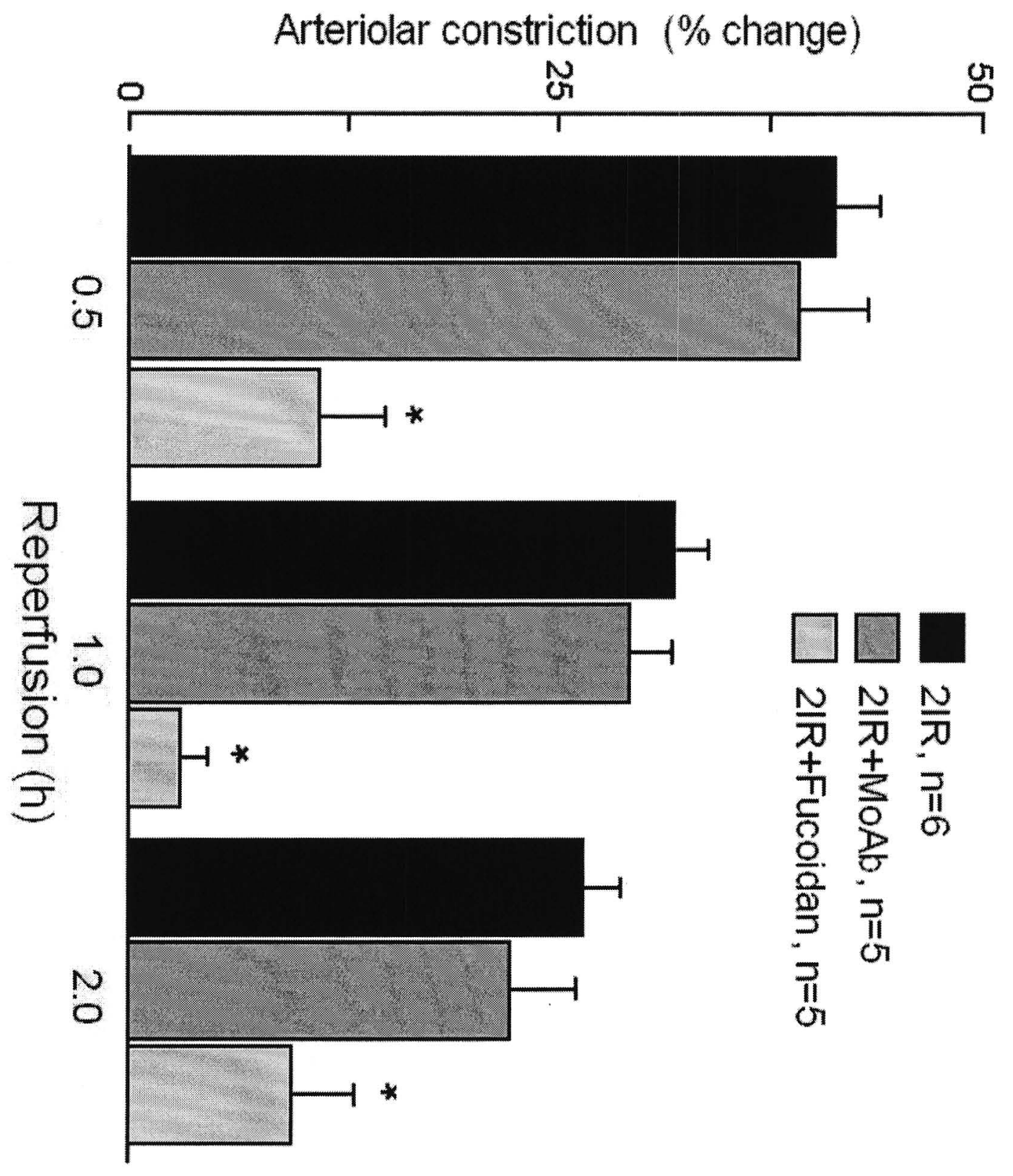

Figure 14 
Figure 15. Platelet-arteriolar wall interactions during reperfusion of the right lung after 2 h of pulmonary ischemia-reperfusion. (A) Rolling platelets. (B) Adhering platelets. Scale bars indicate means \pm SEM, $\mathrm{n}=$ number of animals. 2IR, 2-h ischemia-reperfusion. IgG, nonblocking antibody. MoAb, anti-P-selectin monoclonal antibody. * Indicates $\mathrm{P}<0.001$ comparing of $2 \mathrm{IR}$ with $2 \mathrm{IR}+$ Fucoidan, $2 \mathrm{IR}$ with $2 \mathrm{IR}+\mathrm{MoAb}$ and $2 \mathrm{IR}$ with $2 \mathrm{IR}+1400 \mathrm{~W}$. Note that there were no significant differences between 2IR group and 2IR+IgG group. Note that there were no significant differences between 2IR+Fucoidan group, $2 \mathrm{IR}+\mathrm{MoAb}$ group and $2 \mathrm{IR}+1400 \mathrm{~W}$ group. 


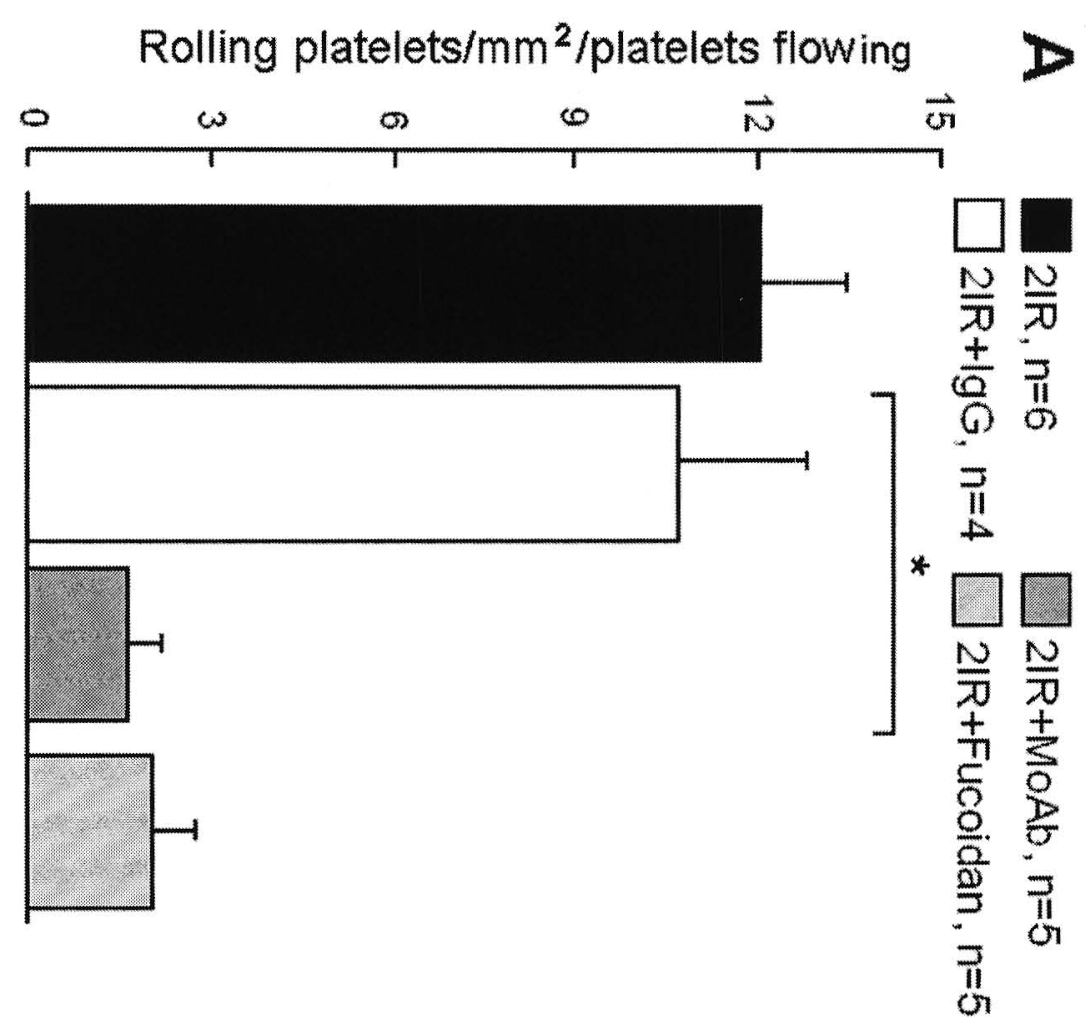

Adhered platelets $/ \mathrm{mm}^{2} /$ platelets flowing

ए

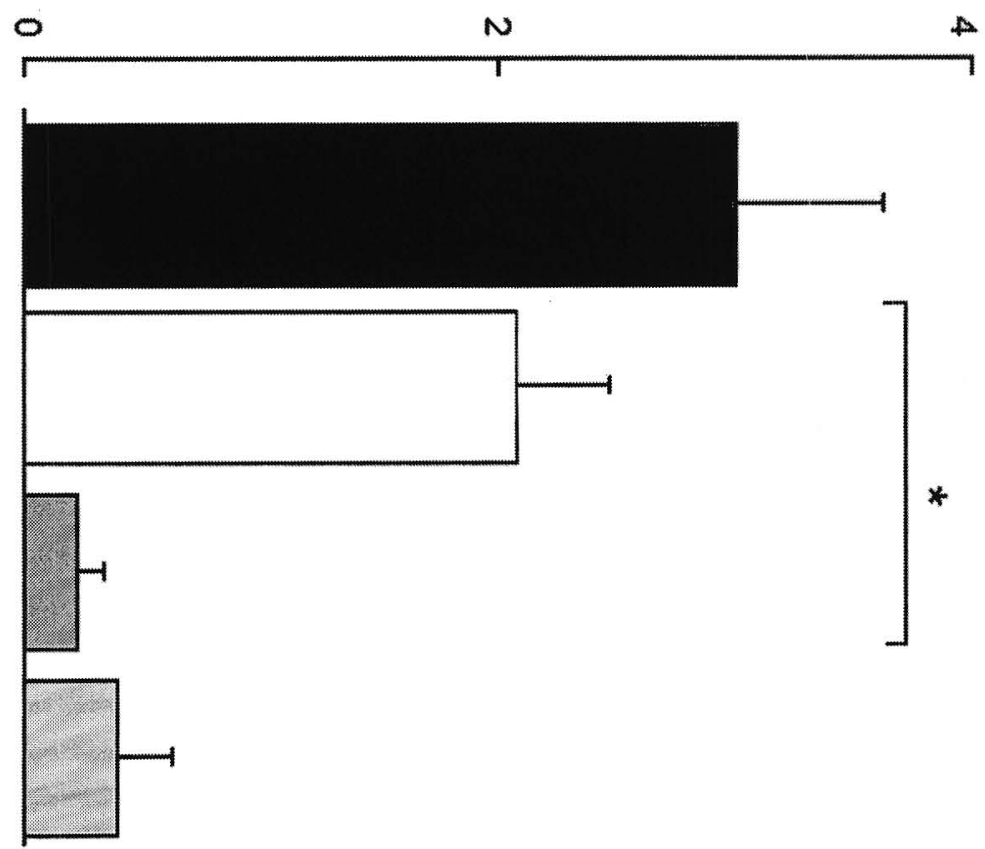

Figure 15 
Figure 16. iNOS expression (A and B) and total NOS activity (C) in the right lungs. $\mathrm{A}$ and $\mathrm{B}$ : after $2 \mathrm{~h}$ of ischemia; $\mathrm{C}$ : after $3 \mathrm{~h}$ of ischemia with and without $1400 \mathrm{~W}$ treatment. Scale bars indicate means \pm SEM. $\mathrm{n}=$ number of animals. * Indicates $\mathrm{p}<0.05$. 

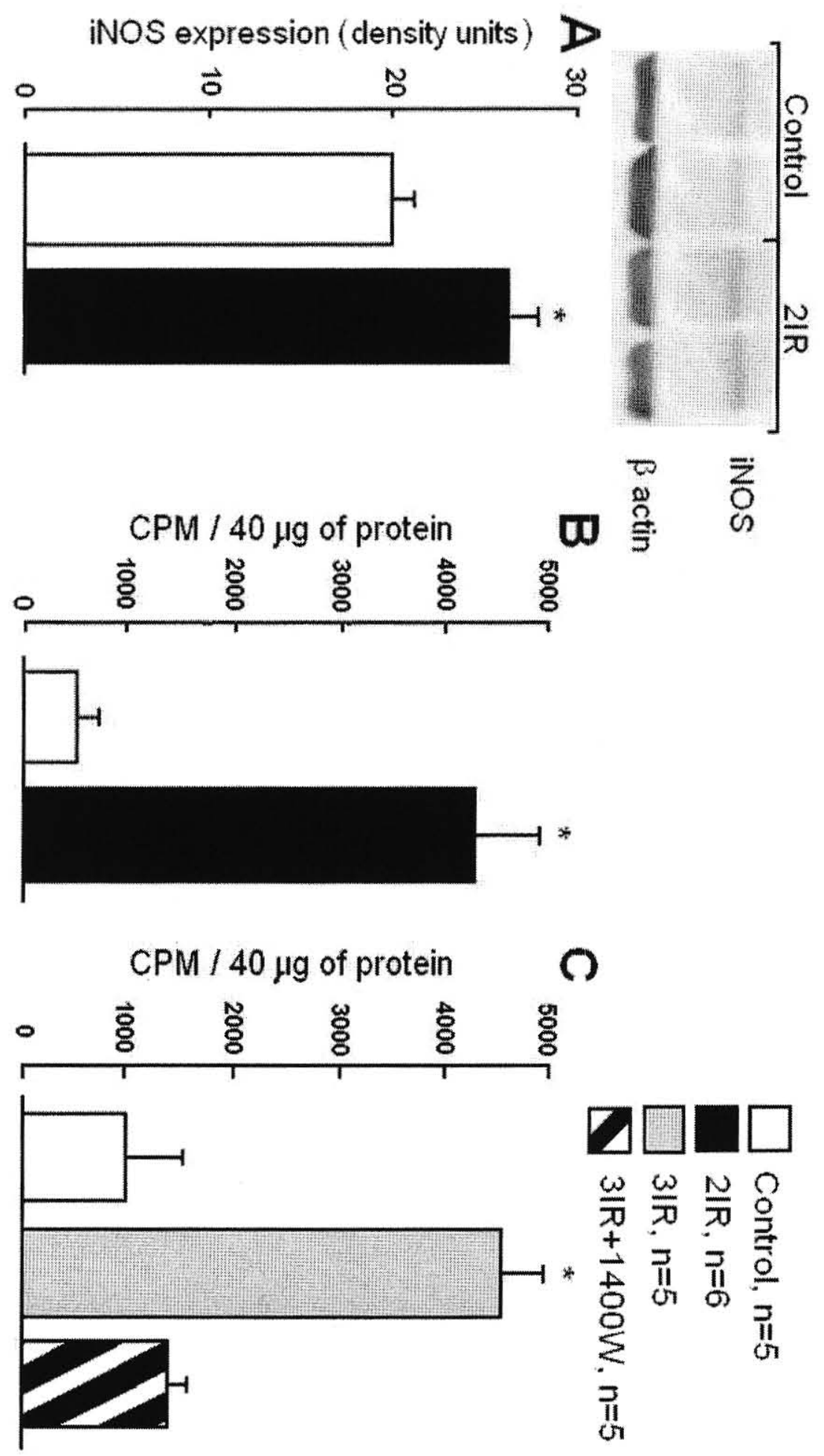

Figure 16 
Figure 17. Platelet rolling (A) and arteriolar constriction (B) during reperfusion time course in $2 I R$ group compare to $2 I R+1400 W$ group. Scale bars indicate means \pm SEM. $\mathrm{n}=$ number of animals. ${ }^{*}$ Indicates $\mathrm{P}<0.03$. 

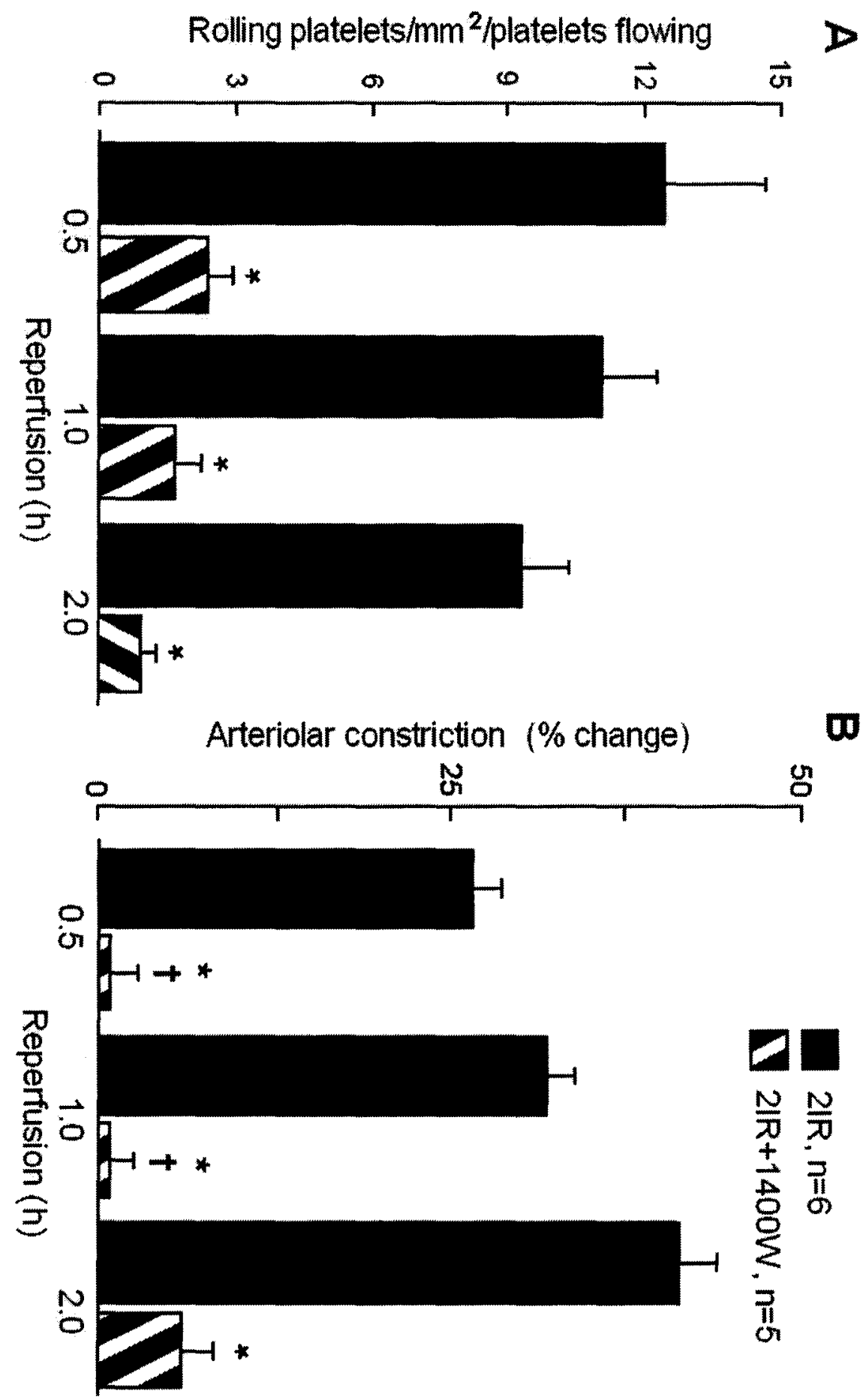

Figure 17 
Figure 18. Platelet and leukocyte rolling during reperfusion of the right lung after $\mathbf{2} \mathrm{h}$ of pulmonary ischemia-reperfusion. (A) Rolling platelets.

(B) Rolling leukocytes. Scale bars indicate means \pm SEM, $n=$ number of animals. * Indicates $\mathrm{P}<0.05$. 


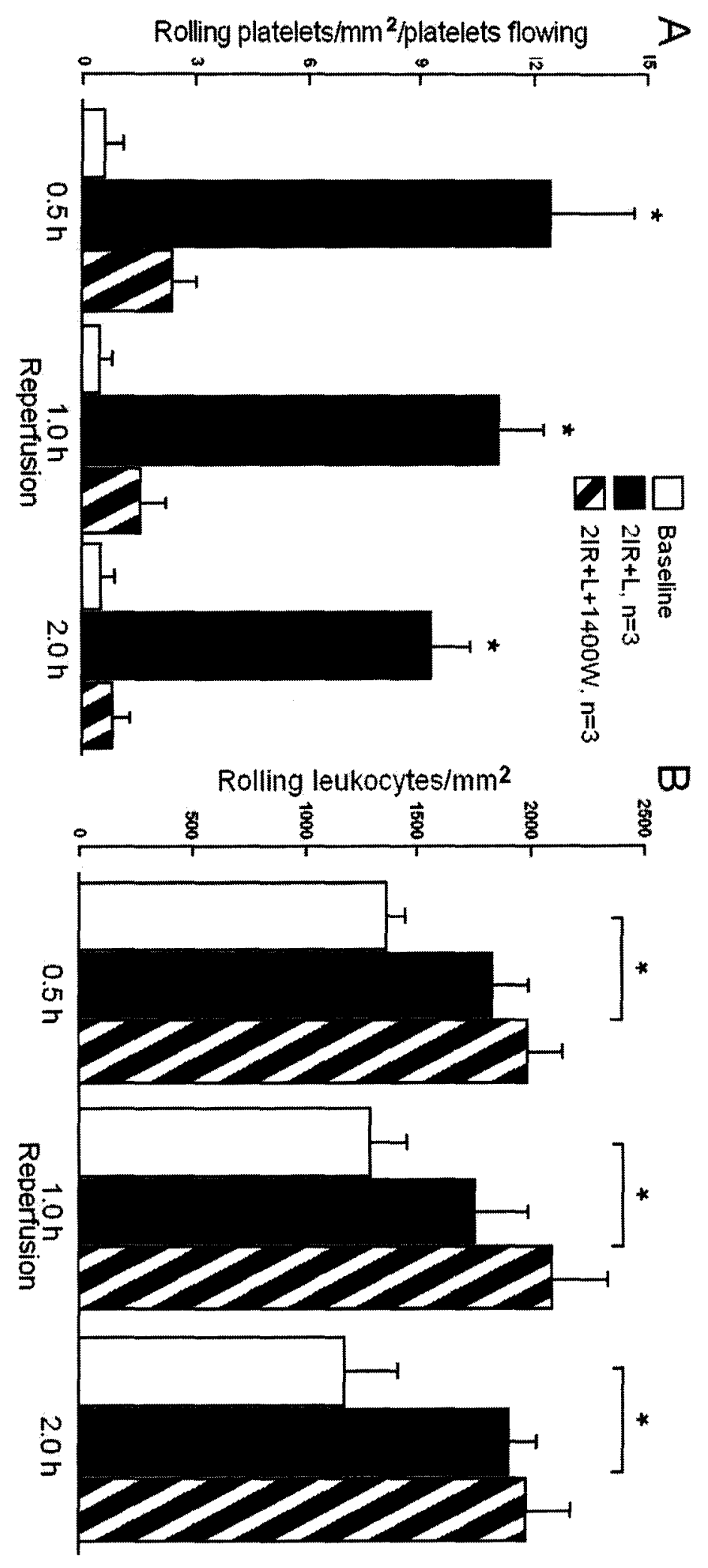

Figure 18 
Figure 19. Platelet adhesion in subpleural arterioles after topical application of $1 \mu \mathrm{M}$ peroxynitrite (in $100 \mu \mathrm{m}$ ). A, before application; B, 15 $\mathrm{s}$ after application; C, $16 \mathrm{~s}$ after application; D, $25 \mathrm{~s}$ after application. Arrows indicate examples of platelets adhered to the arteriolar wall. 

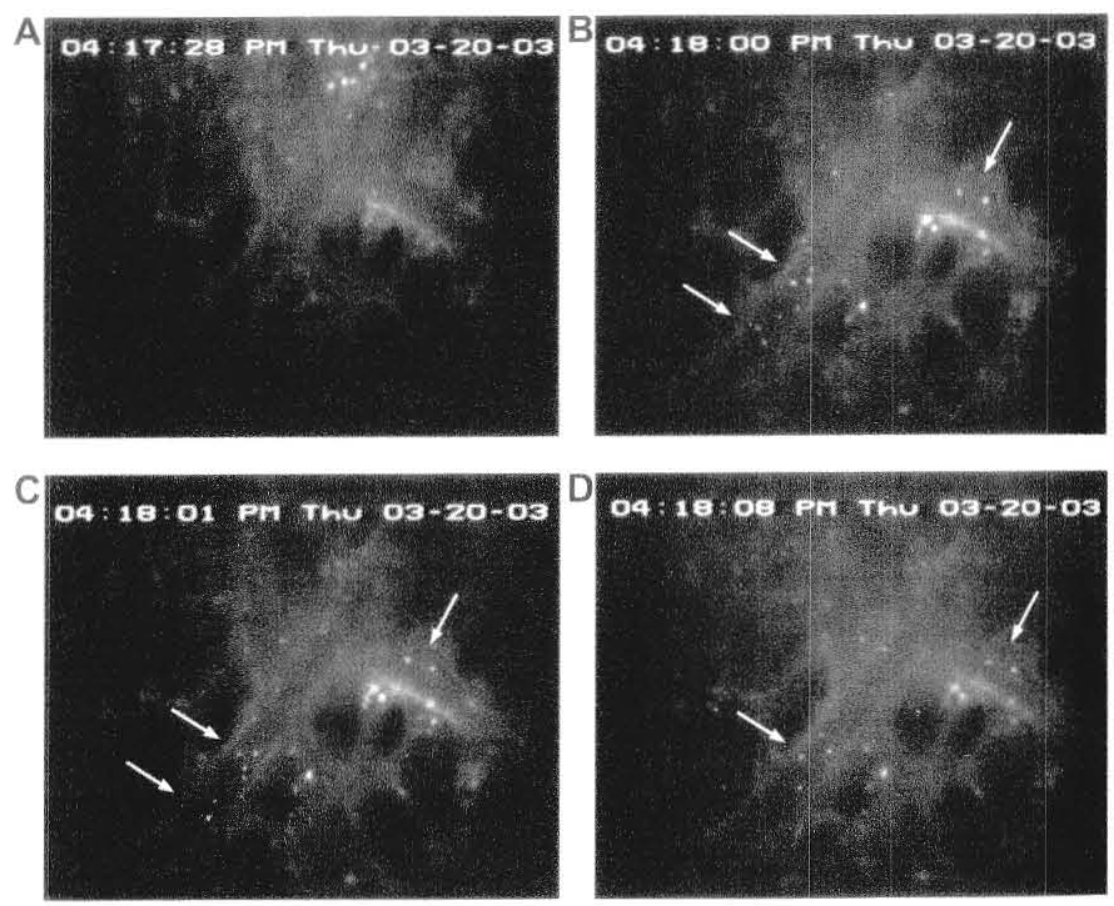

$\overline{100} \mu \mathrm{m}$
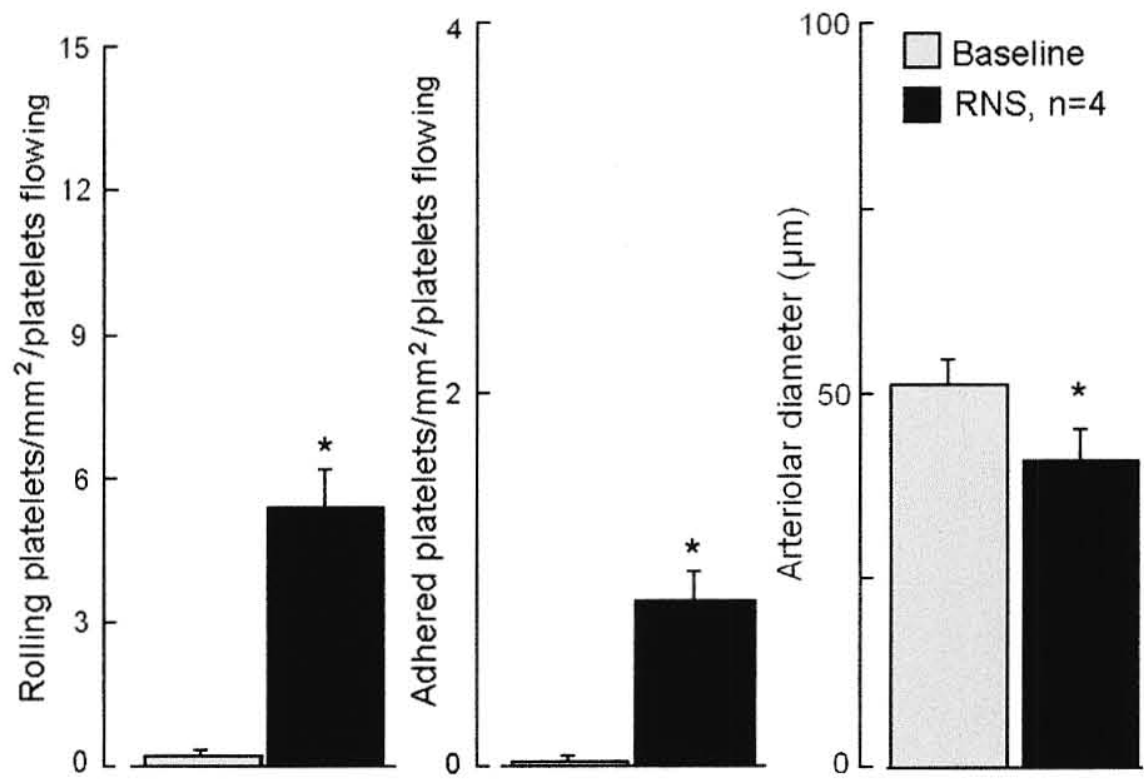

Figure 19 
Figure 20. Comparison of nitrotyrosine expression as a marker of RNS in lung tissue after $2 \mathrm{~h}$ of ischemia with and without $1400 \mathrm{~W}$ treatment. Fluorescence (green) shows positive nitrotyrosine immunostaining. A, negative control; $\mathrm{B}$, non-ischemic lung (control). Note greater nitrotyrosine immunostaining with 2 IR (C) was prevented by $1400 \mathrm{~W}$ (D). 


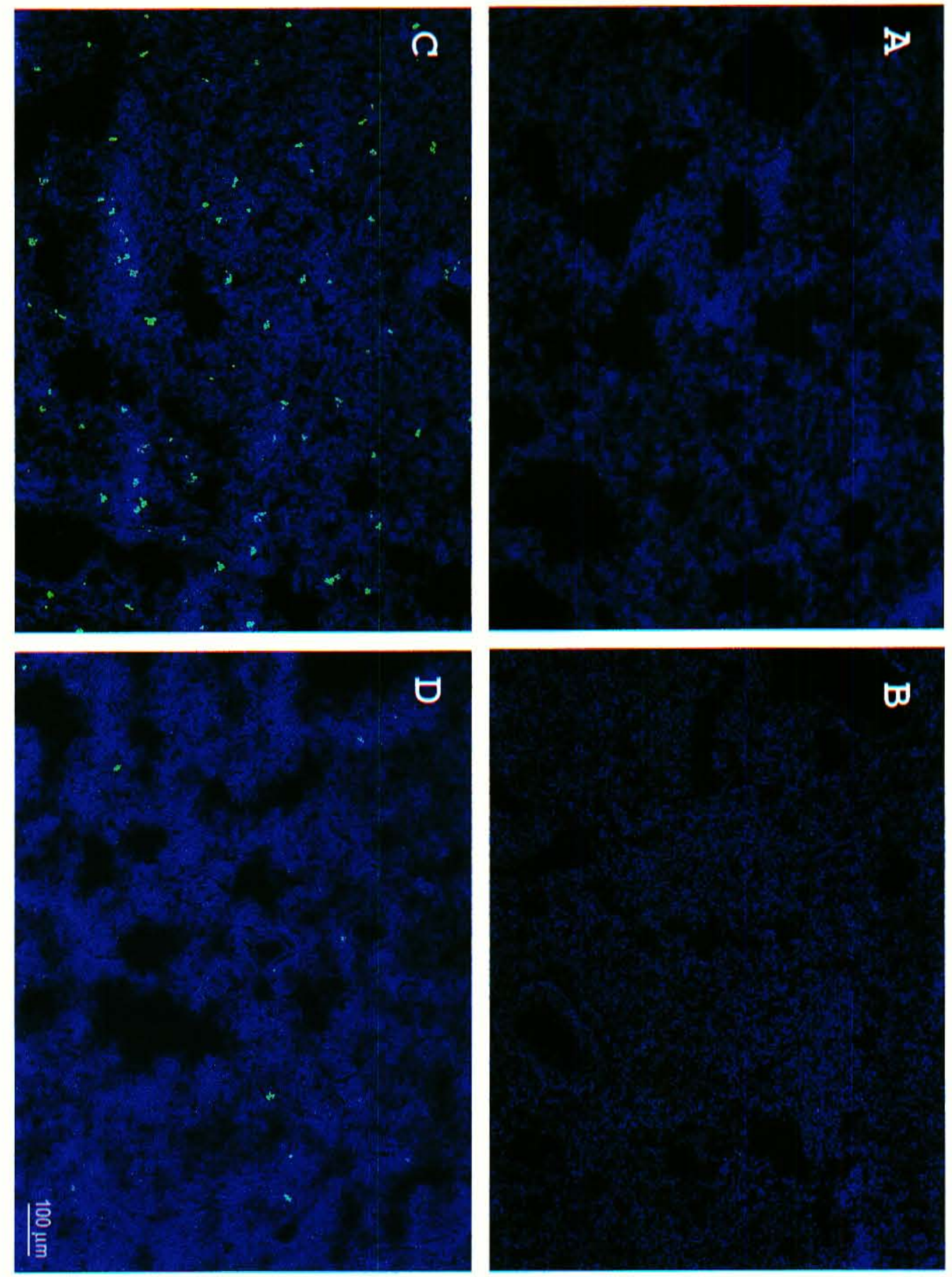

Figure 20 


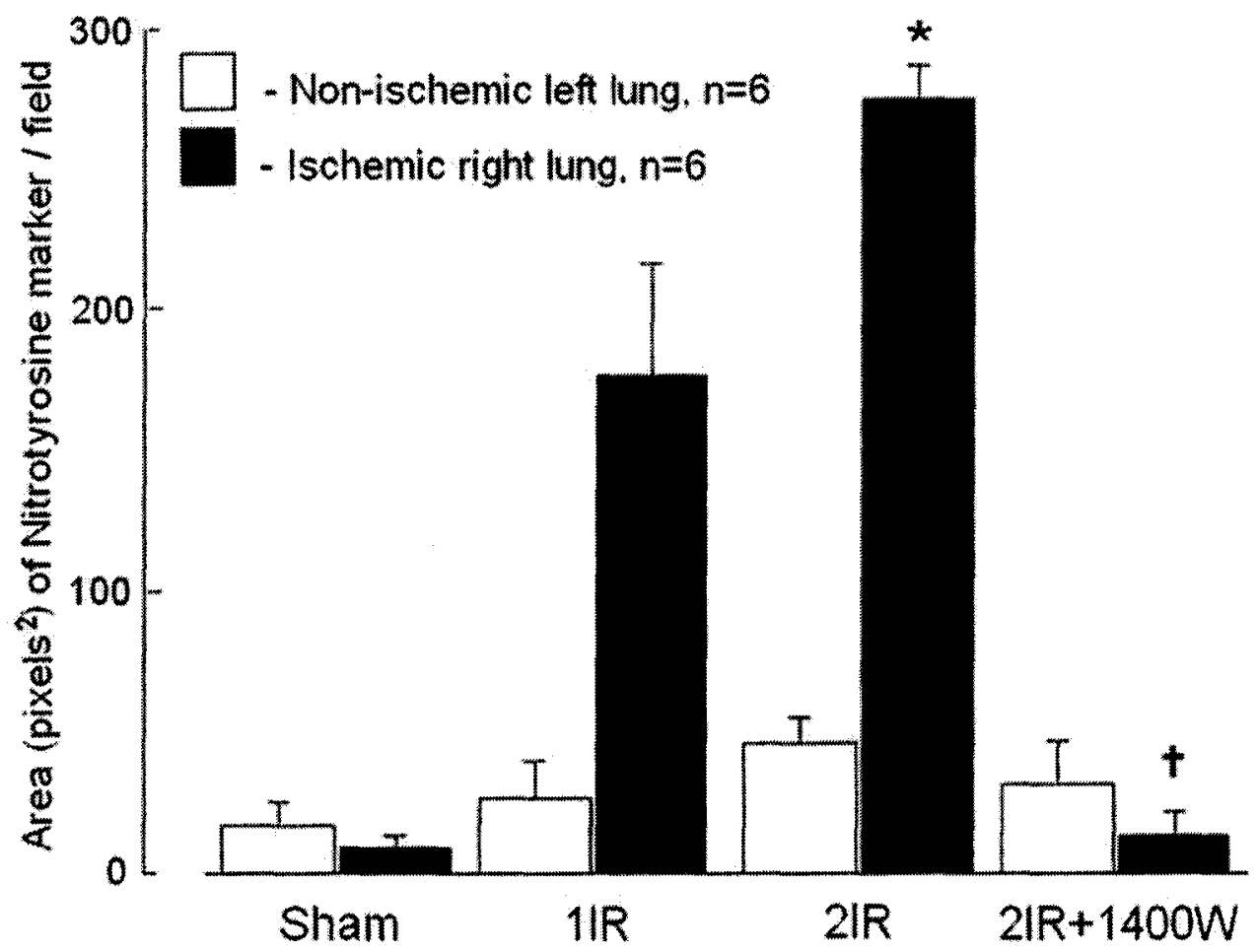

Figure 21. Effect of pulmonary ischemia with and without $1400 \mathrm{~W}$ treatment on nitrotyrosine expression in lung tissue. Scale bars indicate means \pm SEM. $\mathrm{n}=$ number of animals. * Indicates $\mathrm{P}<0.05$ compared to all groups; $\uparrow$ Indicates $\mathrm{P}<0.05$ compared $2 \mathrm{IR}$ ischemic and non-ischemic (sham) groups. 
Figure 22. Comparison of immunofluorescence staining of P-selectin in lung tissue after $2 \mathrm{~h}$ of ischemia and $2 \mathrm{~h}$ of ischemia with $1400 \mathrm{~W}$ treatment. Fluorescence (green, arrows) shows positive P-selectin immunostaining (arrows). A, non-ischemic lung (control). Note greater P-selectin immunostaining in $2 \mathrm{IR}$ (B) compared to control (A) and $2 \mathrm{IR}+1400 \mathrm{~W}$ (C). D, trichrome staining for the section which was taken from the same 2IR block shown in panel B (the area of interest is framed). 

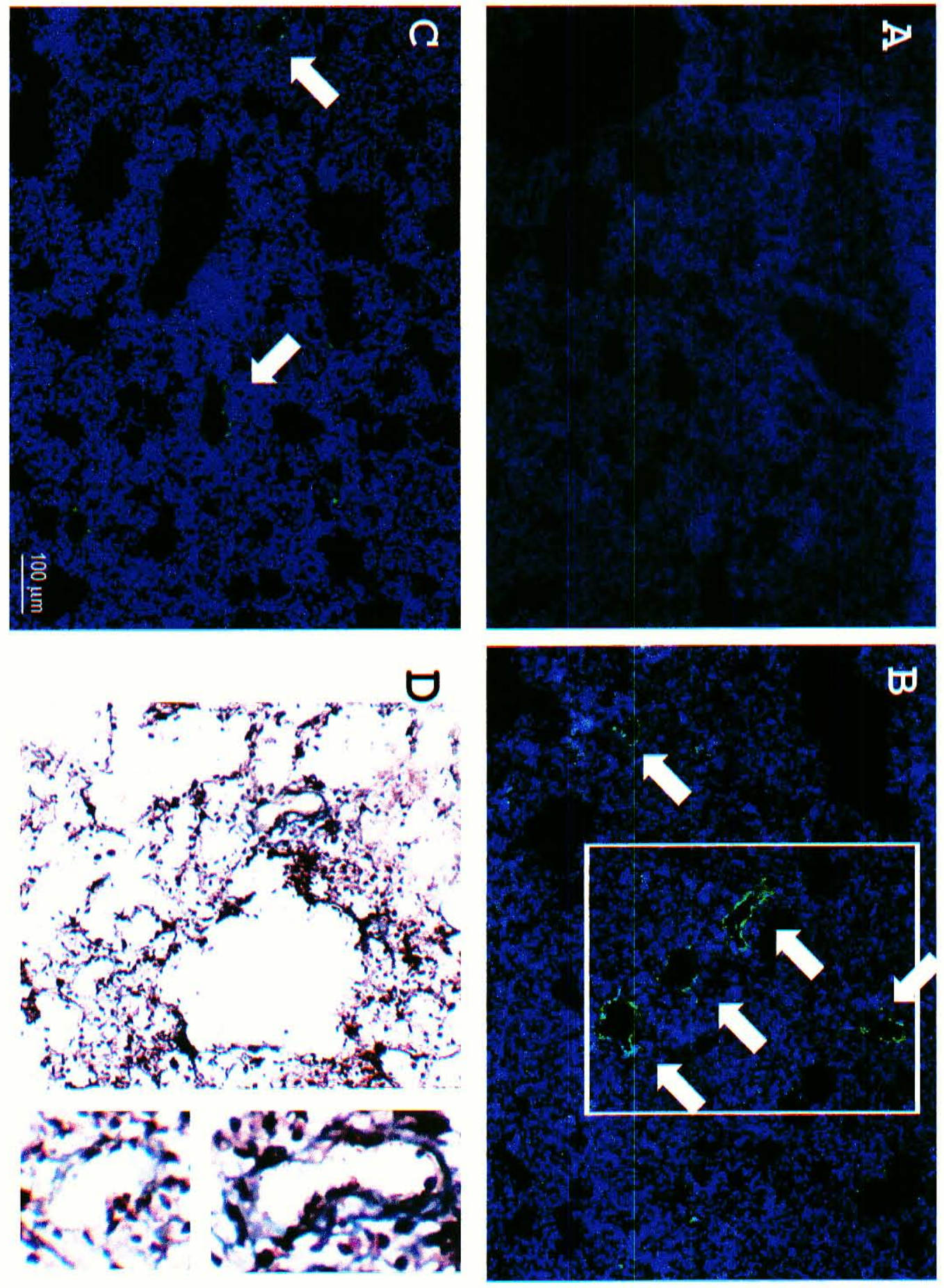

Figure 22 
Figure 23. Scatter diagram of lung P-selectin, plasma P-selectin, and lung nitrotyrosine expression from animals that underwent no ischemia, 5min, 1-h, or 2-h lung ischemia. Correlation coefficient (r) obtained by linear regression. $\mathrm{n}=$ number of animals. $\mathrm{A}$, correlation of nitrotyrosine; $\mathrm{B}$, tissue $\mathrm{P}$ selectin expression versus duration of ischemia; $\mathrm{C}$, correlation of $\mathrm{P}$-selectin expression versus nitrotyrosine expression after $2-\mathrm{h}$ ischemia and reperfusion. 
A

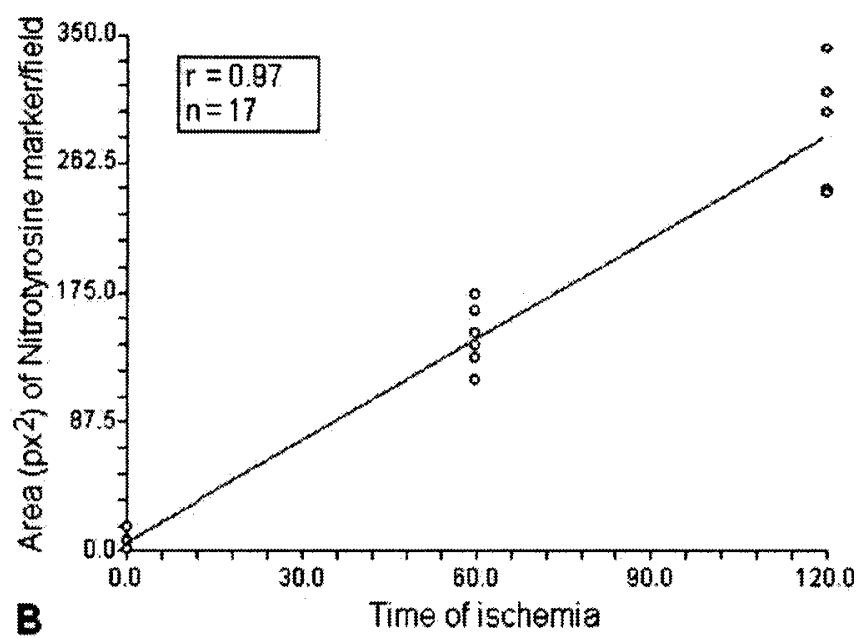

B
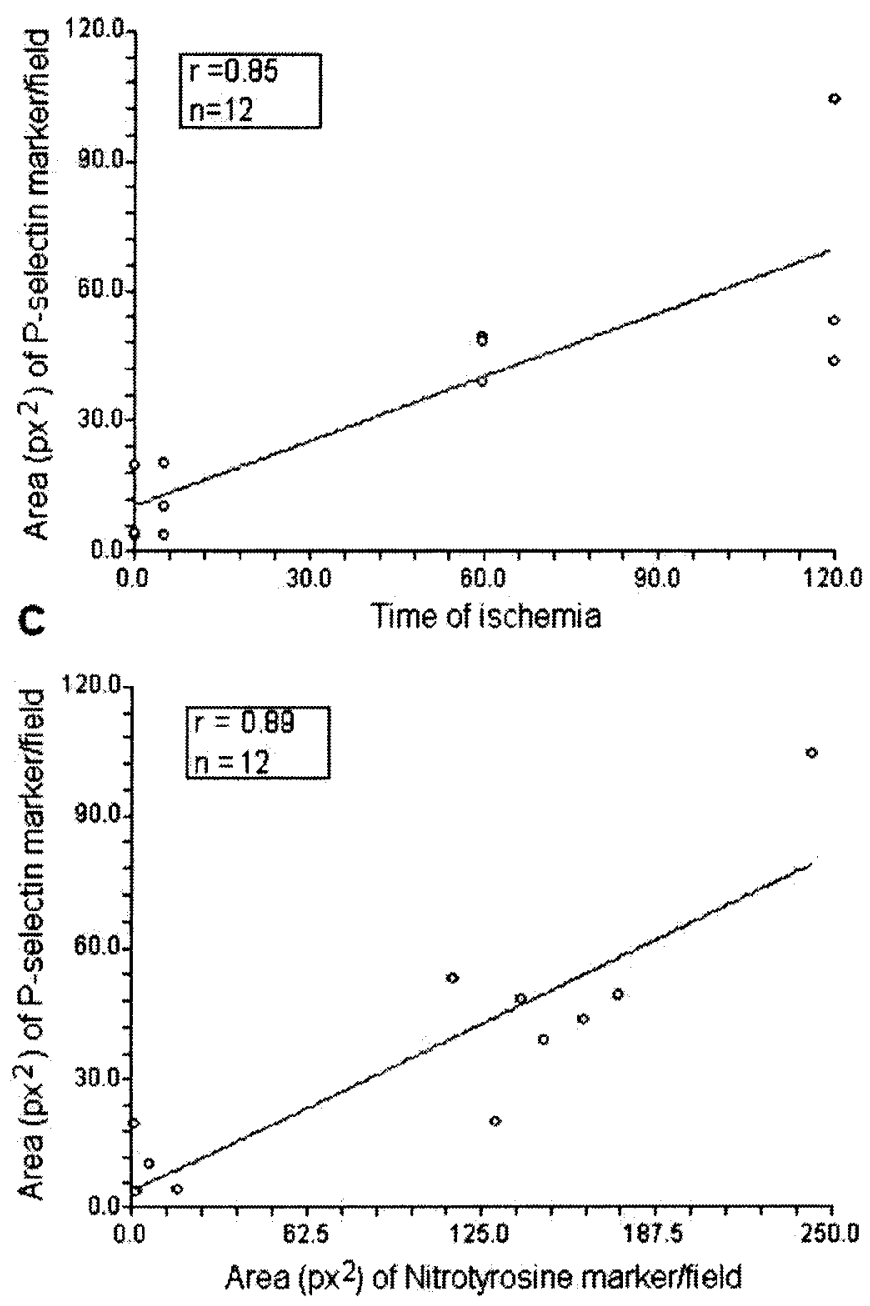

Figure 23 


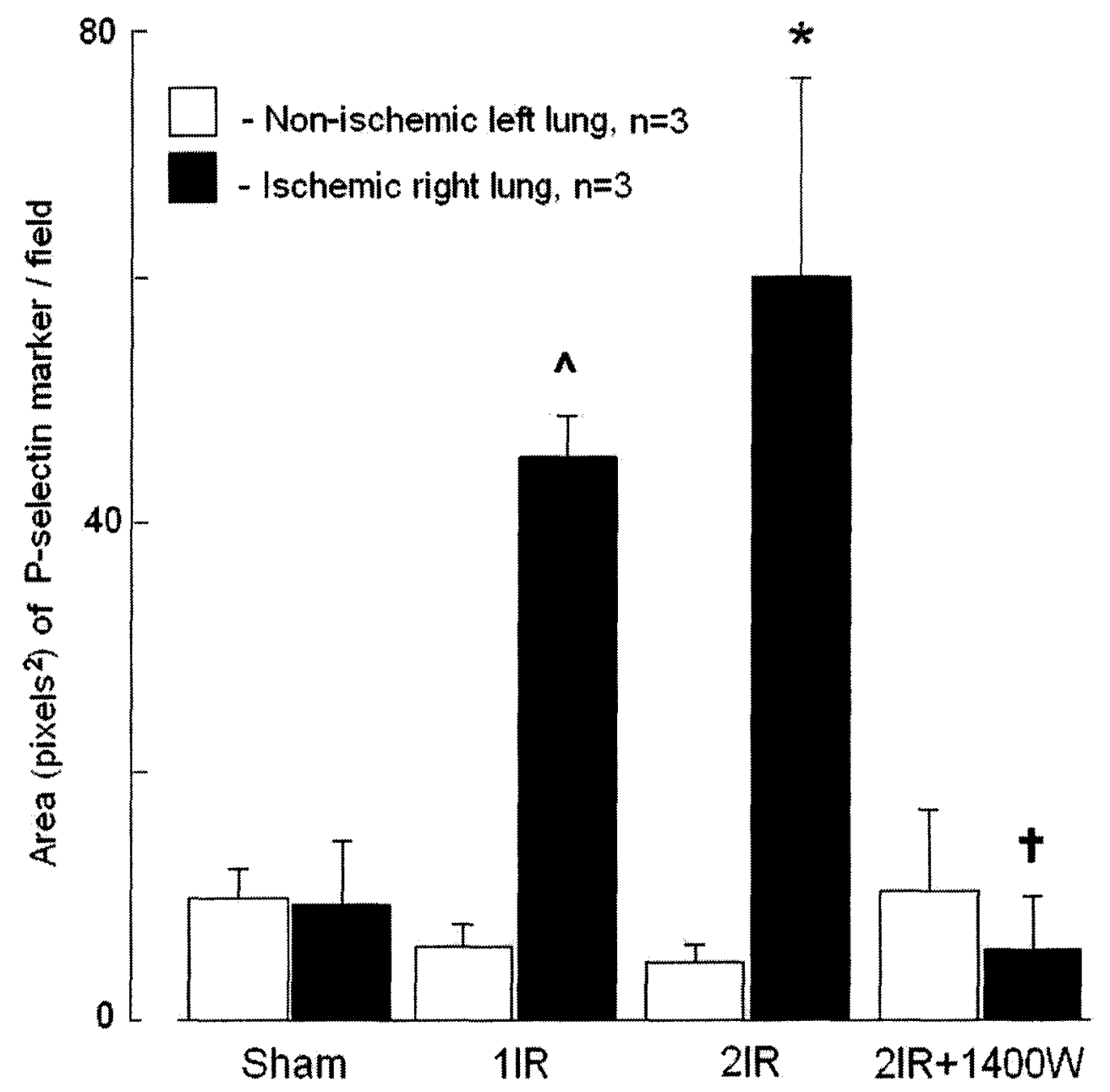

Figure 24. Effect of ischemia duration and $1400 \mathrm{~W}$ treatment on P-selectin expression in lung tissue after $2 \mathrm{~h}$ of reperfusion. Scale bars indicate means \pm SEM. $\mathrm{n}=$ number of animals. ${ }^{*}$ Indicates $\mathrm{P}<0.05$ compare to all groups except 1 IR ischemic lung group; ${ }^{\wedge}$ Indicates $\mathrm{P}<0.05$ compare to all groups except 2 IR ischemic lung group; $\dagger$ Indicates $\mathrm{P}<0.05$ compare to $1 \mathrm{IR}$ and $2 \mathrm{IR}$ ischemic lung groups. 


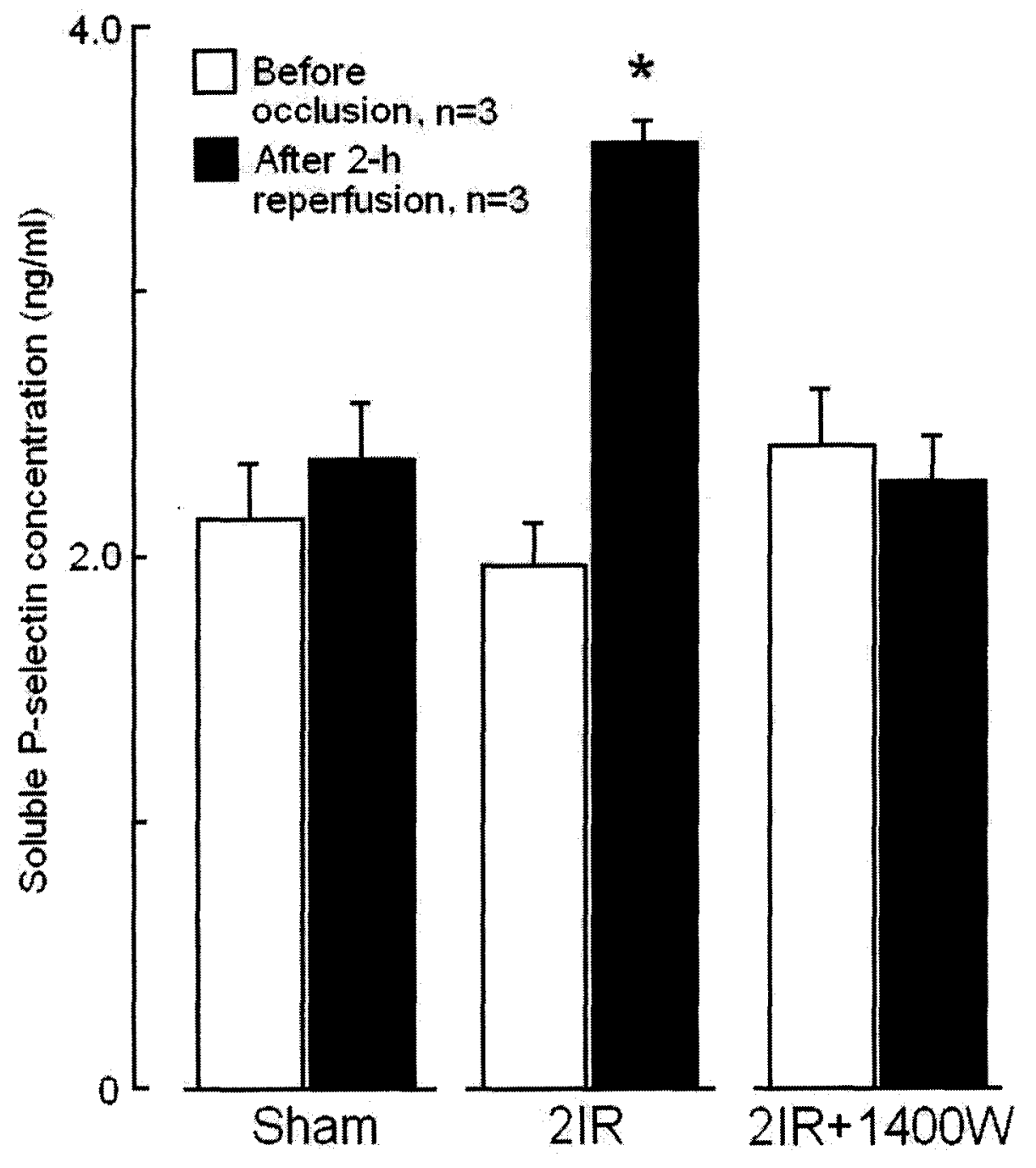

Figure 25. Effect of pulmonary 2 IR with and without $1400 \mathrm{~W}$ treatment on concentration of soluble P-selectin in plasma after $2 \mathrm{~h}$ of reperfusion. Scale bars indicate means \pm SEM. $\mathrm{n}=$ number of animals. ${ }^{*}$ Indicates $\mathrm{P}<0.05$ compare to all groups 
Figure 26. Effects of $1400 \mathrm{~W}$ treatment on platelet-arteriolar wall interactions during reperfusion of the right lung after $2 \mathrm{~h}$ of pulmonary ischemia-reperfusion. (A) Rolling platelets. (B) Adhering platelets. Scale bars indicate means \pm SEM. $\mathrm{n}=$ number of animals. * Indicates $\mathrm{P}<0.05$. 


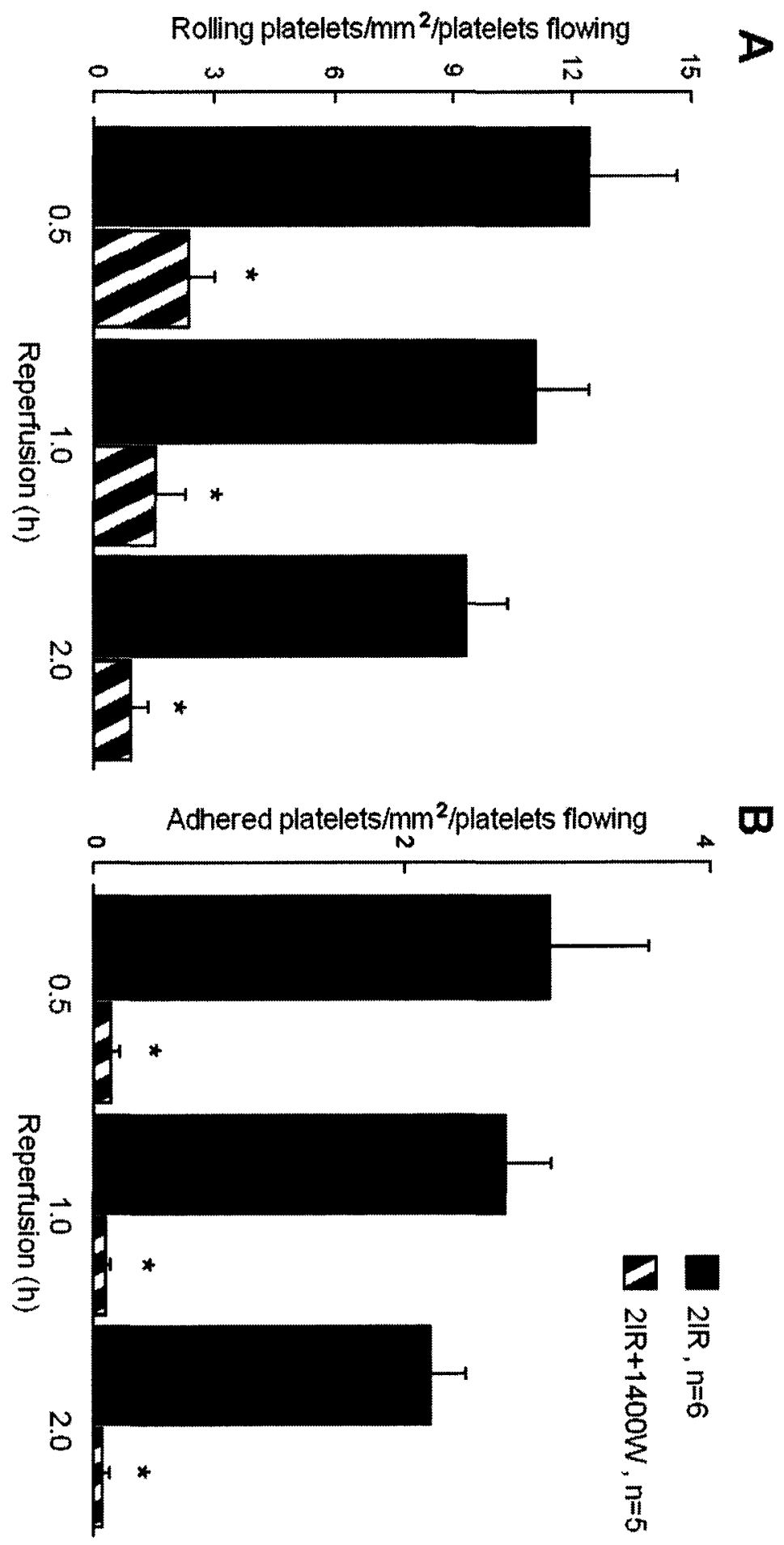

Figure 26 


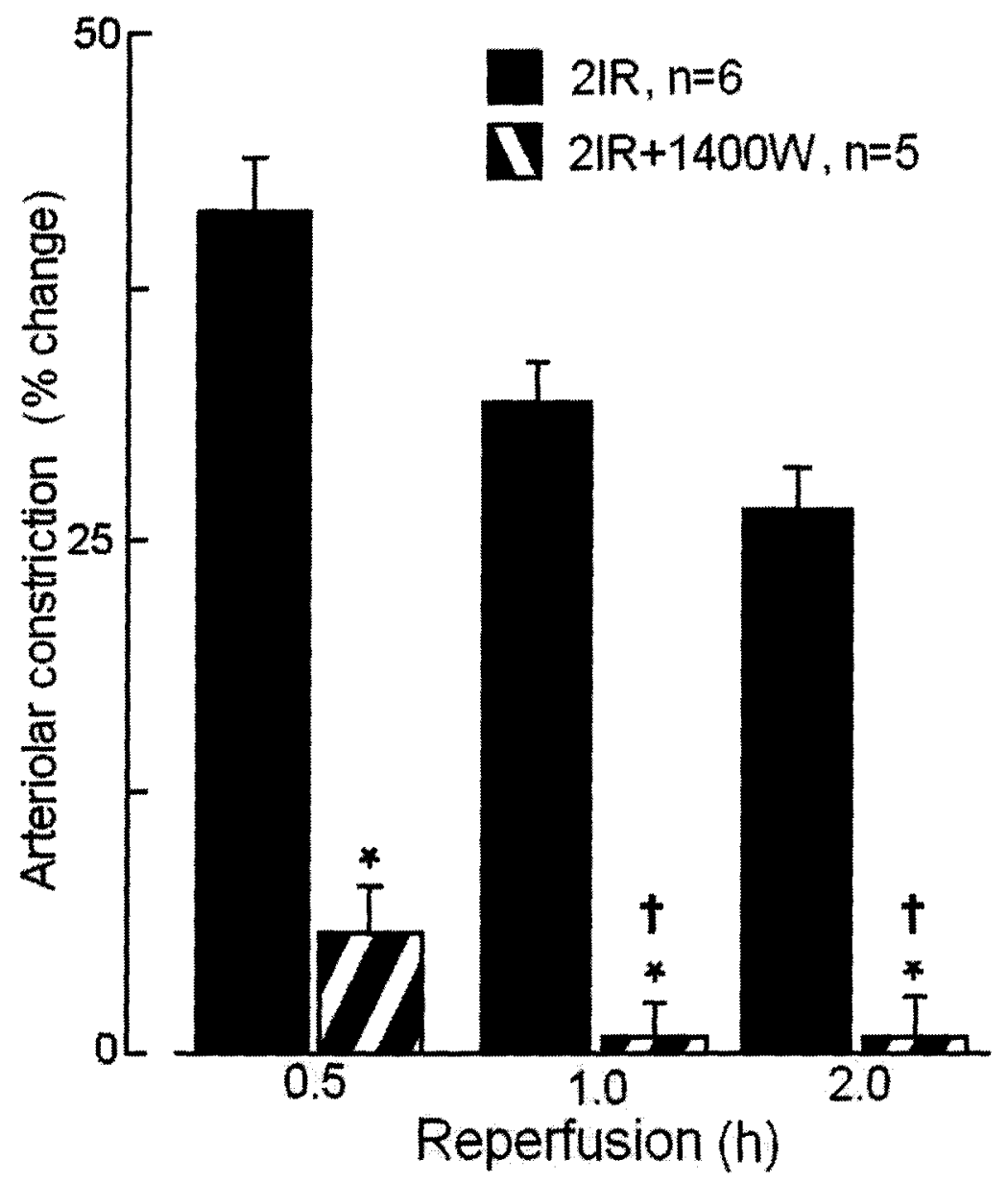

Figure 27. Comparison of effects of $1400 \mathrm{~W}$ treatment on changes in pulmonary arteriolar diameters during the reperfusion time course after $2 \mathrm{~h}$ ischemia. 2IR, ischemia-reperfusion alone (21 arterioles in 6 animals); and $2 \mathrm{IR}+1400 \mathrm{w}$, and $1400 \mathrm{~W}$ (18 arterioles in 5 animals) given I.V. * denotes $\mathrm{P}<0.05$. $\uparrow$ denotes no significant constriction. 
Figure 28. Comparison of effects of MoAb, Fucoidan or $1400 \mathrm{~W}$ treatment on changes in pulmonary arteriolar diameters during reperfusion after 2 h ischemia. 2IR, ischemia-reperfusion alone (21 arterioles in 6 animals); $\mathrm{IR}+\mathrm{MoAb}$, ischemia-reperfusion plus labeled platelets treated with monoclonal antibody to P-selectin (17 arterioles in 5 animals); 2IR+Fucoidan and $2 \mathrm{IR}+1400 \mathrm{w}$, ischemia-reperfusion plus treatment with Fucoidan (13 arterioles in 5 animals) and 1400W (18 arterioles in 5 animals) given I.V. * denotes $\mathrm{P}<0.005$ for comparison of $2 \mathrm{IR}+\mathrm{Fucoidan}$ and $2 \mathrm{IR}+1400 \mathrm{~W}$ with $2 \mathrm{IR}$ and IR $+\mathrm{MoAb}$ groups. ${ }^{\wedge}$ denotes $\mathrm{P}<0.005$ for comparison of $2 \mathrm{IR}+$ Fucoidan with $2 \mathrm{IR}+1400 \mathrm{~W}$ group. $\uparrow$ denotes no significant constriction. 


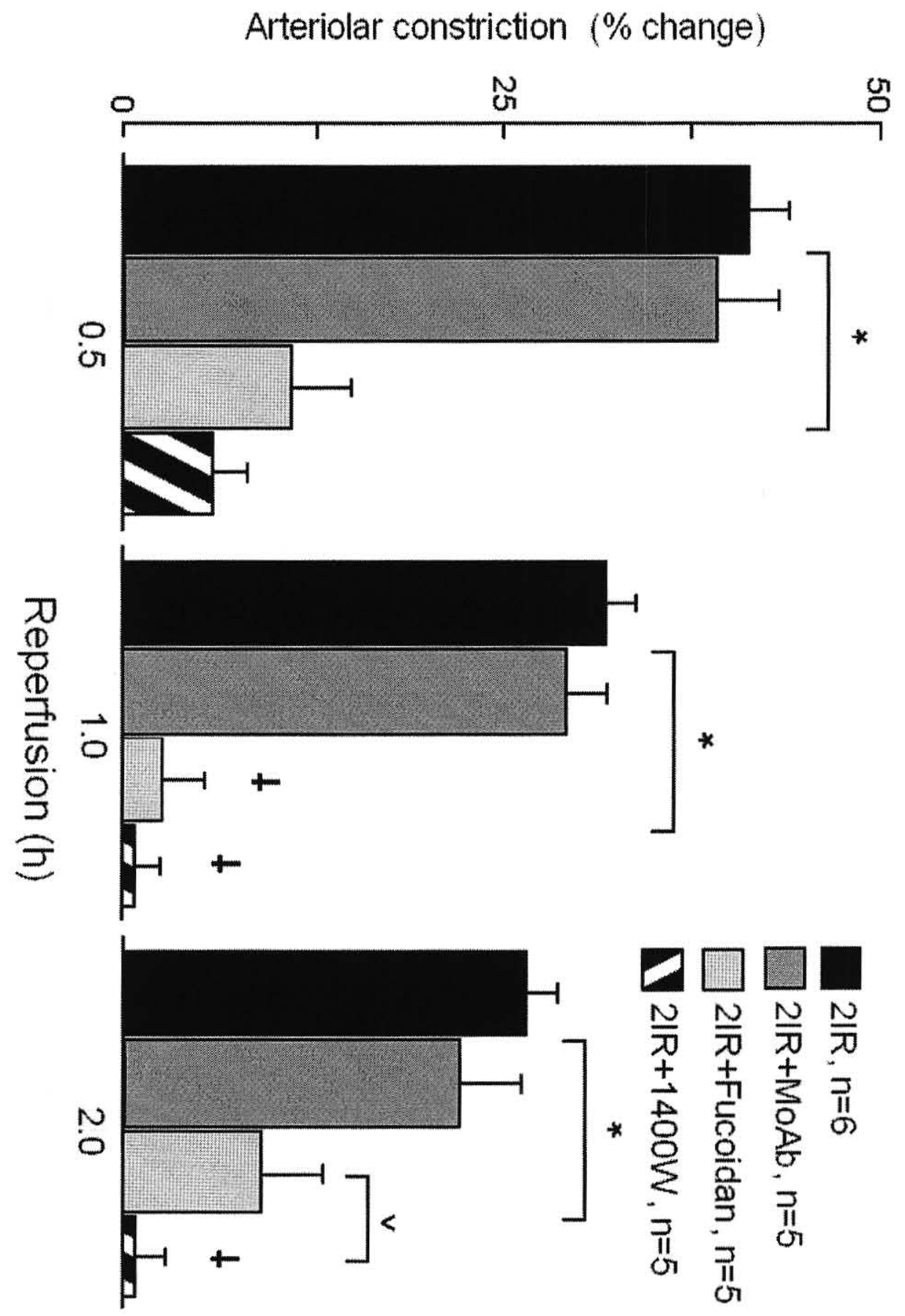

Figure 28 
Figure 29. Platelet-arteriolar wall interactions during reperfusion of the right lung after $2 \mathrm{~h}$ of pulmonary ischemia-reperfusion. (A) Rolling platelets. (B) Adhering platelets. Scale bars indicate means $\pm S E M ; n=$ number of animals; 2IR, 2-h ischemia-reperfusion; MoAb, anti-P-selectin monoclonal antibody. * Indicates $\mathrm{P}<0.001$. Note that there were no significant differences between $2 \mathrm{IR}+$ Fucoidan, $2 \mathrm{IR}+\mathrm{MoAb}$ and $2 \mathrm{IR}+1400 \mathrm{~W}$ groups. 


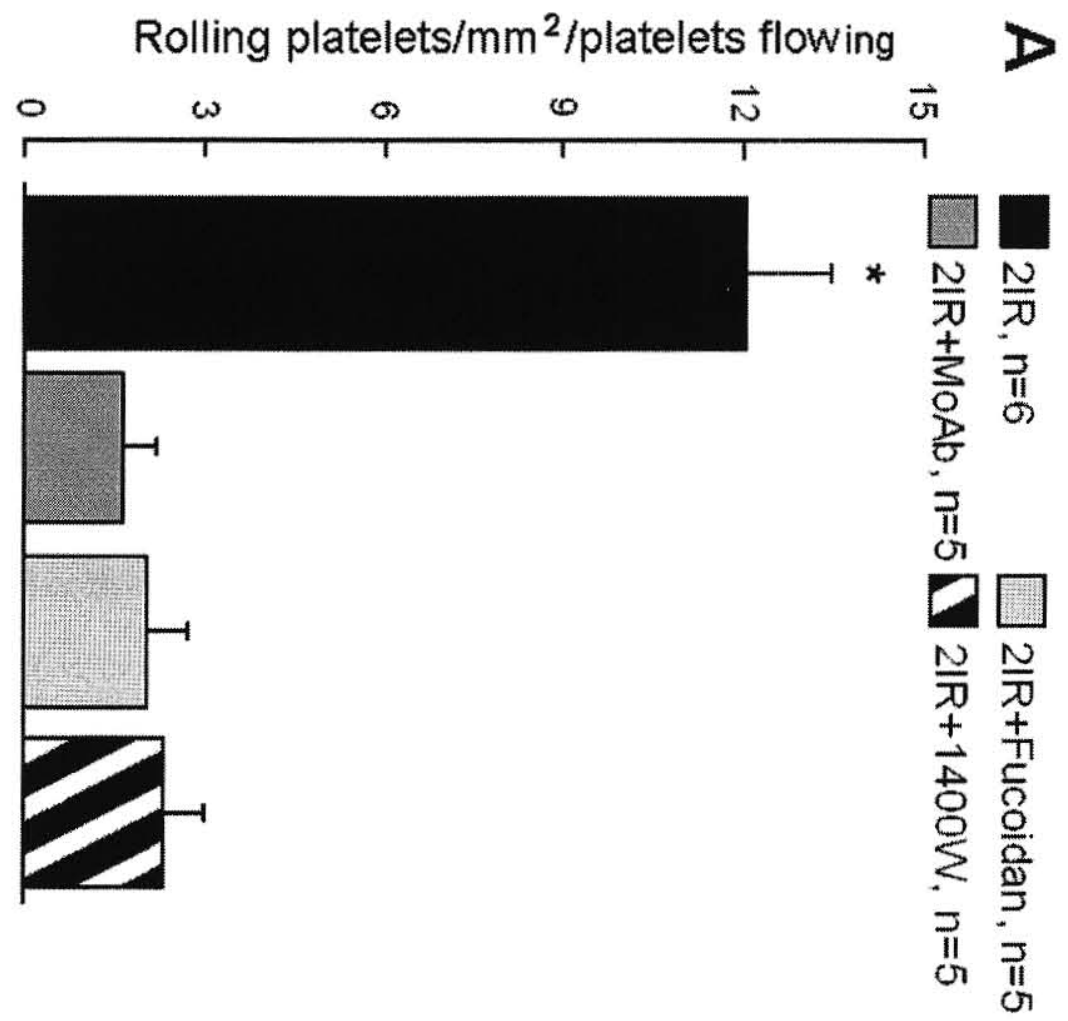

Adhered platelets $/ \mathrm{mm}^{2} /$ platelets flowing

盛

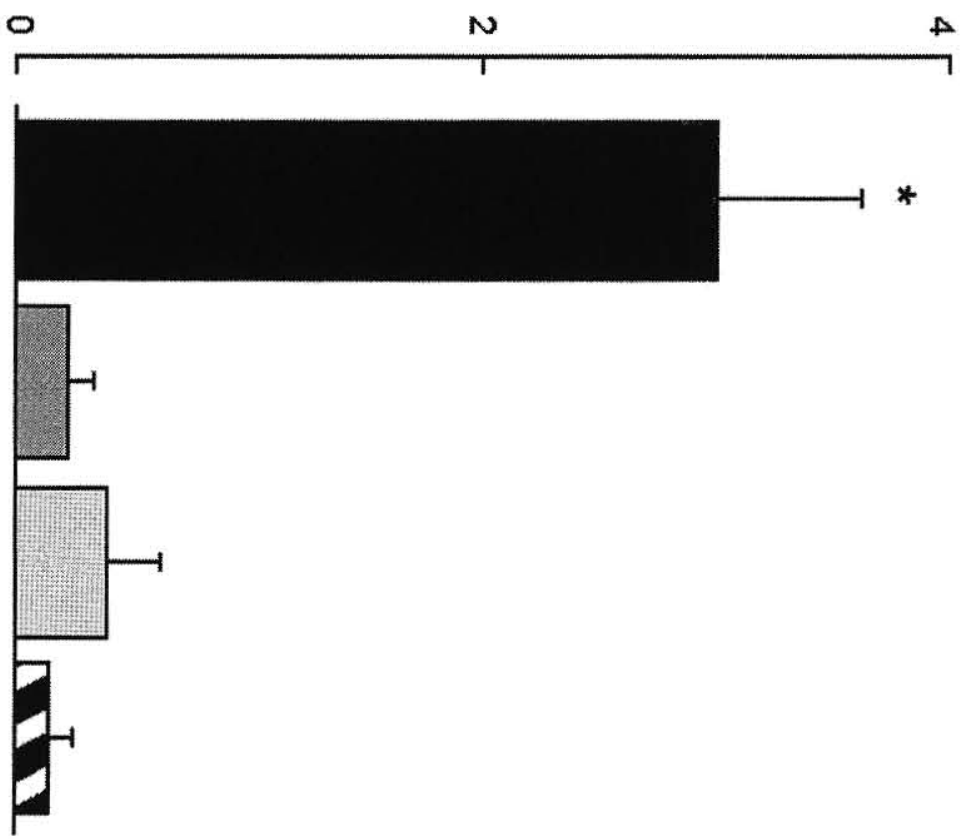

Figure 29 
Figure 30. Comparison of changes in arteriolar diameter (A), platelet rolling (B), and platelet adhesion (C) after $2 \mathrm{~h}$ of pulmonary ischemia with and without $1400 \mathrm{~W}$ treatment. $2 \mathrm{IR}, 2-\mathrm{h}$ ischemia; $2 \mathrm{IR}+1400 \mathrm{~W}, 2-\mathrm{h}$ ischemia with $1400 \mathrm{~W}$ treatment. Scale bars indicate means \pm SEM. There were 5 animals in each group. ${ }^{*}$ denotes significant difference $(\mathrm{p}<0.05)$. 

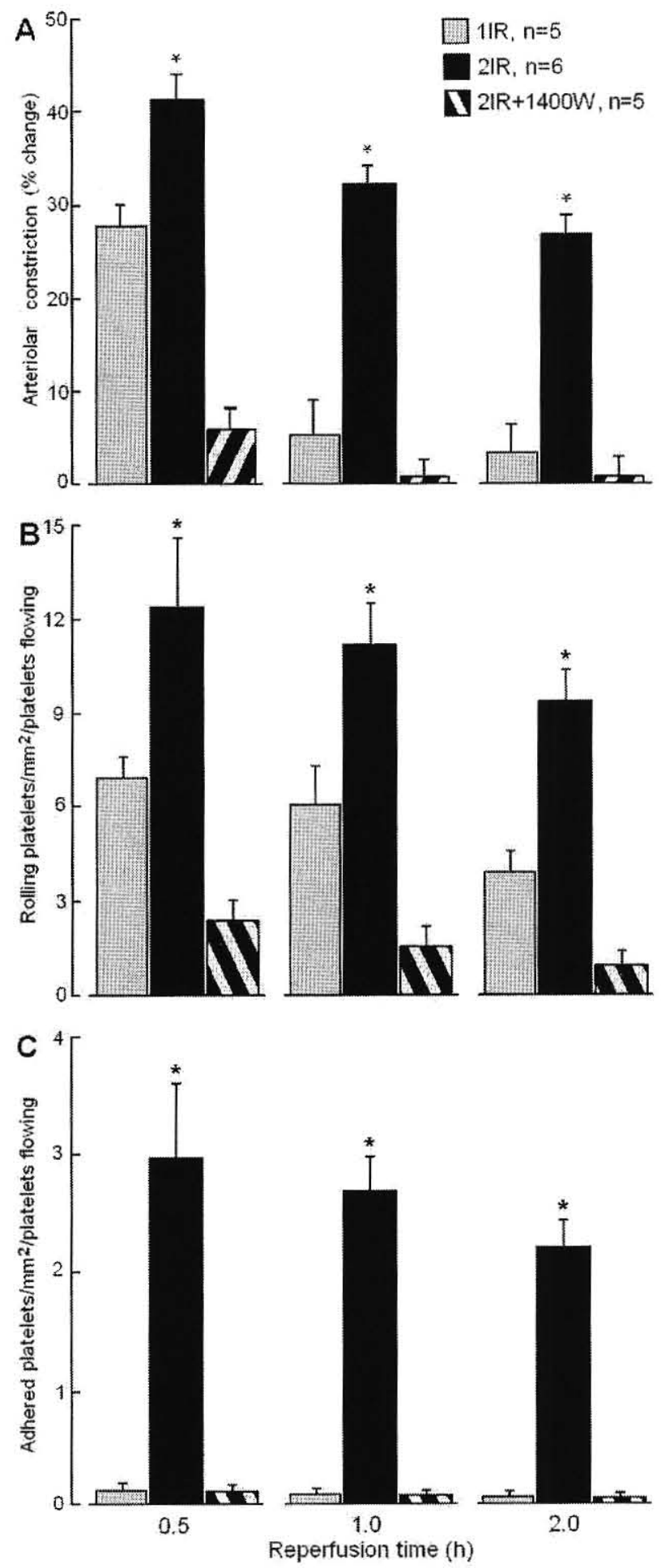

Figure 30 
Figure 31. Effect of pulmonary ischemia on nitrotyrosine expression in lung tissue (A), P-selectin expression in lung tissue (B), and plasma soluble P-selectin (C) after $2 \mathrm{~h}$ of reperfusion. Scale bars indicate mean \pm SEM, $n=$ number of animals. ${ }^{\wedge}$ Indicates $\mathrm{p}<0.05$ compared to all samples (except 2 IR in panel B); * Indicates $\mathrm{p}<0.05$ compare to all samples (except 1 IR in panel B). 

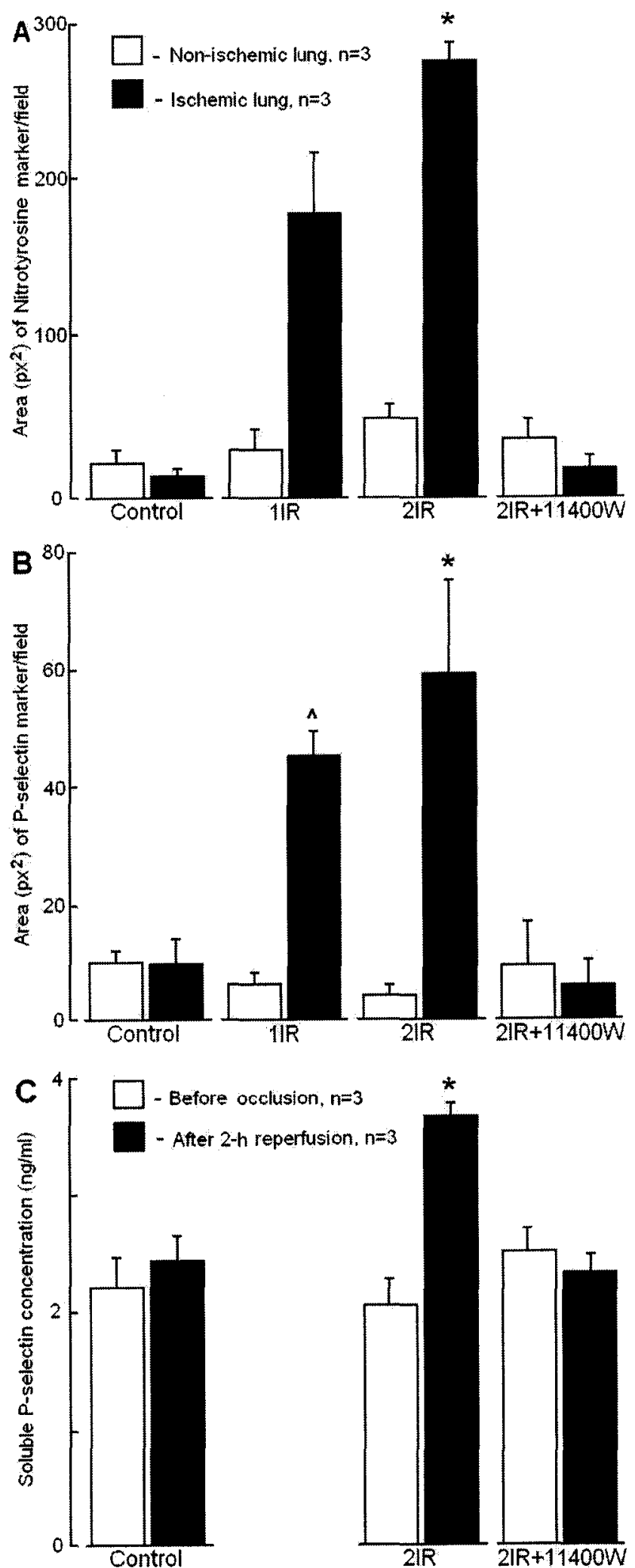

Figure 31 


\section{CHAPTER IV}

\section{DISCUSSION}

1. Effects of IR platelet- and leukocyte-arteriolar wall interactions and arteriolar vasoconstriction during lung reperfusion

Specific aim \#1 addressed the hypothesis that pulmonary ischemiareperfusion induces platelet-arteriolar wall interactions and contributes to pulmonary microvascular constriction during reperfusion by determining if platelet-arteriolar wall interactions occur during lung reperfusion and if they could contribute to pulmonary postischemic microvascular constriction.

During reperfusion of the ischemic lung, platelets were observed rolling and adhering along arteriolar walls when blood flow returned. This process was proportional to the duration of ischemia and did not occur during normal conditions, or in response to a brief occlusion (5 min). By observing individual arterioles over the time course of reperfusion after prolonged ischemia, we found that platelet rolling and adhesion occurred at the beginning of reperfusion (Fig.9). As the ischemic duration increased, the numbers of rolling and adhered platelets increased (Fig.8). After $1 \mathrm{~h}$ of ischemia, platelet rolling increased significantly, but 
there was no adhesion. The amount of platelet rolling in the 2IR group increased about two fold compared to the 1IR group. In addition, after 2-h of ischemia, platelet adhesion increased dramatically. To our knowledge, platelet rolling and adhesion in subpleural arterioles during reperfusion of the intact, ventilated lung, has not been reported previously. Our findings are consistent with the results of others who found that platelets do not normally interact with the endothelium in the systemic microvasculature unless there is some level of activation (2). Comparing velocities of unstimulated platelets with thrombin-activated platelets in pulmonary arterioles, Eichorn et al. (2002) found that platelet-endothelial interactions do not occur unless platelets are activated (9). This observation indicates that the level of platelet adhesion is in proportion to the degree of injury and/or products produced in postischemic tissue.

Our results also show that reperfusion of the lung after 2-h ischemia causes arteriolar diameter to decrease, which subsequently would affect alveolar perfusion. Typically, during reperfusion, we observed that alveolar walls became pale, indicating lack of perfusion. Constriction was greatest at the beginning of reperfusion and continued for at least $2 \mathrm{~h}$, gradually recovering. Similar to platelet rolling and adhesion, the amount of postischemic vasoconstriction was also proportional to the length of ischemia. Control conditions, or brief occlusion, did not decrease arteriolar diameter. After 1 -h of ischemia, diameter was significantly decreased during the first $0.5 \mathrm{~h}$ of reperfusion, but by $1 \mathrm{~h}$ returned to the baseline (Fig.7). As previously shown using the same model of IR (29), a decrease in 
arteriolar diameter during reperfusion corresponded with an increase in pulmonary vascular resistance without a significant change in pulmonary artery pressure or pressure gradient across the lungs. Systemic arterial blood pressure and heart rate did not significantly change throughout our experiments, and the results did not appear to be due to a general haeomodynamic change (Table 1). However, at the very beginning of reperfusion, decreased microvascular diameter could be passive if some vessels are not opened by returning blood flow. It is unlikely that vasoconstriction during reperfusion was due to hypoxia, since $\mathrm{PO}_{2}$ was kept above $100 \mathrm{mmHg}$. In addition, arterial $\mathrm{PCO}_{2}$ and $\mathrm{pH}$ before occlusion were not significantly different throughout the experiments (Table 2). Therefore, the decrease in arteriolar diameter is indicative of vasoconstriction.

During reperfusion after $1-\mathrm{h}$ and $2-\mathrm{h}$ ischemia, the amount of plateletarteriolar wall interactions and amount of arteriolar constriction, tended to decrease with progression of reperfusion time. In the 2IR group, there was a stronger correlation between vasoconstriction with reperfusion time $(r=0.85)$ than in the 1IR group (r=0.6) (Fig.10B and 10A). In addition, in the 2IR group, the decrease in platelet adhesion correlated with reperfusion time $(\mathrm{r}=0.8)$, but the number of rolling platelets did not $(\mathrm{r}=0.66)$ (Fig.10D and 10E). Throughout reperfusion, the amounts of arteriolar constriction and platelet adhesion were highly correlated to each other ( $\mathrm{r}=0.96)$ (Fig.11C).

After 1-h occlusion, platelet rolling was significantly greater than control. Arteriolar diameters were only significantly decreased during the first $0.5 \mathrm{~h}$ of 
reperfusion, and platelet adhesion was not observed (Fig.7 and 8). In contrast, during reperfusion after $2 \mathrm{~h}$ of ischemia, an increased amount of platelet rolling was accompanied by increased of platelet adhesion and indicates that a certain amount of platelet rolling precedes the firm adhesion. This is consistent with the results of others who reported that P-selectin-PSGL-1 interactions trigger a functional upregulation of integrins (CD11b/CD18, Mac-1) which mediate firm adhesion of platelets and leukocytes (168). The observation that after $1 \mathrm{~h}$ of ischemia at $0.5 \mathrm{~h}$ of reperfusion, arteriolar constriction was not accompanied by platelet adhesion indicates that not all of the decrease in pulmonary arteriolar diameter (especially at $0.5 \mathrm{~h}$ ) is platelet mediated.

Platelet- and leukocyte-endothelial interactions involve selectin dependent mechanisms and both are implicated in microvascular dysfunction associated with IR (151). The primary ligand for P-selectin, PSGL-1, is constitutively expressed mostly on endothelial cell and leukocyte membranes (173) and it is possible that platelet rolling along arteriolar walls could be facilitated by interaction of platelet and/or endothelial P-selectin with PSGL-1 expressed on leukocytes. We did experiments to determine if postischemic platelet-arteriolar wall interactions and vasoconstriction could occur independently of leukocyte adhesion. According to our observations, leukocyte rolling was a separate process from plateletendothelial interactions and leukocyte adhesion did not occur during 2-h reperfusion following 2-h ischemia. We found that postischemic platelet-arteriolar wall interactions and vasoconstriction can occur independently of leukocyte adhesion. Platelet, but not leukocyte rolling and adhesion along arterioles correlated 
with microvascular constriction. Pretreatment with an iNOS inhibitor (1400W) significantly decreased platelet rolling, adhesion (Fig.30B, 30C) and vasoconstriction (Fig.30A), but had no significant effect on leukocyte rolling or adhesion (Fig.18). Moreover, when observed simultaneously, platelets and leukocytes had different rolling velocities and were rolling at different sites (Fig. 13). These results suggest that platelet activation during early reperfusion in the ventilated lung is a more significant factor than leukocyte activation in contributing to postischemic arteriolar constriction and decreased alveolar perfusion. This observation is consistent with previous reports that lung IR injury consists of an early (first $2 \mathrm{~h}$ of reperfusion) leukocyte-independent phase (10). However, our results do not exclude the possibility that platelet-endothelial adhesion can also involve leukocyte interactions. In morphologically intact endothelium, Kirton and Nash (2000) found that even small numbers of platelets adhered to the endothelium have the potential to capture flowing neutrophils and facilitate their immobilization at the vessel wall and promote inflammatory and thrombotic interactions (77).

Although, platelet activation and accumulation are implicated in causing reperfusion injury in tissues such as intestine, liver, pancreas, brain, and kidney $(25,43,45)$, the kinetics of platelet-arteriolar wall interactions during lung reperfusion was not described previously. Moreover, the relationship between length of pulmonary ischemia, platelet adhesion and postischemic arteriolar vasoconstriction has not been reported previously. Our results indicate that the 
level of platelet adhesion is in proportion to the degree of IR injury and can be associated with products produced in postischemic tissue.

2. Role of platelet P-selectin in platelet-arteriolar wall interactions and vasoconstriction during lung reperfusion

Specific aim \#2 focused on the role of platelet and lung tissue P-selectin and addressed the hypothesis that pulmonary IR induces platelet-arteriolar wall rolling and adhesion via a P-selectin dependent mechanism, and contributes to pulmonary microvascular constriction during reperfusion.

We found that P-selectin expression in lung tissue was increased significantly in $1 \mathrm{IR}$ and 2IR animals compared to the control group (Fig. 22A,22B and 24) and that there was a high correlation $(\mathrm{r}=0.85)$ with the duration of ischemia (Fig. 23B). Soluble P-selectin (sP-selectin) concentration in plasma samples, which is used as a measure of platelet P-selectin expression (85), was also significantly increased in animals that underwent $2-\mathrm{h}$ ischemia and $2-\mathrm{h}$ reperfusion, compared to the level of sP-selectin before occlusion (Fig. 25).

Platelet rolling and adhesion during reperfusion after two hours of ischemia was significantly inhibited by Fucoidan (Fig15), which also inhibited arteriolar constriction (Fig14). Fucoidan is a polysaccharide ligand for P- and L-selectins that helps mediate the initial rolling and adhesion of activated leukocytes and platelets along endothelial cells $(5,12,25)$. Others showed that Fucoidan, by 
interacting with selectins, prevented neutrophil and platelet rolling, adhesion, and accumulation during lung inflammation (40), myocardial IR injury (33) and inhibited vasoconstriction associated with selectin-mediated arterial injury (6). The effectiveness of Fucoidan in the present experiments suggests that the platelet rolling and adhesion, that we observed in the pulmonary microcirculation during reperfusion, was at least in part, mediated by expression of P-selectin expressed by platelets and endothelial cells.

When platelets or endothelial cells are activated by stimuli such as thrombin, histamine, and reactive oxygen species $(16,28), \mathrm{P}$-selectin is rapidly translocated to the external membrane where it mediates binding to platelets, leukocytes and endothelial cells. In the present study, pretreatment of labeled platelets with an anti P-selectin monoclonal antibody dramatically decreased the IR injury-induced platelet rolling and adhesion to the arteriolar wall (Fig15). Pretreatment of the labeled platelets with the isotype matched non-blocking antibody $(\operatorname{IgG} 1 \kappa)$, did not prevent these platelet-endothelial interactions. These results suggest that $\mathrm{P}$-selectin has a major role in mediating platelet-endothelial rolling and adhesion in pulmonary arterioles during post-ischemic reperfusion of the lung. Our results are consistent with the finding of others that systemic treatment with P-selectin monoclonal antibodies significantly reduces the adhesion of leukocytes and platelets to endothelium after middle cerebral artery occlusion and reperfusion (183). Akers et al (1997) reported that treatment with P-selectin monoclonal antibody attenuated endothelial-dependent relaxation and restoration 
of endothelium after endothelial damage during balloon catheterization (1). In our experiments, in contrast to systemic administration of Fucoidan which binds Pand L-selectin throughout the body, treatment of only the labeled platelets with antibody to P-selectin, which inhibited platelet rolling and adhesion, did not inhibit arteriolar constriction (Fig.14). This result is expected if the endogenous non-treated platelets are free to interact with the endothelium. The non-blocking antibody (IgGlא) had no obvious effect on platelet rolling, adhesion, or arteriolar vasoconstriction during reperfusion. Taken together, these results suggest that vasoconstriction did not cause platelet rolling and adhesion.

Even inactivated platelets may have a small quantity of P-selectin on their surface (31). It is possible that the platelets that were prepared for injection already activated to some degree by the labeling procedure. Such activation however, would not adequately explain the increased rolling and adhesion caused by IR, since rolling and adhesion did not occur with the same platelet preparation in control (non-ischemia) experiments. The small amount of monoclonal P-selectin blocking antibody that was added to the platelets $(25 \mu \mathrm{g})$ prior to injection was about 500 times less than the dose used by others in rabbits to block P-selectin systemically (17). Thus, in our experiments, it is not likely that we completely blocked endothelial P-selectin by adding anti P-selectin antibody to the platelets. Our data, while strongly indicating involvement of platelet P-selectin, does not exclude a role for endothelial P-selectin in the platelet rolling and adhesion during IR in the rabbit lung. Systemic administration of anti-P-selectin antibody would 
block endothelial as well as platelet P-selectin, and also would not exclude the role of endothelial P-selectin. Other molecules could also be interacting with platelet Pselectin. Possible ligands for P-selectin that have been suggested include GlyCAM-1, CD34 and MadCAM-1 (27). Expression of GlyCAM-1 and MadCAM-1 (38) for example, have been found to be elevated during IR-induced lung injury and could also have a role in the platelet responses that we observed. The results of our experiments demonstrate a significant role of platelet P-selectin in initiation of platelet adhesion in IR, but do not exclude the role of other adhesion molecules in post-ischemic platelet rolling and adhesion.

Upon stimulation, endothelial cells in venules of most organs express Pselectin, but expression in arterioles generally appears to be less (41). Although mouse arterioles express a very low level of P-selectin in response to stimulation (19), evidence of significant endothelial P-selectin-dependent platelet adhesion has been reported in this species (25). In the mouse intestine, after one hour of ischemia, Massberg (25) observed that platelets rolled along, or firmly adhered to endothelial cells of arterioles and venules in a manner similar to what has been described for leukocytes. Monoclonal antibodies to P-selectin, given systemically, attenuated platelet rolling and adherence in response to ischemic reperfusion. When P-selectin expression in the intestinal microcirculation was enhanced by IR, no change in platelet immunoreactivity of P-selectin was found during post-ischemic reperfusion (25). Results from their experiments in genetically altered mice indicated that the IR platelet-endothelium interactions were dependent on expression of P-selectin by 
endothelial cells. In our experiments, examination of reperfused lung tissue after 1 or $2 \mathrm{~h}$ of ischemia showed consistent correlation between tissue P-selectin expression and length of pulmonary ischemia. These results strongly suggest that in plateletarteriolar wall interactions, both platelet and endothelial P-selectin may be involved.

Platelet accumulation is implicated as a cause of tissue injury during reperfusion of various organs $(3,25,32,39,42)$. In the isolated perfused dog pancreas and liver, leukocyte and platelet depletion reduced cell damage caused by reperfusion after one hour of ischemia $(22,23)$. Injury was associated with increased production of reactive oxygen species and thromboxane $A_{2}$, and decreased production of prostaglandin $I_{2}$. The authors $(11,35)$ suggested that platelets were a likely source of the thromboxane $A_{2}$ and other pro-inflammatory mediators. Furthermore, P-selectin expressed on already activated platelets, mediates their binding to leucocytes and may lead to release of neutrophil proteases, which are important extracellular signals for further platelet recruitment and amplification (20). Platelet-induced accumulation of leukocytes and particularly neutrophils, can cause damage of the pulmonary vessel wall and may lead to ventilation/perfusion mismatch $(21,30)$.

In addition to the mechanisms described above concerning platelet activation and accumulation, the endothelium normally acts to prevent coagulation and has an important role in production of vasoactive metabolites, which affect platelet activity as well as vascular tone. Endothelial synthesis of nitric oxide for example, decreases platelet aggregation as well as adhesion, and as a vasodilator, 
generally favors anticoagulation by reducing shear stress (2). IR modifies the synthesis and release of substances such as reactive oxygen and nitrogen species, thromboxane $\mathrm{A}_{2}$, platelet activating factor, and serotonin by endothelial cells and platelets and promotes platelet aggregation and accumulation in microvasculature. In addition, IR injury can cause platelet activation, adhesion, and aggregation by disrupting the endothelium and exposing platelets to subendothelial matrix components (2). Von Willebrand factor, for example, causes platelets to adhere to the sub-endothelium at sites of vascular injury and to become activated (16). Thus, there are numerous mechanisms in addition to those that involve P-selectin, which could also affect platelet activation and adhesion in the present study.

3. Role of iNOS and RNS in platelet- arteriolar wall interactions and vasoconstriction during lung reperfusion

Specific aim \#3 examined if an increase in iNOS activity could lead to RNS formation and P-selectin dependent platelet-arteriolar wall interactions during reperfusion. This aim addressed the hypothesis that pulmonary ischemia-reperfusion induces platelet-arteriolar wall interactions via increased P-selectin expression resulting from elevated iNOS activity and subsequent RNS generation.

When animals were pretreated with an iNOS inhibitor (1400W) before 2-h ischemia and 2-h reperfusion, platelet rolling and adhesion, as well as microvascular constriction, were prevented (Fig.30). This finding suggests that a consequence of NO 
production resulting from increased iNOS activity influences platelet-arteriolar wall interactions and vasoconstriction. To our knowledge, this effect of iNOS inhibition on platelet-arteriolar wall interactions during IR has not been previously reported.

Examination of postischemic lung tissue showed that iNOS expression and activity increased in our model of IR. The increase in activity was much greater than the increase in expression. This finding suggests the idea that the increase in the rate of expression lags the increase in enzyme activity. Further expression of iNOS requires an additional synthesis which is time-dependent $(56,57)$. Furthermore, the increase in total NOS activity was prevented by $1400 \mathrm{~W}$, indicating that increased iNOS expression and activity could likely cause NO overproduction in response to ischemia and reperfusion (Fig.16). Low concentrations of NO, constitutively produced by eNOS, inhibit platelet $(157,161)$, leukocyte and endothelial activation $(78,119)$. Since iNOS has been suggested to be responsible for platelet activation during IR injury $(134,160)$, and P-selectin is implicated in these processes $(146,165)$, we hypothesized that overproduction of inducible NO leads to RNS formation and subsequent platelet activation through a P-selectin dependent mechanism.

NO reacts with oxygen radicals which lead to formation of RNS, such as peroxynitrite (65), which is especially relevant in the high oxygen environment of the ventilated, but not perfused lung. Nitrotyrosine is an RNS footprint that has been detected in pathological conditions including IR $(111,153)$. Peroxynitrite is a selective oxidant that reacts with biological molecules and modifies tyrosine in proteins to create nitrotyrosine. It has been reported that ROS and RNS scavengers, 
such as superoxide dismutase (superoxide scavenger) and catalase (hydrogen peroxide scavenger), decrease platelet activation and reperfusion injury $(141,142,162)$. Examination of lung tissue after 1 and $2 \mathrm{~h}$ of ischemia and $2 \mathrm{~h}$ of reperfusion showed that there was a significant increase in nitrotyrosine expression (Fig. 20 and 21). Nitrotyrosine levels in lung tissue subjected to IR correlated with the length of ischemia and which were prevented by iNOS blocking (Fig. 31A). Correlation between RNS expression and platelet adhesion suggests that RNS could be a mediator of platelet-arteriolar wall interactions. The present finding that topical application of RNS (peroxynitrite) to subpleural arterioles caused platelet adhesion to the arteriolar wall (Fig.19) indicates that RNS could cause platelet activation in the pulmonary microvasculature.

There was a consistent correlation between RNS formation and tissue Pselectin expression (Fig. 23). Pretreatment with 1400W decreased RNS formation and lung tissue expression of P-selectin (Fig.24). Increased iNOS activity has been suggested to have a role in platelet activation in several vascular beds via RNS formation and a P-selectin mediated process $(56,119,160)$. Thus, in the case of blood returning to the ischemic, but ventilated lung, it is likely that overproduction of NO via iNOS leads to RNS formation and subsequent platelet activation through a $\mathrm{P}$ selectin dependent mechanism. When iNOS was blocked by $1400 \mathrm{~W}$ in 2IR animals, nitrotyrosine expression was not different from the sham group (Fig.21). Although $1400 \mathrm{~W}$ is a "selective" iNOS inhibitor, it is possible that it could have other actions. Our findings generally agree with what others have reported with regard to iNOS 
inhibition of vascular responses and are similar to what has been found with regard to another iNOS inhibitor such as aminoguanidine $(66,166,184)$.

It is likely that $\mathrm{P}$-selectin expression in lung tissue was from the endothelium, but not platelets, since the lungs were flushed with saline before harvesting. However, we have not determined whether the endothelial P-selectin was expressed in arterioles or venules. We also found that the level of plasma P-selectin, which represents platelet Pselectin expression (176), increased during reperfusion. Moreover, pretreatment with 1400W inhibited lung tissue and plasma expression of P-selectin. This finding suggests that the platelet-endothelial interactions in arterioles of the reperfused rabbit lung were mediated, at least in part, by platelet P-selectin. The present data indicate that P-selectin could be involved in platelet-endothelial interactions, but does not allow distinction between the contribution of platelet or endothelial P-selectin expression in this process. Although leukocyte-endothelial interactions also involve selectin dependent mechanisms and are implicated in IR-induced microvascular dysfunction (124), leukocytes do not appear to be required for the platelet adhesion observed in the present study (Fig. 13).

The present experiments demonstrate that during pulmonary $I R$ in the intact ventilated lung, platelets roll and adhere along pulmonary arterioles in proportion to the length of ischemia. The mechanism of those postischemic platelet-endothelial interactions appears to involve excess production of NO via iNOS which leads to formation of RNS and may result in increased expression of P-selectin. During lung reperfusion, platelet activation and adhesion in arterioles is associated with vasoconstriction that would reduce alveolar perfusion and may be a significant 
component of pulmonary IR injury. Correlation between the length of lung ischemia, postischemic arteriolar vasoconstriction, and its relation to formation of RNS and Pselectin, strongly suggest that NO overexpression by iNOS may induce formation of RNS and increase platelet and endothelial P-selectin expression during lung IR (Fig. 31). In the present study, we have not explored the role of ROS which are also prominently involved in lung reperfusion injury. Although ROS could be linked with some of the platelet-related responses that we have investigated, this issue is beyond the scope of this investigation and was not addressed. Increased platelet-endothelium interactions may result from endothelium dysfunction as well as platelet activation. Further studies are needed to determine the contribution of endothelial and platelet P-selectin and other adhesion molecules in this process. Although we found a correlation between platelet adhesion and a decrease in arteriolar diameter, we have not determined the contribution of the platelet adhesion to this process. Since during IR, RNS may also directly cause the arteriolar constriction, and numerous other factors are involved in this process, further elucidation of mechanisms of platelet involvement in pulmonary microcirculation need to be done to take the next step in answering these important questions.

Our investigation shows that platelet-arteriolar wall adhesion with platelet accumulation in the pulmonary microvasculature and arteriolar constriction are significant factors in pulmonary ischemia, especially during the early phase of reperfusion. Inhibition of platelet-arteriolar wall interactions could help to improve alveolar perfusion in diseases associated with pulmonary ischemia-reperfusion injury. 


\section{REFERENCES}

1. Akers, D., Lefer, D., Chen, I., Wilkens, R., Rice, J., Aurora, H., Osgood, T., Bedi, B., Tenaglia, A., Buda, A., Kadowitz, P. and McNamara, D. (1997). Effects of short-term treatment with a monoclonal antibody to P-selectin on balloon catheterinduced: intinal hyperplasia, re-endothelialization, and attenuation of endothelialdependent relaxation. Molecular and Cellular Biochemistry 176, 13-20.

2. Body, S. (1996). Platelet activation and interactions with the microvasculature. Journal of Cardiovascular Pharmacology 27 (1), 13-25.

3. Bottiger, B., Bohrer, H., Boker, T., Motsch, J., Aulmann, M. and Martin, E. (1996). Platelet factor 4 release in patients undergoing cardipulmonary resuscitation - can reperfusion be impaired by platelet activation? Acta Anaesthesiol Scandinavica 40, 631-635.

4. Butcher, E. (1991). Leukocyte-endothelial cell recognition: three (or more) steps to specificity and diversity. Cell 77, 1033-1036.

5. Celi, A., Lorenzet, R., Furie, B. and Furi, B. (1997). Platelet-leukocyte-endothelial cell interaction on the blood vessel wall. Seminars in Hematology 34(4), 327-335.

6. Chauvet, P., Bienvenu, J., Theoret, J., Latour, J. and Merhi, Y. (1999). Inhibition of platelet-neutrophil interactions by fucoidan reduces adhesion and vasoconstriction after acute arterial injury by angioplasty in pigs. Journal of Cardiovascular Pharmacology 34(4), 597-603.

7. Chintala, M. and Bernardino, V. (1994). Cyclic GMP but not cyclic AMP prevents renal platelet accumulation after ischemia-reperfusion in anesthetized rats. Journal of Pharmacology and Experimental Therapeutics 271(3), 1203-1208.

8. Doerschuk, C. (2001). Mechanisms of leukocyte sequestration in inflamed lungs. Microcirculation 8, 71-88. 
9. Eichorn, M., Ney, L., Massberg, S. and Goeltz, A. (2002). Platelet kinetics in the pulmonary microcirculation in vivo assessed by intravital microscopy. J. Vasc. Res. 39, 330-339.

10. Eppinger M., Jones, M., Deeb, G., Bolling, S. and Ward, P. (1995). Pattern of injury and the role of neutrophils in reperfusion injury of rat lung. Journal of Surgical Research 58, 713-718.

11. Fetkovska N. (1992). Platelet activation by low-density lipoprotein and serotonin: effects of calcium antagonists. J Cardiovasc Pharmacol 19 (3), 25-28.

12. Frenette, P., Moyna, C., Hartwell, D., Lowe, J., Hynes, R. and Wagner, D (1998). Platelet-endothelial interactions in inflamed mesentric venules. Blood 9 (4), 13181324.

13. Gilroy, R., Bhatte, M., Wickersham, N., Pou, N., Loyd, J. and Overholser, K. (1993). Postischemic hypoperfusion during unilateral lung reperfusion in vivo. Am. Rev. Respir. Dis. 147, 276-287.

14. Golino, P., Ambrosio, G., Ragni, M., Pascucci, I., Triggiani, M., Oriente, A., McNatt, J., Buja, L., Condorelli, M., Chiariello, M. and Willerson, J. (1993). Short-term and long-term role of platelet activation factor as a Mediator of In Vivo Platelet Aggregation. Circulation 88(3), 1205-1214.

15. Grace, P. (1994). Ischaemia-reperfusion injury. British Journal of Surgery 81, 637647.

16. Hattori R., Hamilton, K., Fugate, R., McEver, R. and Sims, P. (1989). Stimulated secretion of endothelial von Willebrand factor is accompanied by rapid redistribution to the cell surface intracellular granule membrane protein GMP-140. J. Biol. Chem. 264 (14), 7768-71.

17. Hayashi, H., Koike, H., Kurata, Y., Imanishi, N., Tojo, S. (1999). Protective effect of sialil Lewis $\mathrm{X}$ and anti-P-selectin antibody against lipopolisaccharide-induced acute lung injury in rabbits. Eur. J. Pharmacol. 370(1), 47-56.

18. Itoh, Y., Tomita, M., Tanahashi, N., Takeda, H., Yokoyama, M. and Fukuuchi, Y. (1998). Platelet adhesion to aortic endothelial cells in vitro after thrombin treatment: observation with video-enhanced contrast microscopy. Thrombosis Research 91, 15-21. 
19. Jung, U. and Ley, K. (1997). Regulation of E-selectin, P-selectin, and intercellular adhesion molecule 1 expression in mouse cremaster muscle vasculature. Microcirculation 4(2), 311-319.

20.Kroll, R. and Resendiz, J. Mechanisms of platelet activation. (2003). In "Thrombosis and Hemorrhage" (Joseph Loscalzo and Andrew I Schafer, Eds.). 187-205. Williams and Wilkins Press, Baltimore.

21. Kuhnle G., Reichenspurner, H., Lange, T., Wagner, F., Groh, J., Messmer, K. and Goetz, A. (1998). Microchemodynamics and leukocyte sequestration after pulmonary ischemia and reperfusion in rabbits. Thorac. Cardiovasc. Surg. 115, 937-44.

22. Kuroda, T., Shiohara, E., Homma, T., Furukawa, Y. and Chiba, S. (1994). Effects of leukocyte and platelet depletion on ischemia-reperfusion injury to dog pancreas. Gastroenterology 107, 1125-34.

23. Kuroda, T. and Shiohara, E. (1996). Leukocyte and platelet depletion protects the liver from damage induced by cholestasis and ischemia-reperfusion in the dog. Scandinavian Journal of Gastroenterology 31(2), 182-90.

24. Lominadze, D., Saari, J., Miller, F., Catalfamo, J., Percival, S. and Schuschke, D. (1999). In vitro platelet adhesion to endothelial cells at low shear rates during copper deficiency in rats. The Journal of Trace Elements in Experimental Medicine $12,25-36$.

25. Massberg S., Enders, G., Leiderer, R., Eisenmenger, S., Vestweber, D., Krombach, F. and Messmer, K. (1998). Platelet-endothelial cell interactions during ischemia/reperfusion: The Role of P-Selectin. Blood 92 (2), 507-15.

26. Massberg, S., Enders, G., Eisenmenger, S., Leiderer, R., Vestweber, D., Krombach, F. and Messmer, K. (1999). Platelet-endothelial cell interactions in the postischemic microvasculature. Prog. Appl. Microcirc. 23, 66-81.

27. McEver, R. Interactions of leukocytes with the vessel wall. (1998). In "Thrombosis and Hemorrhage" (Joseph Loscalzo and Andrew I Schafer, Eds.). 321-336. Williams and Wilkins Press, Baltimore.

28. Michelson, A., Ellis, P., Barnard, M., Matic, G., Viles, A. and Kestin, A. (1991). Downregulation of the platelet surface glycoprotein Ib-IX complex in whole blood 
stimulated by thrombin, adenosine diphosphate, or an in vivo wound. Blood, 77(4), 770-779.

29. Miller, D. and Roberts, A. (1999). Pulmonary artery occlusion and reperfusion causes microvascular constriction in the rabbit lung. Ann. Thorac. Surg. 67, 323-328.

30. Mulligan, M., Polley, M., Bayer, R., Nunn, M., Paulson, J. and Ward, P. (1992). Neutrophil dependent acute lung injury requirement for P-selectin (GMP-140). J. Clin. Invest. 90, 1600-1607.

31. Murohara, T., Parkinson, S., Waldman, S. and Lefer, A. (1995). Inhibition of nitric oxide biosynthesis promotes P-selectin expression in platelets: Role of protein kinase C. Arteriosclerosis Thrombosis and Vascular Biology 15, 2068-2075.

32. Okada, Y., Marchevesky, A., Zuo, X., Pass, J., Kass, R., Matloff, J. and Jordan, S. (1997). Accumulation of platlets in rat syngeneic lung transplants. Transplantation 64(6), 801-806.

33. Omata, M., Matsui, N., Inomata, N. and Ohno, T. (1997). Protective effects of polysaccharide fucoidin on myocardial ischemia-reperfusion injury in rats. J. Cardiovasc. Pharmacol. 30, 717-724.

34. Petruzzelli, L., Takami, M. and Humes, H. (1999). Structure and function of cell adhesion molecules. Am. J. Med. 106(4), 467-476.

35. Razzuk, S. and Zellers, T. (1995). Balloon dilation of porcine pulmonary arteries decreases endothelium-dependent relaxations and increases vasoconstriction to aggregating platelets. Circ. 91(4), 1221-1228.

36. Reed, G., Houng, A. and Bianchi, C. Comparative biochemical and ultrastructural studies of P-selectin in rabbit platelets. Comparative Biochemistry and Physiology, Part B 119,729-738.

37. Roberts, A. and Slaaf, D. (1995). Lung microcirculation. In "Microcirculation in Clinical Medicine" (J.H. Barker, G.L. Anderson and M.D. Menger, Eds.). 263275. CRC Press Inc., Boca Raton.

38. Schurmann, G. (1997). Cell adhesion: molecular principles and initial implications for surgery. Chirurg. $68(5), 477-87$.

39. Seibert, A., Haynes, J. and Taylor, A. (1993). Ischemia-reperfusion injury in the isolated rat lung. Am. Rev. Respir. Dis. 147, 270-275. 
40. Shimoaka, M., Ikeda, M., Iida, T., Taenaka, N., Yoshiya, I. and Honda, T. (1996). Fucoidin, a potent inhibitor of leukocyte rolling, prevents neutrophil influx into phorbol-ester-induced inflammatory sites in rabbit lungs. Am. J. Respir. Crit. Care Med. 153, 307-311.

41. Thurston, G., Baluk, P. and McDonald, D. (2000). Determinants of endothelial cell phenotype in venules. Microcirculation 7(1), 67-80.

42. Yadav, S., Howell, D., Steeber, D., Harland, R., Tedder, T. and Clavien, P. (1999). $\mathrm{P}$-selectin mediates reperfusion through neutrophil and platelet sequestration in the warm ischemic mouse liver. Hepatology 29(5), 1494-1501.

43.Zimmerman B. and Granger, D. (1994). Mechanisms of reperfusion injury. Am. J. Med. Sci. 307(4), 284-292.

44. Love S. and Barber R. (2001). Expression of P-selectin and intracellular adhesion molecule-1 in human brain after focal infarction or cardiac arrest. Neuropathology and Applied Neurobiology, 27, 465-473

45. Cooper D. Chitman KD. Williams MC. Granger DN. (2003) Time-dependent platelet-vessel wall interactions induced by intestinal ischemia-reperfusion. American Journal of Physiology - Gastrointestinal \& Liver Physiology. 284(6):G1027-33

46. Roberts AM, Ovechkin AV, Mowbray JG, Robinson TW and Lominadze D. (2004). Effects of pulmonary ischemia-reperfusion on platelet adhesion in subpleural arterioles in rabbits. Microvascular Research, Vol. 67(1), 29-37

47. Koksoy C., Kuzu M., Ergun H., Demirpence E. and Zulfikaroglu B. (2000). Intestinal ischemia and reperfusion impairs vasomotor functions of pulmonary vascular bed. Ann Surg., 231(1), 105-11.

48. Carden, DL, and Granger DN. (2000) Pathophysiology of ischaemia-reperfusion injury. J Pathol 190: 255-266

49. Parks DA, Granger DN. Contributions of ishemia and reperfusion to mucosal lesion formation. Am J Physiol, 1986; 250: G749-53.

50. Mullane KM, Salmon JA, Kraemer R. Leukocyte derived metabolites of arachidonic acid in ischemia induced myocardial injury. Fed Proc 1987; 46: 2422-33. 
51. Khandoga, A, Biberthaler P, Enders G, Axmann S, Hutter J, Messmer K, and Krombach F. (2002) Platelet adhesion mediated by fibrinogen-intercelllular adhesion molecule-1 binding induces tissue injury in the postischemic liver in vivo. Transplantation 74: 681-688

52. Jang Y, Lincoff AM, Plow EF, et al. (1994). Cell adhesion molecules in coronary artery disease. J Am Coll Cardiol.;24:1591-601.

53. Khandoga A., Biberthaler P., Messmer K., Krombach F. (2003). Plateletendothelial cell interactions during hepatic ischemia-reperfusion in vivo: a systematic analysis. Microvasc Res. 65(2):71-7

54. Oredsson S, Plate G, Qvarfordt P Experimental evaluation of oxygen free radical scavengers in the prevention of reperfusion injury in skeletal muscle. Eur J Surg. 1994 Feb;160(2):97-103.

55.Zhou J., Jin G., Yi Y., Zhang J. and Huang X. (2003). Role of nitric oxide and peroxynitrite anion in lung injury induced by intestinal ischemia-reperfusion in rats. World J Gastroenterol. 9(6):1318-22

56. McDonald M., Abdelrahman M., Cuzzocrea S. and Thiemermann C. (2003). Tyrphostin reduces the organ injury in haemorrhagic shock: role of inducible nitric oxide synthase. Resuscitation. 58(3):349-361

57. Al-Majed A., Khattab M., Raza M., Al-Shabanah O. and Mostafa A. (2003). Potentiation of diclofenac-induced anti-inflammatory response by aminoguanidine in carrageenan-induced acute inflammation in rats: The role of nitric oxide. Inflamm Res. 52(9):378-82

58. Vural K. and Oz M. (2000). Endothelial adhesivity, pulmonary hemodynamics and nitric oxide synthesis in ischemia-reperfusion. Eur J Cardiothorac Surg, 18 348352

59. Moncada S., Higgs E. (1993). The L-arginine-nitric oxide pathway. N Engl J Med 329:2002-2012.

60. Nathan C. (2002). Inducible nitric oxide synthase in the tuberculous human lung. Am J Respir Crit Care Med. 15;166(2):130-131 
61. Weinberger B., Heck D., Laskin D. and Laskin J. (1999). Nitric oxide in the lung: therapeutic and cellular mechanisms of action. Pharmacol Ther. 1999 Dec;84(3):401-11

62. Ishibe Y., Liu R., Ueda M., Mori K. and Miura N. (1999). Role of inhaled nitric oxide in ischaemia-reperfusion injury in the perfused rabbit lung. $\mathrm{Br} \mathrm{J}$ Anaesth. 1999 Sep;83(3):430-5.

63. Bhabra M., Hopkinson D., Shaw T., Hooper T. (1997). Attenuation of lung graft reperfusion injury by a nitric oxide donor. J Thorac Cardiovasc Surg. 113(2):327-334

64. Radomski M. and Salas E. (1995). Nitric oxide - biological mediator, modulator and factor of injury: its role in the pathogenesis of atherosclerosis. Atherosclerosis 118 Suppl, S69-S80

65. Naidu B., Fraga C., Salzman A., Szabo C., Verrier E. and Mulligan M. (2003). Critical role of reactive nitrogen species in lung ischemia-reperfusion injury. $\mathrm{J}$ Heart Lung Transplant. 22(7):784-93

66. Buttery L., Springall D. and Chester A. et al. (1996). Inducible nitric oxide synthase is present within human atherosclerotic lesions and promotes the formation and activity of peroxynitrite. Lab Invest, 75, 77-85

67. Luoma J., Stralin P., Marklund S. et al. (1998). Expression of extracellular SOD and iNOS in macrophages and smooth muscle cells in human and rabbit atherosclerotic lesions: colocalization with epitopes characteristic of oxidized LDL and peroxynitrite-modified proteins. Arterioscler Thromb Vasc Biol, 18, 157-167

68. Cuzzocrea, S., Chatterjee P., Mazzon E., Dugo L., Sarro A., Van de Loo F., Caputi A. and Thiemermann C. (2002). Role of Induced Nitric Oxide in the Initiation of the Inflammatory Response After Postischemic Injury Shock 18(2,)169-176

69. Lander H. (1997). Role of Induced Nitric Oxide in the Initiation of the Inflammatory Response after Postischemic Injury. An essential role for free radicals and derived species in signal transduction. FASEB J 11:118-124

70. Nishijima K., Kiryu J., Tsujikawa A., Honjo M., Nonaka A., Yamashiro K., Tanihara H., Tojo J., Ogura Y. and Honda Y. (2001) In vivo evaluation of plateletendothelial interactions after transient retinal ischemia. Investigative Ophthalmology and Visual Science.; 42:2102-2109 
71. Matata B. and Galinanes M., (2002). Peroxynitrite is an essential component of cytokines production mechanism in human monocytes through modulation of nuclear factor-kappa B DNA binding activity. J Biol Chem 277, 2330-2335

72. Liaudet L., Soriano F. and Szabo C. (2000). Biology of nitric oxide signaling. Crit Care Med 28, N37-52.

73. Nishijima, K., Kiryu, J., Tsujikawa, A., Miyamoto, K., Honjo, M., Tanihara, H., Nonaka, A., Yamashiro, K., Katsuta, H., Miyahara, S., Honda, Y. and Ogura, Y. (2004). Platelets Adhering to the Vascular Wall Mediate Postischemic LeukocyteEndothelial Cell Interactions in Retinal Microcirculation Investigative Ophthalmology and Visual Science; 45:977-984

74. Hernandez LA, Grisham MB, Twohig B, Arfors KE, Harlan JM, Granger DN. (1987). Role of neutrophils in ischemia-reperfusion-induced microvascular injury. Am J Physiol;253:699-703.

75. Jaeschke H, Farhood A, Smith CW. (1990). Neutrophils contribute to ischemia/reperfusion injury in rat liver in vivo. FASEB J. 1990;4:3355-3359

76. Theilmeier G, Lenaerts T, Remacle C, Collen D, Vermylen J, Hoylaerts MF. (1999). Circulating activated platelets assist THP-1 monocytoid/endothelial cell interaction under shear stress. Blood. 1999;94:2725-2734

77. Kirton CM, Nash GB. (2000). Activated platelets adherent to an intact endothelial cell monolayer bind flowing neutrophils and enable them to transfer to the endothelial surface. J Lab Clin Med;136:303-313

78. McQuillan LP, Leung GK, Marsden PA, Kostyk SK, Kourembanas S (1994) Hypoxia inhibits expression of eNOS via transcriptional and posttranscriptional mechanisms. Am J Physiol 267:H1921-1927

79. Bombeli T, Schwartz BR, Harlan JM. (1998). Adhesion of activated platelets to endothelial cells: evidence for a GPIIbIIIa-dependent bridging mechanism and novel roles for endothelial intercellular adhesion molecule 1 (ICAM-1), alphavbeta3 integrin, and GPIbalpha. J Exp Med;187:329-339

80. Dardik R, Shenkman B, Tamarin I. (2002). Factor XIII mediates adhesion of platelets to endothelial cells through alpha(v)beta(3) and glycoprotein IIb/IIIa integrins. Thromb Res;105:317-323 
81. Piccardoni P, Evangelista V, Piccoli A, de Gaetano G, Walz A, Cerletti C. (1996). Thrombin activated human platelets release two NAP 2 variants that stimulate polymorphonuclear leukocytes. Thromb Haemost;76:780-785

82. Faint RW. (1992). Platelet-neutrophil interactions: their significance. Blood Rev;6:83-91

83. Ruf A, Patscheke H. (1995). Platelet-induced neutrophil activation: plateletexpressed fibrinogen induces the oxidative burst in neutrophils by an interaction with CD11C/CD18. Br J Haematol;90:791-796

84. Carvalho-Tavares J, Hickey MJ, Hutchison J, Michaud J, Sutcliffe IT, Kubes P. (2000). A role for platelets and endothelial selectins in tumor necrosis factoralpha-induced leukocyte recruitment in the brain microvasculature. Circ Res. $87: 1141-1148$

85. Caine G. and Blann A. (2003). Soluble P-selectin should be measured in citrated plasma, not in serum. Br J Haematol 121, 530-532

86. Eppinger M., Ward P., Jones M., Bolling S. and Deeb G. (1995). Disparate effects of nitric oxide on lung ischemia-reperfusion injury. Ann Thorac Surg 60, 11691175.

87. Okabayashi K., Triantafillou A., Yamashita M., Aoe M., DeMeester S., Cooper J. and Patterson G. (1996). Inhaled nitric oxide improves lung allograft function after prolonged storage. J Thorac Cardiovasc Surg 112, 293-299

88. Virlos IT, Inglott FS, Williamson RC and Mathie RT. (2003). Differential expression of pulmonary nitric oxide synthase isoforms after intestinal ischemiareperfusion. Hepatogastroenterology, 50(49):31-6

89. Perrot M., Liu M., Waddell T. and Keshavjee S. (2003). Ischemia-Reperfusioninduced Lung Injury. American Journal of Respiratory and Critical Care Medicine, 167: 490-511.

90. Al-Mehdi A., Shuman H., Fisher A. (1997). Intracellular generation of reactive oxygen species during nonhypoxic lung ischemia. Am J Physiol; 272:L294-L300

91. Fisher A., Dodia C., Tan Z., Ayene I. and Eckenhoff R. (1991). Oxygendependent lipid peroxidation during lung ischemia. J Clin Invest; 88:674-679 
92. Eckenhoff R., Dodia C., Tan Z., Fisher A. (1992). Oxygen-dependent reperfusion injury in the isolated rat lung. J Appl Physiol; 72:1454-1460

93. Fisher A. and Dodia C. (1981). Lung as a model for evaluation of critical intracellular $\mathrm{PO}_{2}$ and PCO. Am J Physiol; 241:E47-E50

94.Zhao G., Al Mehdi A., Fisher A. (1997). Anoxia-reoxygenation versus ischemia in isolated rat lungs. Am J Physiol; 273:L1112-L1117.

95. Al Mehdi A., Zhao G., Dodia C., Tozawa K., Costa K., Muzykantov V., Ross C., Blecha F., Dinauer M. and Fisher A. (1998). Endothelial NADPH oxidase as the source of oxidants in lungs exposed to ischemia or high $\mathrm{K}+$. Circ Res; 83:730-737

96. Lansman J. Endothelial mechanosensors: going with the flow. (1988). Nature;331:481-482

97. Al Mehdi A., Zhao G. and Fisher A. (1998). ATP-independent membrane depolarization with ischemia in the oxygen-ventilated isolated rat lung. Am J Respir Cell Mol Biol;18:653-661

98. Minamiya Y, Tozawa K, Kitamura M, Saito S. and Ogawa J. (1998). Plateletactivating factor mediates intercellular adhesion molecule-1-dependent radical production in the nonhypoxic ischemia rat lung. Am J Respir Cell Mol Biol;19:150-157

99. Moore TM, Khimenko P, Adkins WK, Miyasaka M, Taylor AE. (1995). Adhesion molecules contribute to ischemia and reperfusion-induced injury in the isolated rat lung. J Appl Physiol; 78:2245-2252

100. Naka Y, Toda K, Kayano K, Oz M. and Pinsky J. (1997). Failure to express the $\mathrm{P}$-selectin gene or P-selectin blockade confers early pulmonary protection after lung ischemia or transplantation. Proc Natl Acad Sci USA; 94:757-761

101. Kapelanski DP, Iguchi A, Niles SD, Mao HZ. (1993). Lung reperfusion injury is reduced by inhibiting a CD18-dependent mechanism. $J$ Heart Lung Transplant; 12:294-306

102. DeMeester SR, Molinari MA, Shiraishi T, Okabayashi K, Manchester JK, Wick MR, Cooper JD, Patterson GA. (1996). Attenuation of rat lung isograft reperfusion injury with a combination of anti-ICAM-1 and anti-beta2 integrin monoclonal antibodies. Transplantation; 62:1477-1485 
103. Steinberg J., Mao H., Niles S., Jutila M. and Kapelanski D. (1994). Survival in lung reperfusion injury is improved by an antibody that binds and inhibits L- and E-selectin. J Heart Lung Transplant;13:306-318

104. Demertzis S., Langer F., Graeter T., Dwenger A., Georg T. and Schafers H. (1999). Amelioration of lung reperfusion injury. Eur J Cardiothorac Surg;16:174-180

105. Reignier J, Sellak H, Lemoine R, Lubineau A, Mazmanian G, Detruit H, Chapelier A. and Herve P. (1997). Prevention of ischemia-reperfusion lung injury by sulfated Lewis(a) pentasaccharide: The Paris-Sud University Lung Transplantation Group. J Appl Physiol; 82:1058-1063

106. Schmid R, Yamashita M, Boasquevisque C, Ando K, Fujino S, Phillips L, Cooper J. and Patterson G. (1997). Carbohydrate selectin inhibitor CY-1503 reduces neutrophil migration and reperfusion injury in canine pulmonary allografts. J Heart Lung Transplant; 16:1054-1061

107. Stammberger U, Hamacher J, Hillinger S. and Schmid RA. (2000). sCR1sLe ameliorates ischemia/reperfusion injury in experimental lung transplantation. $\mathrm{J}$ Thorac Cardiovasc Surg; 120:1078-1084

108. Ogawa S, Gerlach H, Esposito C, Pasagian-Macaulay A, Brett J. and Stern D. (1990). Hypoxia modulates the barrier and coagulant function of cultured bovine endothelium: increased monolayer permeability and induction of procoagulant properties. J Clin Invest; 85:1090-1098

109. Perrot M., Sekine Y, Fischer S, Waddell TK, McRae K, Liu M, Wigle D. and Keshavjee S. (2002). Interleukin-8 release during early reperfusion predicts graft function in human lung transplantation. Am J Respir Crit Care Med; 165:211-215

110. Oz MC, Liao H, Naka Y, Seldomridge A, Becker DN, Michler RE, Smith CR, Rose EA, Stern DM, Pinsky DJ. (1995). Ischemia-induced interleukin-8 release after human heart transplantation: a potential role for endothelial cells. Circulation; 92:II428-II432

111. Nakazawa H, Fukuyama N, Takizawa S, Tsuji C, Yoshitake M, Ishida H. (2000). Nitrotyrosine formation and its role in various pathological conditions. Free Radic Res., 33(6):771-84 
112. De Greef K., Ysebaert D., Ghielli M., Vercauteren S., Nouwen E., Eyskens E. and De Broe M. (1998). Neutrophils and acute ischemia-reperfusion injury. J Nephrol, 11 (3), 110-122

113. Blann A., Nadar S. and Lip G. (2003). The adhesion molecule P-selectin and cardiovascular disease. European Heart Journal, 24(24) , 2166-2179

114. Johnston G., Cook R. and McEver R. (1989). Cloning of GMP-140, a granule membrane protein of platelets and endothelium: sequence similarity to proteins involved in cell adhesion and inflammation. Cell 56, 1033-1044

115. Kameda H., Morita I., Handa M. (1997). Re-expression of functional p-selectin molecules on the endothelial cell surface by repeated stimulation with thrombin. Br J Haematol 97, 348-355

116. Khew-Goodall Y., Butcher C., Litwin M. et al., (1996)Chronic expression of P-selectin on endothelial cells stimulated by the T-cell cytokine, interleukin-3. Blood 87 4, 1432-1438

117. Gotsch U., Jager U., Dominis M. et al., (1994). Expression of P-selectin on endothelial cells is upregulated by LPS and TNF-alpha in vivo. Cell Adhes Commun 1, 7-14

118. Weller A., Isenmann S. and Vestweber D. (1992). Cloning of the mouse endothelial selectins. Expression of both E-selectin and P-selectin is inducible by tumor necrosis factor alpha. J Biol Chem 267 21, 15176-15183

119. Armstead V., Minchenko A., Schuhl R. et al., (1997). Regulation of P-selectin expression in human endothelial cells by nitric oxide. Am J Physiol 2732 Pt 2, H740-H74;6.

120. Minamino T., Kitakaze M., Sanada S. et al., (1998). Increased expression of Pselectin on platelets is a risk factor for silent cerebral infarction in patients with atrial fibrillation: role of nitric oxide. Circulation $9817,1721-1727$

121. Merten M. and Thiagarajan P. (2000). P-selectin expression on platelets determines size and stability of platelet aggregates. Circulation 102, 1931-1936

122. Elstad M., La Pine T., Cowley F. et al., (1995). P-selectin regulates plateletactivating factor synthesis and phagocytosis by monocytes. J Immunol 1554 , 2109-2122 
123. Furie B. and Furie B. (1996). P-selectin induction of tissue factor biosynthesis and expression. Haemostasis 26 Suppl 1, 60-65

124. Celi A., Pellegrini G., Lorenzet R. et al., (1994). P-selectin induces the expression of tissue factor on monocytes. Proc Natl Acad Sci USA 91 19, 8767-8771

125. Cherry P., Omar H., Farrell K., Stuart J. and Wolin M. (1990). Superoxide anion inhibits cGMP-associated bovine pulmonary arterial relaxation. Am J Physiol 259, H1056-H1062

126. Liu J., Simon, L., Phillips, J. and Robin E. (1977). Superoxide dismutase (SOD) activity in hypoxic mammalian systems. J Appl Physiol 42, 107-110

127. Marczin N., Ryan, U. and Catravas, J. (1992). Methylene blue inhibits nitrovasodilator- and endothelium-derived relaxing factor-induced cyclic GMP accumulation in cultured pulmonary arterial smooth muscle cells via generation of superoxide anion. J Pharmacol Exp Ther 263, 170-179

128. Demiryürek A. and Wadsworth R. (1999). Superoxide in the pulmonary circulation Pharmacology \& Therapeutics 84(3), 355-365

129. Yang W. and Block E. (1995). Effect of hypoxia and regeneration on the formation and release of reactive oxygen species by porcine pulmonary artery cells. J Cell Physiol 164, 414-423

130. Barnard, M., Robertson, B., Watts B. and Turrens, J. (1997). Role of nitric oxide and superoxide anion in spontaneous lung chemiluminescence. Am J Physiol 272, L262-L267

131. Jian, Z.-J., Yang, Z., Mason, G.L., Slauson, D.O. and Bochsler, P.N. (1995). Regulation of superoxide anion generation in bovine alveolar macrophages by bacterial lipoplysaccharide, serum proteins, and modulators of signal transduction. Inflammation 19, 637-650

132. De Keulenaer G., Chappell D., Ishizaka N., Nerem R., Alexander R. and Griendling K. (1998). Oscillatory and steady laminar shear stress differentially affect human endothelial redox state: role of a superoxide-producing NADH oxidase. Circ Res 82, 1094-1101 
133. Xia Y., Dawson V., Dawson, T., Snyder, S. and Zweier J. (1996). Nitric oxide synthase generates superoxide and nitric oxide in arginine-depleted cells leading to peroxynitrite-mediated cellular injury. Proc Natl Acad Sci USA 93, 6770-6774

134. Moro M., Darley-Usmar V., Goodwin D., Read N., Zamora-Pino R., Feelisch M., Radomski M. and Moncada S. (1994). Paradoxical fate and biological action of peroxynitrite on human platelets. Proc Natl Acad Sci U S A. 5;91(14):6702-6

135. Sakuma T., Takahashi K., Ohya N., Kajikawa O., Martin T., Albertine K. and Matthay M. (1999) Ischemia-reperfusion lung injury in rabbits: mechanisms of injury and protection Am J Physiol Lung Cell Mol Physiol 276: L137-L145

136. Hamvas A., Park C., Palazzo R., Liptay M., Cooper J. and Schuster D. (1992) Modifying pulmonary ischemia-reperfusion injury by altering ventilatory strategies during ischemia. J Appl Physiol. 73(5):2112-9.

137. Kubes P., Jutila M. and Payne D. (1995). Therapeutic potential of inhibiting leukocyte rolling in ischemia/reperfusion. J. Clin. Invest. 95: 2510-2519

138. Wickersham N., Loyd J., Johnson J., McCain R. and Christman J. (1999). Acute inflammation in a sheep model of unilateral lung ischemia: the role of interleukin-8 recruitment of polymorphonuclear leukocytes. Am. J. Respir. Cell Mol. Biol. 9: 199-204

139. Wiklund, L., McGregor, C.G.A. and Miller, V.M., (1996). Effects of prolonged exposure to oxygen-derived free radicals in canine pulmonary arteries. Am J Physiol 270, pp. H2184-H2190

140. Lu Y., Hellewell P. and Evans T. (1997) Ischemia-reperfusion lung injury: contribution of ischemia, neutrophils, and hydrostatic pressure. Am. J. Physiol. 273 (Lung Cell. Mol. Physiol. 17): L46-L54

141. Oredsson S., Plate G., Qvarfordt P. (1994). Experimental evaluation of oxygen free radical scavengers in the prevention of reperfusion injury in skeletal muscle. Eur J Surg. 1994 Feb;160(2):97-103

142. Porta C., Maiolo A., Tua A., Grignani G. (2000). Amifostine, a reactive oxigen species scavenger with radiation- and chemo-protective properties, inhibits in vitro platelet activation induced by ADP, collagen or PAF. Haematologica. 85(8):820-5. 
143. Krishnadasan B., Naidu B., Byrne K., Fraga C., Verrier E. and Mulligan M. (2003) The role of proinflammatory cytokines in lung ischemia-reperfusion injury. J Thorac Cardiovasc Surg ;125(2):261-72

144. White, C.W., Avraham, K.B., Shanley, P.F. and Groner, Y., (1991). Transgenic mice with expression of elevated levels of copper-zinc superoxide dismutase in the lungs are resistant to pulmonary oxygen toxicity. J Clin Invest 87 , pp. 2162-2168.

145. Schreck, R. and Baeuerle, P.A., (1994). Assessing oxygen radicals as mediators in activation of inducible eukaryotic transcription factor NF-kappa B. Methods Enzymol 234, pp. 151-163

146. Kanwar S. and Kubes P. (1995). Nitric oxide is an antiadhesive molecule for leukocytes. New Horiz., 3(1):93-104

147. Idell S. Adult respiratory distress syndrome: do selective anticoagulants help? (2002) Am J Respir Med. 1(6):383-91.

148. Messent M., Griffiths J. and Evans T. (1993). Pulmonary vascular reactivity and ischaemia reperfusion injury in the rat. Clin Sci 85:71-75.

149. Pearse D. and Sylvester J. (1996). Vascular injury in isolated sheep lungs. Am J Respir Crit Care Med 153:196-202.

150. Fullterton D., Hahn A., Koike K., Banerjee A. and Harken A. (1993). Intracellular mechanisms of pulmonary vasomotor dysfunction in acute lung injury caused by mesenteric ischemia-reperfusion. Surgery 114(2):360-367.

151. Kurose I., Wolf R., Grisham M., and Granger D. (1994). Modulation of ischemia/ reperfusion-induced microvascular dysfunction by nitric oxide. Circ. Res. 74:376-382.

152. Ambrosio G. and Tritto I. (1999). Reperfusion injury: experimental evidence and clinical implications. Am Heart J 138 (2 pt 2):69-75.

153. Beckman J. and Koppenol W. (1996). Nitric oxide, superoxide, and peroxynitrite: the good, the bad, and ugly. Am J Physiol. 271(5 Pt 1):C1424-37.

154. Kanno S., Lee P., Zhang Y., Ho C., Griffith B., Shears L. and Billiar T. (2000). Attenuation of Myocardial Ischemia/Reperfusion Injury by Superinduction of Inducible Nitric Oxide Synthase Circulation. 101:2742 
155. Moncada S., Palmer R. and Higgs E. (1991). Nitric oxide: physiology, pathophysiology, and pharmacology. Pharmacol Rev.;43:109-142

156. Forstermann U., Closs E., Pollock J., et al. (1994). Nitric oxide synthase isozymes: characterization, purification, molecular cloning, and functions. Hypertension. 23:1121-1131

157. Loscalzo J. Nitric Oxide Insufficiency, Platelet Activation, and Arterial Thrombosis. (2001). Circulation Research; 88:756

158. Merten M., Chow T., Hellums D. and Thiagarajan P. (2000). A new role for Pselectin in shear-induced platelet aggregation. Circulation; 102:2045-2050.

159. Stampler J., Single D. and Loscalzo J. (1992). Biochemistry of nitric oxide and its redox-activated forms. Science 258: 1898-1902.

160. Dröge W. Free radicals in the hysiological control of cell function. (2002). Physiol Rev. I:48-80

161. Radomski M., Moncada S. (1993). Regulation of vascular homeostasis by nitric oxide. Thromb Haemost. 1;70(1):36-41.

162. Seki, S., Flavahan, N.A., Smedira, N.G. and Murray, P.A., 1999. Superoxide anion scavengers restore NO-mediated pulmonary vasodilation after lung transplantation. Am J Physiol 45, pp. H42-H46

163. Barillari G, Albonici L, Incerpi S, Bogetto L, Pistritto G, Volpi A, Ensoli B and Manzari V. (2001). Inflammatory cytokines stimulate vascular smooth muscle cells locomotion and growth by enhancing $\alpha_{5} \beta_{1}$ integrin expression and function. Atherosclerosis 154(2): 377-385.

164. Hampton JR, Harrison AJ, Honour AJ, Mitchell JR. (1967). Platelet behavior and drugs used in cardiovascular disease. Cardiovasc Res;1:101-106

165. Horowitz JD. Nitrovasodilators. In: Loscalzo J, Vita JA. (2000). Nitric Oxide and the Cardiovascular System. Totowa, NJ: Humana Press: 383-409.

166. Garvey E., Oplinger J., Furfine E., Kiff R., Laszlo F., Whittle B. and Knowles R. (1997). 1400W Is a Slow, Tight Binding, and Highly Selective Inhibitor of Inducible Nitric-oxide Synthase in Vitro and in Vivo. 272:8, 4959-4963 
167. Bryk R, Wolff D. (1998). Mechanism of inducible nitric oxide synthase inactivation by aminoguanidine and L-N6-(1-iminoethyl)lysine. Biochemistry: 7;37(14):4844-52

168. Andre P. (2004). P-selectin in haemostasis. British Journal of Haematology, 126, 298-306.

169. Stenberg, P.E., McEver, R.P., Shuman, M.A., Jacques, Y.V. \& Bainton, D.F. (1985) A platelet alpha-granule membrane protein (GMP-140) is expressed on the plasma membrane after activation. Journal of Cell Biology, 101, 880-886.

170. Bonfanti, R., Furie, B.C., Furie, B. \& Wagner, D.D. (1989) PADGEM (GMP140) is a component of Weibel-Palade bodies of human endothelial cells. Blood, 73, 1109-1112.

171. Michelson, A.D. (1998) Increased platelet reactivity and circulating monocyteplatelet aggregates in patients with stable coronary artery disease. Journal of American College of Cardiology, 31, 352-358.

172. Hartwell, D.W., Mayadas, T.N., Berger, G., Frenette, P.S., Rayburn, H., Hynes, R.O. \& Wagner, D.D. (1998) Role of P-selectin cytoplasmic domain in granular targeting in vivo and in early inflammatory responses. Journal of Cell Biology, 143, 1129-1141.

173. Vandendries ER, Furie BC, Furie B. (2004). Role of P-selectin and PSGL-1 in coagulation and thrombosis. Thromb Haemost Sep;92(3):459-66.

174. Hidari, K.I., Weyrich, A.S., Zimmerman, G.A. \& McEver, R.P. (1997) Engagement of P-selectin glycoprotein ligand-1 enhances tyrosine phosphorylation and activates mitogen-activated protein kinases in human neutrophils. Journal of Biological Chemistry, 272, 28750-28756

175. Yang J., Furie B.C., and Furie B. (1999). The biology of P-selectin glycoprotein ligand-1: its role as a selectin counter-receptor in leukocyteendothelial and leukocyte platelet interaction. Thromb Haemost 81, 1-7.

176. Michelson AD, Barnard MR, Hechtman HB, MacGregor H, Connolly RJ, Loscalzo J, and Valeri CR. (1996). In vivo tracking of platelets: circulating degranulated platelets rapidly lose surface P-selectin but continue to circulate and function. Proc Natl Acad Sci USA 93, 11877-11882. 
177. Tate, R.M., Morris, H.G., Schroeder, W.R. and Repine, J.E., (1984). Oxygen metabolites stimulate thromboxane production and vasoconstriction in isolated saline-perfused rabbit lungs. J Clin Invest 74, pp. 608-613

178. Smedira, N., L. Gates, R. Hastings, C. Jayr, T. Sakuma, J. F. Pittet, and M. A. Matthay. (1991). Alveolar and lung liquid clearance in anesthetized rabbits. J. Appl. Physiol. 70: 1827-1835.

179. Sekido, N., N. Mukaida, A. Harada, I. Nakanishi, Y. Watanabe, and K. Matsushima. (1993). Prevention of lung reperfusion injury in rabbits by a monoclonal antibody against interleukin-8. Nature 365: 654-657.

180. Greef K, Ysebaert D, Ghielli M, Vercauteren S, Nouwen E, Eyskens E, Broe M. (1998). Neutrophils and acute ischemia-reperfusion injury. J Nephrol; 3(11), 110-122.

181. Deeb GM, Grum CM, Lynch MJ, Guynn TP, Gallagher KP. (1990). Neutrophils are not necessary for induction of ischemia reperfusion lung injury. $\mathrm{J}$ Appl Physiol; 68: 374-81.

182. Steimle C, Guynn TP, Morganroth ML, Bolling SF, Carr K, Deeb GM. (1992). Neutrophils are not necessary for ischemia reperfusion lung injury. Ann Thorac Surg; 53: 64-73.

183. Ishikawa M, Cooper D, Arumugam T, Zhang J, Nanda A, Granger D. (2004). Platelet-Leukocyte-Endothelial Cell Interactions after Middle Cerebral Artery Occlusion and Reperfusion. Journal of Cerebral Blood Flow \& Metabolism. 24(8):907-915.

184. Roberts A., A.Ovechkin, Collins K., Li R., Gozal E., Gozal D. (2002). Inhibition of inducible nitric oxide synthase attenuates increased pulmonary vascular resistance during lung ischemia-reperfusion in rabbits. Exper Biol, I-A77. 


\section{CURRICULUM VITAE}

NAME: $\quad$ Alexander V. Ovechkin

ADDRESS: $\quad 9232$ Wendell Circle, Apt. \#20

Louisville, KY, USA, 40299

Work telephone: (502) 852-3627

Office telephone: (502) 852-6835

E-mail: avovec01@louisville.edu

BIRTHDATE: November 17, 1957

EDUCATION: - Doctor of Medicine (MD), Perm State Medical Academy, Russia, 1975-1981

- Master of Medical Science (MS), University of Louisville, USA, 1999-2002

- Doctor of Philosophy in Medical Science (PhD), Perm State Medical Academy, Russia, 1989-1996

- PhD Graduate Program (Physiology \& Biophysics), University of Louisville, USA, $1999-2005$

TRAINING: $\quad$ - Residency in Surgery, Perm State Medical Academy, Russia, $1981-1982$

- Clinical Internship in Gastrointestinal Surgery, Perm State Medical Academy, Russia, 1987 - 1989 
- Postdoctoral Fellowship, Moscow State Medical Academy, Russia, 1996-1999

- Postdoctoral Fellowship, University of Louisville, USA, 2004 Present

AWARDS: $\quad$ - General Surgery Faculty Research Award,

Perm State Medical Academy, Russia, 1994

- N. Fedorow Fellow in Gasrtointestinal Surgery

Moscow Medical Academy, Russia, 1997

- XIV International Medical Conference

The Best Presentation Award, Finland, 1997

- Research Committee Travel Awards, University of Louisville, 2002, 2003, 2004, 2005

- Kentucky Biomedical Research Infrastructure Network

Travel Awards, 2002, 2003, 2004

PROFESSIONAL EXPERIENCE:

\begin{tabular}{l|l|l|l|l} 
Dates & \multicolumn{1}{|c|}{ Title/Position } & \multicolumn{1}{|c|}{ Institution } & Degree & \multicolumn{1}{|c}{ Supervisor } \\
\hline $08.81-$ & $\begin{array}{l}\text { MD, Surgeon - } \\
\text { Resident }\end{array}$ & $\begin{array}{l}\text { Chemushka District } \\
\text { Hospital of the Perm } \\
\text { Region, Russia }\end{array}$ & MD & $\begin{array}{l}\text { George } \\
\text { Moroshkin }\end{array}$ \\
\hline $01.82-$ & $\begin{array}{l}\text { MD, Surgeon, } \\
\text { Staff }\end{array}$ & $\begin{array}{l}\text { Chemushka District } \\
\text { Hospital of the Perm } \\
\text { Region, Russia }\end{array}$ & MD & $\begin{array}{l}\text { George } \\
\text { Moroshkin }\end{array}$ \\
\hline $01.84-$ & $\begin{array}{l}\text { MD, Surgeon, } \\
\text { Staff }\end{array}$ & Perm Hospital \#9, Russia & MD & Uriy Mironov \\
\hline 07.87 & $\begin{array}{l}\text { MD, Surgeon - } \\
07.89\end{array}$ & $\begin{array}{l}\text { Perm State Medical } \\
\text { Intern }\end{array}$ & MD & Vasiliy Repin \\
\hline $08.89-$ & $\begin{array}{l}\text { MS, Graduate } \\
\text { student }\end{array}$ & $\begin{array}{l}\text { Perm State Medical } \\
\text { Academy, Russia, }\end{array}$ & PhD & Vasiliy Repin \\
\hline 07.96 & $\begin{array}{l}\text { Perm State Medical } \\
\text { Academy, Russia, }\end{array}$ & MD, PhD & Eugeniy Vagner \\
08.99 & Fellow & Perm Hospital \#9, Russia & MD & Uriy Mironov \\
\hline $07-92-$ & Medical director & &
\end{tabular}




\section{PROFESSIONAL}

SOCIETIES: $\quad$ - Member of Russian Surgical Society, 1981

- Member of Russian Endoscopy Society, 1990

- Member of Endoscopic Surgery Society, 1991

- Member of American Physiological Society, 2002

INVENTIONS: - New method of esophago-intestinal interconnection after gastrectomy, Perm, Moscow, Russia, 1995

- New method of intestinal reservoir formation

after gastrectomy, Perm, Moscow, Russia, 1995

\section{PUBLICATIONS:}

- Abstracts:

1. Ovechkin A., Repin V., A.Vozgoment, M.Repin, A.Shestov and V.Perepelicin: Organization of the Surgical Service for patients with Gastric and Duodenal Bleeding. Int. Med. Conf. (Finland), p 78-80, 1997.

2. Ovechkin A., A. Roberts, Gozal E., Gozal D. Pulmonary vascular responsiveness changes following intermittent and sustained hypoxia in rats. Annual Research Conference, University of Louisville, USA, 2001

3. Collins K., A. Roberts, A.Ovechkin, Li R., Gozal E., Gozal D. Pulmonary microvascular constrictions during lung ischemia-reperfusion in rabbits is decreased by inhibition of inducible nitric oxide synthase. Annual Research Conference, University of Louisville, USA, 2001

4. Roberts A., A.Ovechkin, Collins K., Robinson T. Modification of pulmonary ischemia-reperfusion induced microvascular constriction in rabbits by nitric oxide synthase inhibitor. American Lungs Association Medical Conference "The 2001 Respiratory Rumble”, Lexington, KY, USA, 2001.

5. Ovechkin A., A. Roberts, Gozal E., Gozal D. Pulmonary vascular responsiveness changes following intermittent and sustained hypoxia in rats. Exp Biol, 1-2, 2002

6. Roberts A., A.Ovechkin, Collins K., Li R., Gozal E., Gozal D. Inhibition of inducible nitric oxide synthase attenuates increased pulmonary vascular resistance during lung ischemia-reperfusion in rabbits. Exp Biol, I-A77, 2002. 
7. Ovechkin A., A. Roberts, K. Collins, T. Robinson, and D. Lominadze Inhibition of inducible nitric oxide synthase attenuates increased platelet adhesion in pulmonary arterioles during lung ischemia-reperfusion in rabbits. Exp Biol I-A416, 2003

8. Roberts A., A.Ovechkin, K.Collins, and E.Arteel Ischemic preconditioning inhibits increased pulmonary vascular resistance during lung ischemia-reperfusion in rabbits. Exp Biol, I-A415, 2003.

9. Roberts A., Ovechkin A., Lominadze D., Collins K., Robinson T. Increased matrix metalloproteinase activity is associated with platelet-arteriolar interactions during pulmonary ischemia-reperfusion. Exp Biol, A618, 2004.

10. Collins K., Ovechkin A., Robinson T., Roberts A. Ischemic preconditioning improves lung tissue nitric oxide availability during postischemic reperfusion of the intact lung. Exp Biol, A619, 2004.

11. Collins-Sedoris K., Gozal E., Ovechkin A., Roberts A. Ischemic preconditioning improves tissue nitric oxide bioavailability by stimulating post-translational interaction between endothelial nitric oxide synthase and heat shock protein 90 during reperfusion. Res Lou, GR 20, 2004

12. Smart L., Collins K., Ovechkin A., Tyagi S., Moshal K., Lominadze D., Robinson T., Roberts A. Inhibition of inducible nitric oxide synthase prevents MMP activation and platelet adhesion during pulmonary ischemia-reperfusion. Res Lou, SMED 35, 2004

13. Ovechkin A., Roberts A., Collins K., Robinson T., Lominadze D. Early postischemic vasoconstriction correlates with platelet but not leukocyte adhesion in pulmonary arterioles in rabbits. Exp Biol, A617, 2004.

14. Smart L., Collins K., Ovechkin A., Tyagi S., Moshal K., Lominadze D., Robinson T., Roberts A. Inhibition of inducible nitric oxide synthase prevents MMP activation and platelet adhesion during pulmonary ischemia-reperfusion. Res Lou, SMED 35, 2004

15. Ovechkin A., Tyagi N., Rodriguez W. Tyagi S. Role of Matrix Metalloproteinase9 in Endocardial Apoptosis in Congestive Heart Failure. Res Lou, PRF 33, 2004.

16. Ovechkin A. and Tyagi S. Role of MMP-9 in cardiac remodeling. Joint Intern Conf of Intern Society for Heart Research and Intern Acad of Cardiovasc Science, Ahmedabad, India, 2004.

17. Roberts A., Moshal K., Smart L., Ovechkin A., Sedoris K., Lominadze D., Robinson T., Tyagi S. Increased MMP activity and platelet adhesion in subpleural arterioles during pulmonary ischemia-reperfusion are attenuated by iNOS inhibition in rabbits. Exp Biol, 2005, II-710.11, A1328.

18. Sedoris K., Gozal E., Ovechkin A., Roberts A. Pulmonary ischemic preconditioning stimulates protein-protein interaction between eNOS and Hsp90 in 
lung tissue and improves nitric oxide bioavailability during reperfusion in rabbits. Exp Biol, 2005, II-683.23, A1216.

19. Tyagi N., Ovechkin A., Tyagi S. Mechanism of Decreased Nitric Oxide Bioavailability by Homocysteine in Microvascular Endothelial Cells. Exp Biol, 2005, II-937.26, A1681.

20. Ovechkin A., Tyagi N., Rodriguez W, Tyagi S. Role of MMP-9 in endocardial apoptosis in congestive heart failure in mice. Exp Biol, 2005, II-709.19, A1325.

Books:

1. Ovechkin A.: Surgical Treatment of the Organic Complications after Gastric Resection and Vagotomy in Ulcer Disease. Perm St. Med. Acad. Press. 153 p., 1996.

2. Repin V., A.Ovechkin and M.Repin: Reconstructive Surgery in Ulcer Disease. Perm St. Univ. Press. 140 p., 1998.

Peer-reviewed papers:

1. Repin V., V.Dvoryanskih, A.Ovechkin and M.Repin: Operative Treatment of Chronic Duodenal Obstruction after Radical Operations on the Stomach in Ulcer Disease. Clin. Surg. J., Kiev. p 30-32, 5:1989

2. Repin V., A.Ovechkin and O.Gudkov: Surgical Treatment of Organic Complications after Ulcer Surgery. J. of clinical surgery. Perm St. Med. Inst. Press, $p$ 51-53,8:1993.

3. Repin V., A.Ovechkin and O.Gudkov. The Surgical Treatment of Organic Complications in Ulcer Disease. Perm St. Med. Inst. Press, p 26-29, 7:1993.

4. Repin V., A.Ovechkin and M. Repin: Surgical Treatment of Duodenal Disorders after Gastric Resection. Perm Clin. Surg. J., p 23-26, 1996

5. Repin V., A.Vozgoment, A. Kuptsova, A.Ovechkin and O.Gudkov. Surgical Treatment of Peritonitis When Source of Infection was not eliminated. Perm St. Med. Inst. Press, p 26-27, 1997.

6. Repin V. and A.Ovechkin: Surgical Treatment of Gastric Peptic Ulcer after previous operations. The minimally invasive surgery and surgical anatomy in practical medicine and experiment. Perm St. Med. Acad. Press, p 26-28, 1998.

7. Ovechkin A.: Surgical Treatment of the Reflux-gastritis after Gastric Surgery. Perm St. Med. Acad. Press, p 49-53, 1999.

8. Roberts A., A.Ovechkin, Mowbray J., Robinson T., Lominadze D. Effects of 
pulmonary ischemia-reperfusion on platelet adhesion in subpleural arterioles in rabbits. Microvascular Research, 67, p.29-37, 2004.

9. Reddy H., S. Koshy, S. Wasson, K. Aggarwal, L. Tejwani, A. Ovechkin, S.Tyagi. Echocardiography predicts adverse cardiac remodeling in heart failure. Experimental Clinical Cardiology, 9(2): 112-116, 2004

10. Moshal KS, Tyagi N, Moss V, Henderson B, Steed M, Ovechkin A, Aru GM, Tyagi SC. Early induction of matrix metalloproteinase-9 transduces signaling in human heart end stage failure. J Molec Cell Cardiol. 2005. Submitted.

11. Ovechkin A., Lominadze D., Sedoris K., Gozal E., Robinson T., Roberts A. Inhibition of Inducible Nitric Oxide Synthase attenuates platelet adhesion in subpleural arterioles during lung reperfusion in rabbits. Amer J Appl Physiol, 2005. In revision.

12. Moshal KS, Tyagi N, Henderson B, Ovechkin AV, Tyagi SC. Protease activated receptor and endothelial-myocyte uncoupling in chronic heart failure. Am J Physiol (Heart \& Circulationry Physiol), 2005. In press.

13. Tyagi N, Moshal KS, Lominadze D, Ovechkin AV, Tyagi SC. Hcy-dependent cardiac remodeling and endothelial-myocyte coupling in two kidney one clip Goldblatt hypertension mouse model. Canad J Physiol \& Pharmacol, in revision, 2005.

14. Ovechkin A.,Tyagi N, Rodriquez W, Moshal KS, Tyagi SC. . Role of MMP-9 in endocardial apoptosis in chronic heart failure in mice. Am J Physiol (Heart \& Circulationry Physiol), 2005. Submitted. 